\title{
The influence of reviewers' characteristics on their evaluations of instructional technology integration
}

Christine Marie Weigandt

West Virginia University

Follow this and additional works at: https://researchrepository.wvu.edu/etd

\section{Recommended Citation}

Weigandt, Christine Marie, "The influence of reviewers' characteristics on their evaluations of instructional technology integration" (2005). Graduate Theses, Dissertations, and Problem Reports. 3428.

https://researchrepository.wvu.edu/etd/3428

This Dissertation is protected by copyright and/or related rights. It has been brought to you by the The Research Repository @ WVU with permission from the rights-holder(s). You are free to use this Dissertation in any way that is permitted by the copyright and related rights legislation that applies to your use. For other uses you must obtain permission from the rights-holder(s) directly, unless additional rights are indicated by a Creative Commons license in the record and/ or on the work itself. This Dissertation has been accepted for inclusion in WVU Graduate Theses, Dissertations, and Problem Reports collection by an authorized administrator of The Research Repository @ WVU.

For more information, please contact researchrepository@mail.wvu.edu. 
The Influence of Reviewers' Characteristics on Their Evaluations of Instructional Technology Integration

Christine Marie Weigandt

\author{
Dissertation submitted to the \\ College of Human Resources and Education at \\ West Virginia University \\ in partial fulfillment of the requirements for the degree of
}

\author{
Doctor of Education \\ in \\ Technology Education
}

\author{
David L. McCrory, Ph.D., Chair \\ D.J. Hendricks, Ed.D. \\ Neal Shambaugh, Ph.D. \\ Richard T. Walls, Ph.D. \\ Jaci L. Webb-Dempsey, Ph.D. \\ Department of Advanced Educational Studies \\ Morgantown, West Virginia \\ 2005
}

Keywords: reviewers, evaluators, instructional leaders, subjective assessment, bias, instructional technology, web-based instruction, personal characteristics 


\begin{abstract}
The Influence of Reviewers' Characteristics on Their Evaluations of Instructional Technology Integration
\end{abstract}

\title{
Christine Weigandt
}

The purpose of this study was to determine what effect the personal characteristics of reviewers might have on their reviews. The participants in this study were nine instructional leaders who used a rubric to evaluate P-12 teachers' web-based instructional units, but still scored them differently.

The characteristics examined in this study included the reviewers' styles of teaching, personal computer use, concerns about instructional technology integration, professional positions, perceived roles, and personal criteria for what makes a good web-based instructional unit.

The study employed both quantitative and qualitative research methodologies. The quantitative instruments used were the Stages of Concern Questionnaire (SoCQ), the Principles of Adult learning Scale (PALS), and the Survey of Computer Use (SCU). The qualitative methods used were interviews of the instructional leaders and coding and compiling of comments made by the instructional leaders when they were evaluating the units.

The results of this study indicate that the reviewers who had teaching styles that were more "learner-centered" were inclined to pass more units than their "teacher-centered" counterparts. The reviewers who had the lowest concerns overall about technology passed less units than those with higher technology concerns. Reviewers who were not in P-12 teaching positions passed more units, while the reviewer whose job it was to teach technology in the public school system passed the least. In addition, the group identified as "advanced" appeared to be judged more stringently, and the group identified as "beginners" appeared to be evaluated more generously. Other factors were less clear; however, when interviewed, the reviewers mentioned various factors that may have influenced their scoring, including their perceptions of their roles and their personal feelings about the participants.

The results of this study imply that reviewers, even when using a rubric, will still incorporate their own opinions and expertise into their reviews. When choosing and assigning reviewers, characteristics that might have an effect should be kept in mind and controlled as much as possible by having at least three reviewers for each product being evaluated and by balancing groups of reviewers by assigning reviewers with similar characteristics to different groups. 


\section{Acknowledgements}

I wish to offer my sincere thanks all the members of my committee. Each of you contributed to this work in your own special, but very important way. To my chair, Dr. David McCrory, who was always there for me from the very beginning, thank you for always having faith in what I was doing and for knowing just what to say to "make it all better.” To Dr. Richard Walls, who was such an inspiration, thank you for keeping me going even when I wanted to quit. To Dr. Jaci Webb-Dempsey, who made me feel like I could do this even when I thought I could not, thank you for your constant support and assistance. To Dr. DJ Hendricks, who was unfailingly enthusiastic and helpful, thank you for your advice and guidance. To Dr. Neal Shambaugh, who was always there for me as a source of support, thank you "answering the call” at the end when I was in need.

There are several other people I would like to thank, who were invaluable in the completion of the project. Thank you to Dr. John Wells for the opportunity to work in Trek 21, which started it all. Thank you to Dr. Ernest Goeres, for helping out at the last minute with my defense. I would like to offer a special thank you to the instructional leaders who participated in this study, who gave their time, their knowledge, and their enthusiasm so freely. I also would like to thank my friends, family, and co-workers for their help and overwhelming support.

Finally, I would like to thank my daughter, Genny Yosco, who was the source of both my greatest inspiration and my greatest distraction, each exactly when I needed it. 
Table of Contents

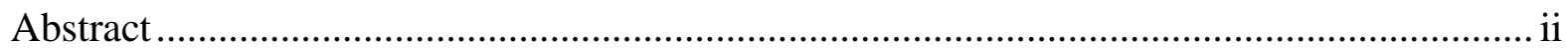

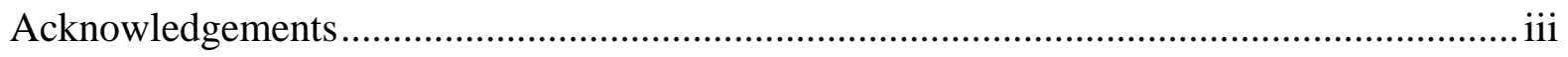

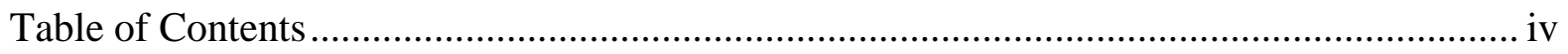

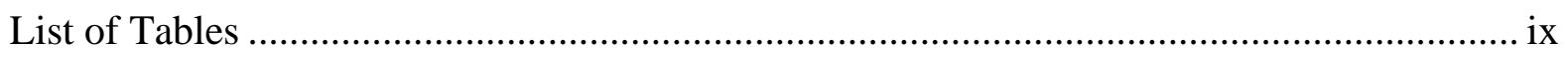

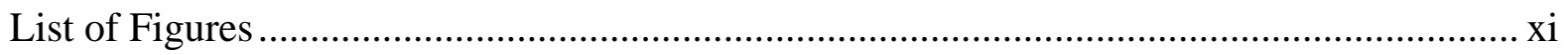

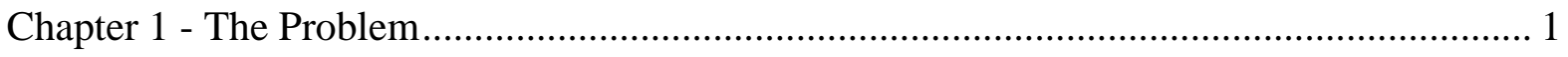

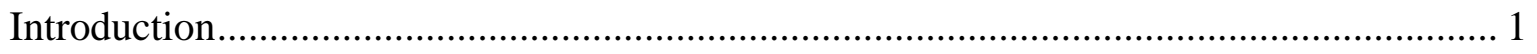

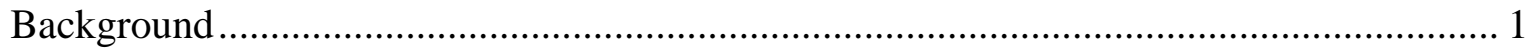

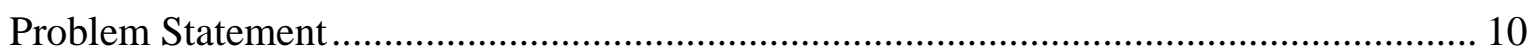

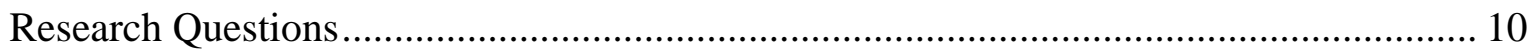

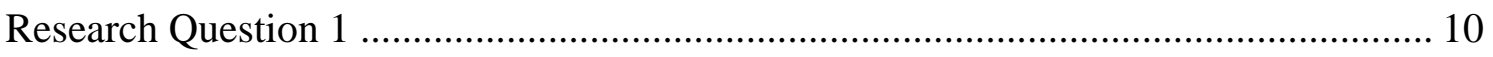

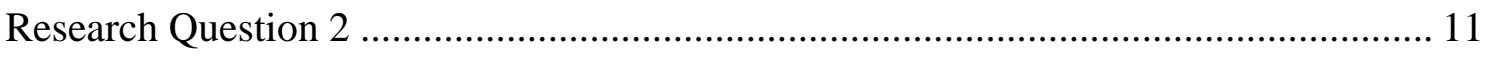

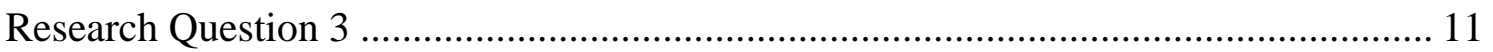

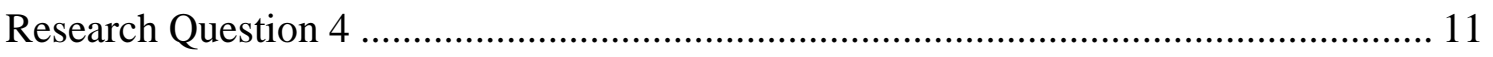

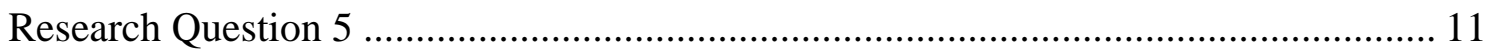

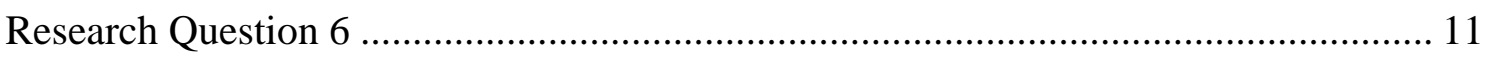

Rationale for the Problem/Research Questions ........................................................... 11

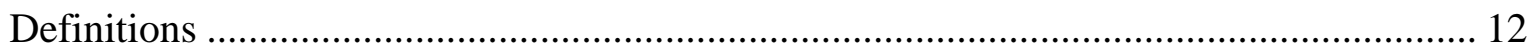

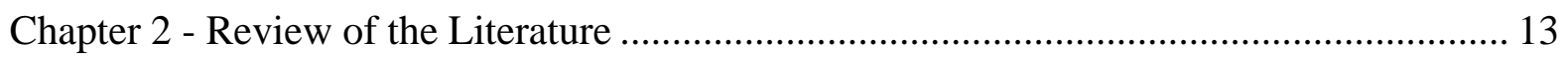

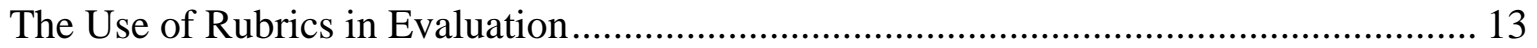

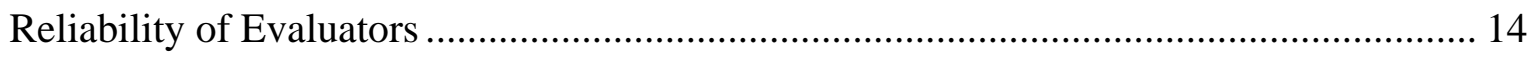

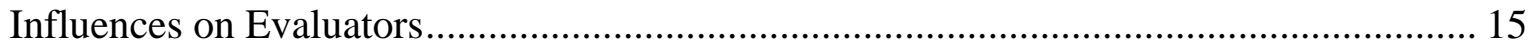


Mixed Method Designs in Research.................................................................................. 23

The Use of Surveys in Research .............................................................................. 24

The Use of Coding in Research ............................................................................... 24

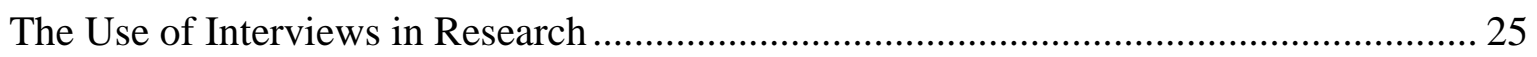

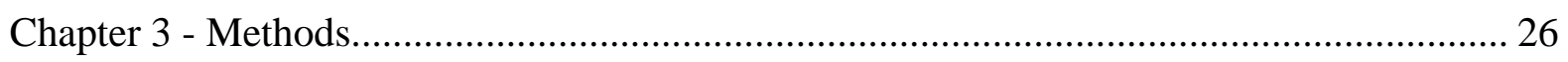

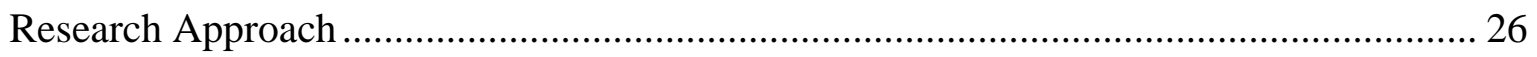

Research Design ................................................................................................ 26

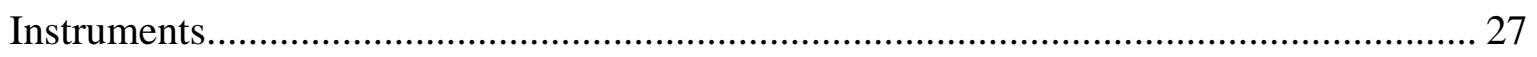

The Principles of Adult Learning Scale (PALS) …………............................................ 27

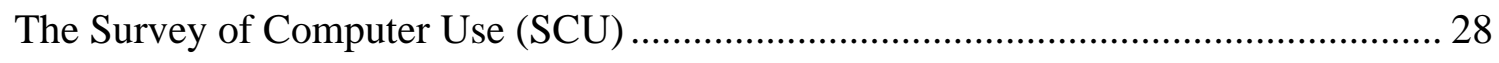

The Stages of Concern Questionnaire (SoCQ) …………............................................... 30

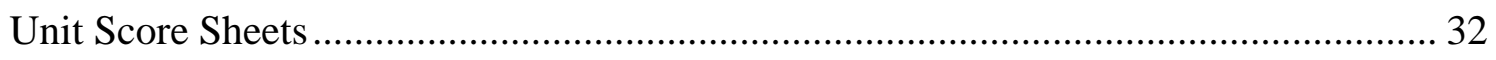

Unit/Lesson Feedback Sheets .................................................................................. 32

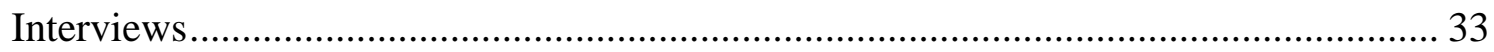

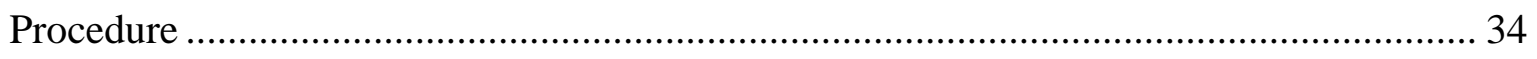

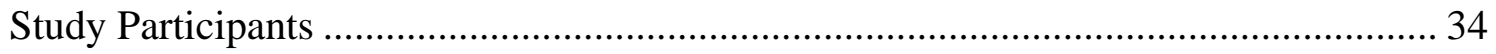

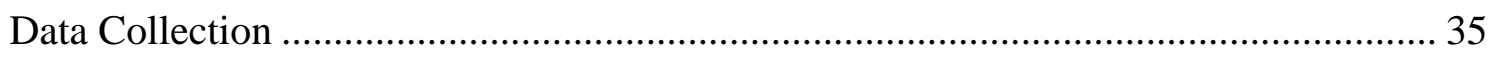

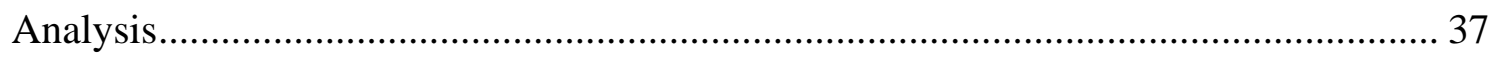

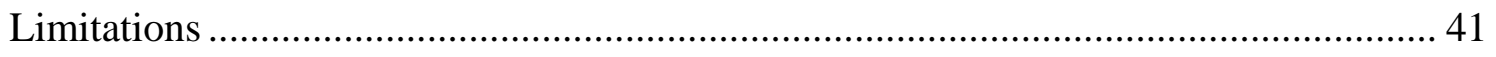

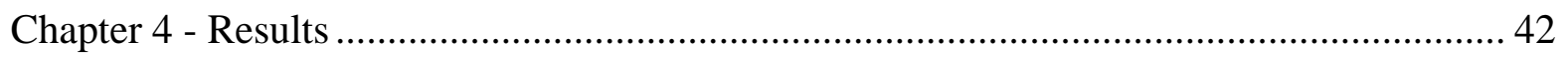

Instructional Leaders Reviewing Group A ...................................................................... 42

Instructional Leaders’ Backgrounds ........................................................................... 42

PALS Scores of Instructional Leaders Reviewing Group A.............................................. 44 
SCU Scores of Instructional Leaders Reviewing Group A............................................... 44

SoC Scores of Instructional Leaders Reviewing Group A ………………………......... 45

Instructional Leaders’ Reviews of Group A Units ....................................................... 47

Instructional Leaders Reviewing Group B ................................................................... 55

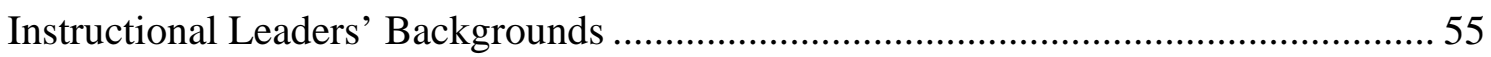

PALS Scores of Instructional Leaders Reviewing Group B ............................................ 57

SCU Scores of Instructional Leaders Reviewing Group B.............................................. 57

SoC Scores of Instructional Leaders Reviewing Group B............................................... 58

Instructional Leader’s Reviews of the Group B Units...................................................... 59

Instructional Leaders Reviewing Group C ..................................................................... 65

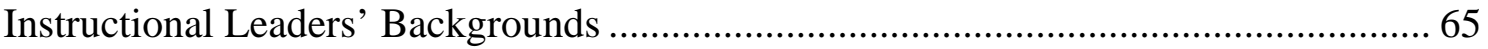

PALS Scores of Instructional Leaders Reviewing Group C.............................................. 67

SCU Scores of Instructional Leaders Reviewing Group C............................................. 67

SoC Scores of Instructional Leaders Reviewing Group C............................................. 68

Instructional Leaders’ Reviews of Group C Units ......................................................... 69

Chapter 5 - Conclusion ..................................................................................................... 77

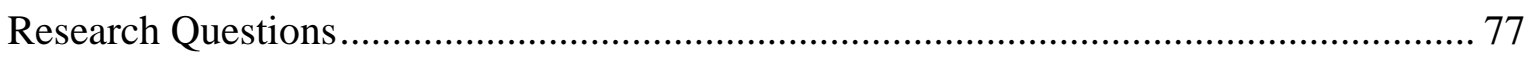

Research Question 1 ................................................................................................... 77

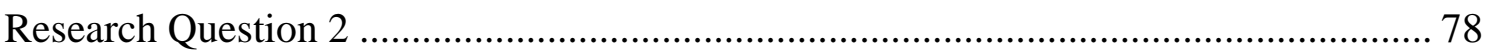

Research Question 3 .............................................................................................. 79

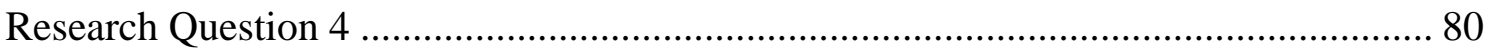

Research Question 5 .............................................................................................. 82

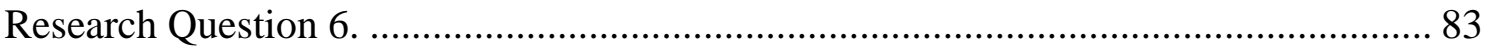




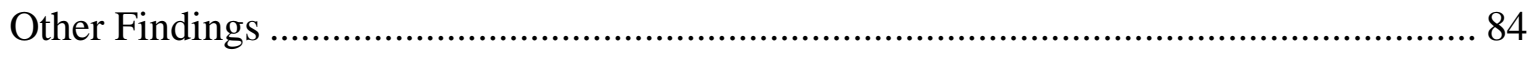

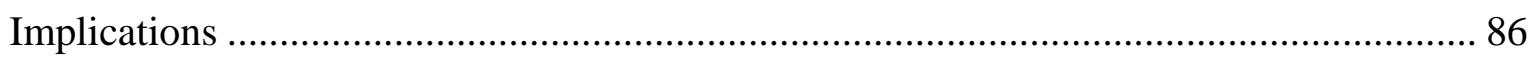

Suggestions for Further Study …………….......................................................... 88

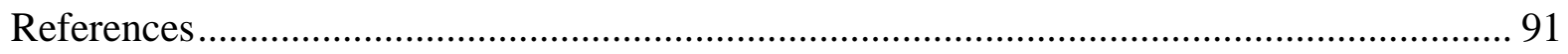

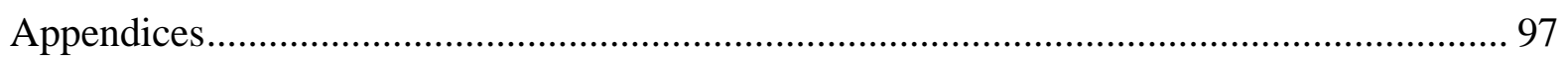

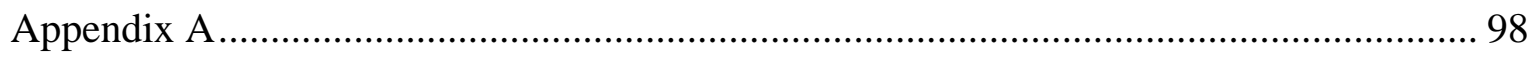

Trek 21 Rubric-Score Sheet-Unit/Lesson Feedback Sheet............................................... 98

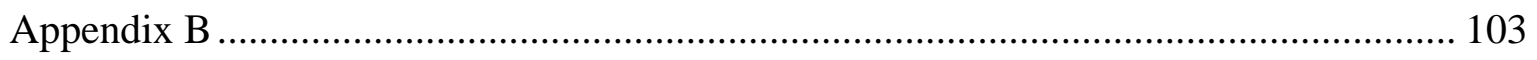

Survey of Computer Use (SCU) ............................................................................ 103

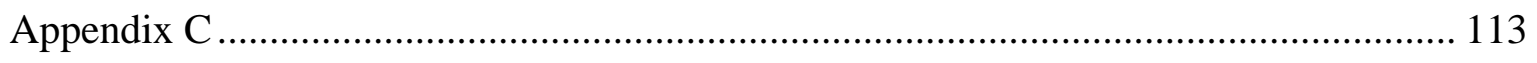

Principles of Adult Learning Scale (PALS)................................................................. 113

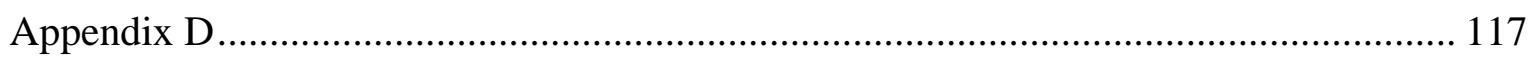

Stages of Concern Questionnaire (SoCQ) ................................................................. 117

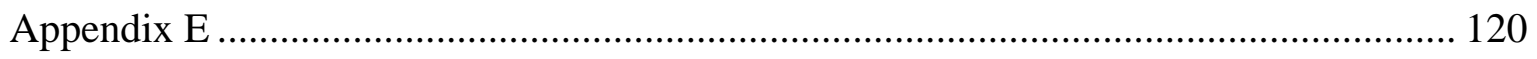

Example of Coded Combined Unit/Lesson Feedback Sheet and Unit Score Sheet ..... 120

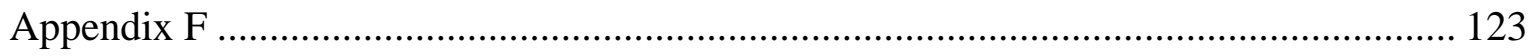

Code Book for Combined Unit/Lesson Feedback Sheet and Unit Score Sheet............. 123

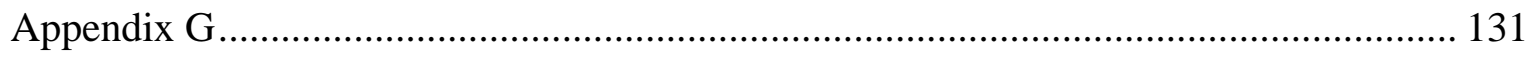

Phone Text for Initial Contact of Study Participants ................................................... 131

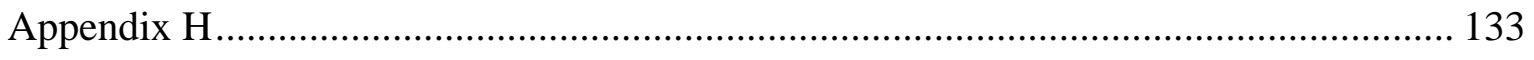

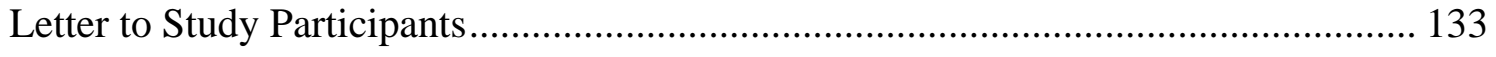

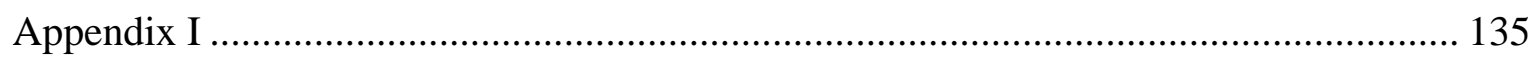

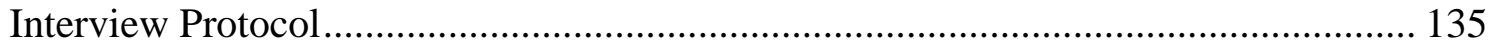




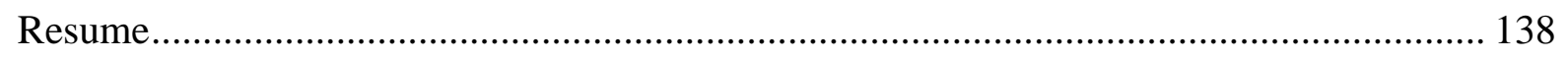




\section{List of Tables}

Table 1 Instructional Leaders' Posting Decisions............................................................... 9

Table 2 The Seven Stages of Concern Based on the CBAM ............................................. 30

Table 3 Sample Data Comparison Chart......................................................................... 38

Table 4 Data Sources and Relationship to Research Questions.......................................... 40

Table 5 Instructional Leaders’ Group Total Posting Decisions for Group A Units ............. 47

Table 6 Instructional Leaders’ Individual Posting Decisions for Group A Units .................. 48

Table 7 Instructional Leaders’ Number of Negative and Positive Comments on Group A

Units

Table 8 Differences in Pedagogical, Technical, and Generic Comments on Group A Units 49

Table 9 Instructional Leaders’ Positive and Negative Pedagogical and Technical Comments

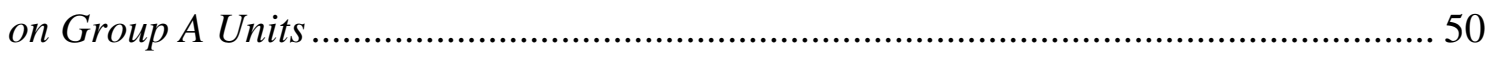

Table 10 Major Findings for the Instructional Leaders Reviewing Group A Units .............. 55

Table 11 Instructional Leaders’ Group Total Posting Decisions for Group B Units ........... 60

Table 12 Instructional Leaders’ Individual Posting Decisions for Group B Units ............... 60

Table 13 Instructional Leaders’ Number of Negative and Positive Comments on Group B

Units

Table 14 Differences in Pedagogical, Technical, and Generic Comments on Group B Units...

Table 15 Instructional Leaders' Positive and Negative Pedagogical and Technical Comments

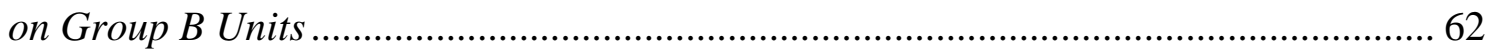

Table 16 Major Findings for the Instructional Leaders Reviewing Group B Units .............. 64

Table 17 Instructional Leaders’ Group Total Posting Decisions for Group C Units ........... 69 
Table 18 Instructional Leaders’ Individual Posting Decisions for Group C Units.

Table 19 Instructional Leaders’ Number of Negative and Positive Comments on Group C

Units.

Table 20 Differences in Pedagogical, Technical, and Generic Comments on Group C Units

Table 21 Instructional Leaders' Negative and Positive Pedagogical and Technical Comments

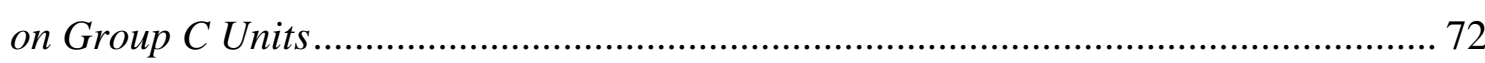

Table 22 Major Findings for the Instructional Leaders Reviewing Group C Units.............. 76 


\section{List of Figures}

Figure 1. Survey of Computer Use Scores of Instructional Leaders Reviewing Group A .... 45

Figure 2. SoC Scores of Instructional Leaders Reviewing Group A ................................. 47

Figure 3. Comparison of Instructional Leaders’ Comment Themes on Group A Units ........ 51

Figure 4. Survey of Computer Use Scores of Instructional Leaders Reviewing Group B..... 58

Figure 5. SoC Scores of Instructional Leaders Reviewing Group B................................. 59

Figure 6. Comparison of Instructional Leaders’ Comment Themes on Group B Units......... 63

Figure 7. Survey of Computer Use Scores of Instructional Leaders Reviewing Group C..... 67

Figure 8. SoC Scores of Instructional Leaders Reviewing Group C................................. 68

Figure 9. Comparison of Instructional Leaders’ Comment Themes on Group C Units........ 73 


\section{Chapter 1 - The Problem}

\section{Introduction}

Evaluation is evolving from objective assessment, such as multiple-choice exams, into more subjective formats, such as performance assessment, portfolio assessment, and other methods that rely on judging by humans (Johnson, McDaniel \& Willeke, 2000). Programs that rely on judges to evaluate often use training, evaluation tools, and other methods to achieve impartiality. The concept of agreement in scoring between independent evaluators is referred to as inter-rater reliability (Moskal, 2000). However, when using human judges, it is nearly impossible to achieve consensus (MacMillan, 2000).

Studies of agreement among evaluators have come to different conclusions as to the ability to control variability in scoring (Brennan, 1995; Johnson, McDaniel, \& Willeke, 2000; Pomplun, Sundbye, \& Kelly, 1996). This study does not attempt to determine whether it is possible, or even desirable, to make a totally impartial group of evaluators. The purpose of this study is to determine some of the characteristics of evaluators that might influence their ratings. While there have been many studies into the variability among evaluators, the reasons for such variability have rarely been investigated (Baume \& Yorke, 2002; Hout, 1990; Lam, 1995). In order to develop a greater understanding of the factors that influence evaluators, this study will examine a specific group of evaluators and the reasons behind their evaluations of teachercreated web-based units produced during the Trek 212002 Summer Institute, a U.S. Department of Education professional development project.

\section{Background}

From August of 2001 to May of 2003, I worked for the Trek 21 project, a U.S. Department of Education PT3 grant at West Virginia University. “Trek 21: Educating Teachers as Agents of Technological Change” (Wells, 1999) was a PT3 implementation grant from the U. 
S. Department of Education. Grants from the PT3 Initiative provide funding for programs to develop technologically proficient educators who are prepared to meet the needs of $21^{\text {st }}$ century learners. The College of Human Resources and Education at West Virginia University (WVU) was originally awarded the three-year grant in 1999, making the project well established by the time I joined it.

My job was a part-time, graduate assistant position, which paid for my graduate degree tuition and the necessities of life for my 10-year-old daughter, Genny, and myself while I pursued a Master's and a Doctorate degree in Technology Education. In addition, the job gave me valuable, practical experience in integrating technology into education, as well as working with many different teachers and other educators.

I had become a single parent when Genny was $2 \frac{1 / 2}{2}$ years-old, and when she was fiveyears-old, I began working toward a Bachelor of Arts degree in psychology through distance learning, while working full-time. When I graduated in December of 2000, I decided to pursue an advanced degree. I chose Technology Education because I thought it would be a good fit with my background in computers, psychology, distance learning, and the arts. I discovered a program in Technology Education at West Virginia University, and moved from New Jersey to West Virginia to begin working full-time on a Master’s degree. After one year at WVU, I discovered that the Trek 21 project was looking for a graduate assistant, and was lucky enough to obtain a position that would have a major effect on my education over the next two years.

The goal of the Trek 21 project was to prepare pre-service teachers to use technology in education. To accomplish that goal, the project hosted a three-week professional development institute each summer for in-service pre-school through high school teachers, where they learned how to use instructional technologies in their teaching. Trek 21 delivered P-12 Summer 
Institutes during the three years of the project. During these institutes, the teacher-participants were shown how and why to use different instructional technologies, including web authoring packages such as Microsoft FrontPage and Macromedia DreamWeaver, Microsoft PowerPoint, Adobe Portable Document File (PDF) formats, digital cameras, video and audio, and online quiz and activity generators.

During each Summer Institute, the teacher-participants developed a five-lesson webbased instructional unit for use the following fall. The units were expected to reflect pedagogically sound instruction, appropriate uses of instructional technologies, and a minimum of one integrated Instructional Technology (IT) and one integrated telecollaborative activity. In addition, the units were expected to demonstrate good web design, with well-described teacher and student procedures including enough information to enable other teachers to make use of it for their classes.

I was hired for the final two years of the project, and was involved in the planning and delivery of the last P-12 institute the project held. The 2002 institute hosted 35 teacherparticipants from West Virginia counties surrounding the university, with teachers ranging from pre-school to high school grade levels.

In order to ensure that the units produced during the institute met the goals of the project, they were evaluated according to a rubric (Appendix A) created by Trek 21 with input from past institute participants. In the final institute year, the units were reviewed by nine instructional leaders. The instructional leader group consisted of seven practicing P-12 teachers and two higher education faculty members. The instructional leaders were master teachers who performed two roles during the 2002 institute: (1) assisting the teacher-participants in incorporating the integration of instructional technologies into their current teaching practices, 
and (2) evaluating the finished units. The incorporation of the instructional leaders was based on peer mentoring approach model, where practicing teachers are given training and support in order to perform as facilitators, trainers, and coaches to other professionals (Holahan, Jurkat, and Friedman, 2000; Ingwerson, 1997; Riel and Becker, 2000). Some of the instructional leaders had been participants of previous institutes, some had previously been instructional leaders but not participants, and some had been both.

Prior to the 2002 institute, the 35 teacher-participants had been divided into three groups, based on their computer skills and experience. The Survey of Computer Use, or SCU, (Appendix B) was used to determine to which group the teacher-participants would be assigned: the Beginner’s Group, the Intermediate Group, and the Advanced Group. The Survey of Computer Use was a combination of several different instruments. The first part of the Survey of Computer Use was based on a questionnaire developed by Kimball (1996) as part of his doctoral dissertation on the plans to incorporate technology into the California school system. The second part was based on the CODE 77 rubrics designed by Johnson (1998) to measure the efficacy of a Minnesota school district formal staff development program that trained teachers how to use technology. The Survey of Computer Use instrument provided ratings on the institute participants' and the instructional leaders' basic technology use (such as software and hardware experience), Internet use (such as email use, web page construction, and the use of the Internet as a teaching tool), advanced teacher technology use (such as information literacy skills, evaluation of technology for the classroom, and how often they used certain applications for classroom instruction and management), student-centered technology (such as how often the their students used certain applications), and learning strategies (to what extent the participants' students were engaged in certain strategies such as discovery learning and cooperative learning). Through the 
Survey of Computer Use, 11 teacher-participants were identified as beginners, 10 were identified as intermediate, and 14 were identified as advanced.

The instructional leaders also were divided into three groups of three instructional leaders each before the institute, each assigned to work during the institute with a particular group. The instructional leaders were placed in groups to make a balanced mix of technical experience, teaching styles, and leadership skills. After the institute, the instructional leaders were regrouped into three new groups, with each of the three instructional leaders in one group assigned to evaluate all of the units in one of the three teacher-participant groups, allowing for three separate evaluations of each unit in the group. The regrouping of the instructional leaders was done to allow each unit to be evaluated by one instructional leader who had worked closely with the groups’ participants during the institute, providing for one instructional leader who was familiar with each unit and its author and two instructional leaders who had less familiarity. These two reviewers had each worked with one of the other two groups.

Using numeric ratings scales from the rubric, each instructional leader made a final evaluation of the unit as either appropriate to post without changes or as requiring changes before posting. In addition, the instructional leaders made comments as to the strengths they found in the units, as well as suggestions for improvement (which was actually a gentle way of pointing out any weaknesses observed).

The instructional leaders used a Unit Score Sheet as a tool to evaluate the units. This sheet reflected the elements of the rubric. The Unit Score Sheet consisted of three sections:

- Evaluation of the unit overview - The instructional leaders scored the unit overview on each of five elements from the rubric based on a three-point scale. Next to each element, 
space was available for the instructional leaders to write comments and suggestions clarifying the numeric scores.

- Evaluation of each of the lessons - The instructional leaders scored the units' five lessons on each of nine elements from the rubric based on a three-point scale. Next to each element, space was available for the instructional leaders to write comments and suggestions clarifying the numeric scores.

- Overall Unit Rating - The score on the unit overview combined with the average score of all the lessons guided each instructional leader in coming to a final decision on each unit. This decision would be that the unit must be revised before posting, that the unit could be posted as written, or that the unit could be posted and was an exceptional example.

To support the scores on the Unit Score Sheets, the instructional leaders also filled out a Unit/Lesson Feedback Sheet for each unit. They were instructed to list at least three strengths and three suggestions for each unit overview and lesson.

Reviewing the units was a particularly difficult job, because, while certain standards were required by the project, the participants had worked extremely hard during the three weeks and were very sensitive about their finished products. The instructional leaders were given two intensive training sessions on evaluating the units using the rubric. At the first meeting, Dr. John Wells explained the goals and objectives for the participants of the summer institutes. Then Dr. Deborah Wells introduced the instructional leaders were to the rubric they would use to score the units. Dr. D. Wells explained each item on the rubric as it related to a particular part or feature of the unit. In addition, she described the ratings scale of 1-3, and led the group in a discussion of the criteria for each item on the rubric (for example, for the item relating to the title of the lesson plan, the ratings were: 
- $\quad$ Vague $(1$ point $)=$ The title is too long, and does not capture the theme of the lesson.

- $\quad$ Developing (2 points) = The lesson title is brief, but does not capture the theme of the lesson.

- $\quad$ Accomplished (3 points) $=$ The lesson title is brief, and creatively summarizes the theme of the lesson.

Finally, Dr. D Wells presented examples of different elements from units from previous summer institutes, and led the group in discussion what they felt these elements should be rated, based on the rubric.

At the second training session, the training continued in a discussion-rating-discussion format (Pomplun, Sundbye, \& Kelly, 1996). Dr Deborah Wells reviewed the rubric and again lead the group in a discussion of the applicable criteria and ratings for the units. She then presented different elements of units using examples from past institutes, and had the instructional leaders individually them using paper forms. After each element, the group discussed and compared ratings among the instructional leaders and compared the instructional leaders' ratings with those that the element of that particular unit had actually received when it was originally reviewed.

I became involved in the instructional leaders' evaluations of the units while doing a project in preparations for a “Continuity Meeting” scheduled for the fall after the summer institute. During my time with Trek 21, I worked on many different projects, most of which were long term. However, one task appeared to be accomplishable within a day. This was a list of which 2002 institute units were assessed by the instructional leaders as "passing for posting” to the Trek 21 website and which units were assessed as “requiring revisions” before posting. Because this would be important to the participants - they would either be getting a letter saying 
that their unit was good enough to post or that it was not - it was important to be particularly careful in tallying the scores. I made a chart with a row for each unit, containing four columns: three to allow for each individual instructional leader's overall assessment of the unit - either $Y$ or $N$, and one for a final decision (this would be based on the majority opinion). I decided to put each instructional leader's initials next to their score. This would allow me to double-check the data. It was at this point that I began to notice something very interesting. It seemed that some instructional leaders had mostly $Y$ scores while some others had much more $N$ scores. I was not sure if this really indicated any real inconsistencies in the scoring. It was possible that the instructional leaders who gave mostly $N$ scores simply had reviewed the worst units, and the instructional leaders who gave mostly $Y$ scores had reviewed the best ones. I thought it would be worthwhile to investigate further.

To be better able to compare the scoring of the instructional leaders, I split the chart of scores into three groups: the Beginner Group participants (Group A), the Intermediate Group participants (Group B), and the Advanced Group participants (Group C). After further examination, I determined that, of the 11 units in the Group A, the instructional leaders approved 9 for posting, and required revisions on 2. Of the 9 units approved for posting, 5 were unanimous decisions. Of the 2 units requiring revisions, 1 decision was unanimous. The instructional leaders were split on whether the other 5 units should be posted or if they needed revisions.

Of the 10 units in the Group B, the instructional leaders approved 9, and required revisions on 1 . Of the 9 approved, 5 decisions were unanimous, while 4 were not, and the 1 unit requiring revisions was also a split-decision. This group had a total of 5 unanimous decisions and 5 split-decisions. 
Of the 14 units in Group C, the instructional leaders approved 6 for posting, and 8 for revisions. Of the 6 approved units, 3 were unanimous decisions. Of the 8 units requiring revisions, 5 were unanimous decisions. This made for a total of 8 unanimous decisions, and 6 split-decisions in this group. Table 1 shows the instructional leaders' posting decisions.

Table 1

Instructional Leaders’ Posting Decisions

\begin{tabular}{|l|l|l|}
\hline Instructional Leader* & Number of Units Passed & Number of Units Not Passed \\
\hline Group A & & \\
\hline Ione & $10(91 \%)$ & $1(9 \%)$ \\
\hline Felicity & $8(73 \%)$ & $3(27 \%)$ \\
\hline Sarah & $6(55 \%)$ & $5(45 \%)$ \\
\hline Group B & & \\
\hline Elizabeth & $10(100 \%)$ & $0(0 \%)$ \\
\hline Farrah & $9(90 \%)$ & $1(10 \%)$ \\
\hline Nancy & $5(50 \%)$ & $5(50 \%)$ \\
\hline Group C & & \\
\hline Maria & $9(64 \%)$ & $5(36 \%)$ \\
\hline Sam & $6(43 \%)$ & $8(57 \%)$ \\
\hline Theresa & $3(21 \%)$ & $11(79 \%)$ \\
\hline \multicolumn{2}{|l}{} \\
\hline$*$ The Instructional Leaders’ names have been changed to protect their privacy \\
\hline
\end{tabular}

Despite two days of training on the assessment of the units and lessons and the use of an evaluation rubric, there was a wide range in individual ratings by the instructional leaders. There appeared to be other factors, beyond the criteria on the rubric, which influenced the instructional leaders’ evaluations of the units.

As a part of my GA position, I performed an initial investigation of this in a preliminary study of six of the instructional leaders (Weigandt \& Wells, 2003). This study compared some of the characteristics of Group A and Group C. This was a short conference proceedings paper, and led me to believe that a more in-depth study, with additional questions, a more 
comprehensive investigation of instructional leader ratings, research into similar studies, and most importantly, the addition of the instructional leaders from Group B, would shed more light on how these reviewers performed this particular evaluation.

\section{Problem Statement}

Certain types of evaluations in educational settings, such as performance assessment and portfolio assessment, require judgments by the evaluators. In order to achieve impartiality, methods have been designed to assist the evaluators in making objective assessments. These include tools such as rubrics and rating scales.

When the judges performing evaluations are experts in the subjects being assessed, they often apply their own experience and expertise to their ratings, and this affects their use of rubrics and other evaluation tools (Lumley, 2002; Sadler, 1989). Inter-rater reliability is difficult to achieve, particularly when the tasks being evaluated are complex and highly individualized (Dunbar, Koretz, \& Hoover, 1991; Miller \& Legg, 1993). Research into inter-rater reliability has provided different conclusions as to the ability to create groups of raters who will evaluate products in the same way (Brennan, 1995; Johnson, McDaniel, \& Willeke, 2000; Pomplun, Sundbye, \& Kelly, 1996). Studies have found varying degrees of differences and similarities in evaluations by judges, but there has been little research on how these evaluators' backgrounds, experience, and characteristics influenced their perceptions of the products being judged (Baume \& Yorke, 2002; Hout, 1990). As performance assessment becomes more prevalent, is important to understand how judges’ unique qualities may affect their evaluations.

\section{Research Questions}

Research Question 1. How did the Trek 21 instructional leaders’ personal computer use skills influence their evaluations of the institute participants' web-based instructional units? 
Research Question 2. How did the instructional leaders' styles of teaching influence their evaluations of the institute participants' web-based instructional units?

Research Question 3. How did the instructional leaders' concerns about Instructional Technology integration influence their evaluations of the institute participants' web-based instructional units?

Research Question 4. How did the instructional leaders' professional positions influence their evaluations of the institute participants' web-based instructional units?

Research Question 5. How did the instructional leaders' perceptions of their roles and the roles of the participants influence their evaluations of the institute participants' web-based instructional units?

Research Question 6. How did each instructional leader's personal criteria for what makes a good unit or lesson influence his or her evaluations of the institute participants' webbased instructional units?

\section{Rationale for the Problem/Research Questions}

While a diverse group of instructional leaders as mentors can aid in achieving pedagogically and technically well-developed instructional units, it is important to be aware that this diversity can also influence their individual evaluations. Instruments such as rubrics often are used to minimize such inconsistencies when variation is expected due to different educators teaching and assessing the same or similar content (Goodrich, 1997). Rubrics are often used when an evaluator's personal standards may influence his or her judgment (Brookhart, 1999). However, Lumley (2002) explains that, different evaluators, even when interpreting the rating categories in the same way, sometimes apply the scale in different ways. The difference is often in the importance they give to various components of the scale's descriptors and how they make decisions when interpreting the wording on the scales. Evaluators do not stop having expert 
reactions, complex thoughts, and conflicting feelings about what they are scoring simply because they have been trained in the use of a rubric (Lumley, 2002; Sadler, 1989). These individual characteristics affect not only instruction, but also interpretation and application of assessment instruments. In the choice, training, and assignment of evaluators, consideration should be given as to how individual characteristics may affect their evaluations of web-based instructional units and lessons.

\section{Definitions}

Instructional Leaders (ILs) - Teacher leaders who are experienced in teaching and in teaching with technology. Six of the nine instructional leaders were P-12 teachers and past participants of earlier Trek 21 Summer Institutes. One of these also had experienced working as both an instructional leader and a reviewer. The other three, one P-12 teacher and two college faculty members, had not been past participants, but had acted as instructional leaders and reviewers in a previous institute. These instructional leaders also acted as the reviewers of the completed participant units. Throughout the literature, individuals who have acted in the same capacity are designated by various descriptions. These descriptions include: reviewers, raters, judges, assessors, and markers.

P-12 - Pre-kindergarten through $12^{\text {th }}$ grade, indicating grade levels of pre-elementary school through high school.

Rubric - The evaluation tool used by the reviewers to evaluate the participants' units. This tool was designed by Dr. John G. Wells, the director of Trek 21, with Dr. Deborah L. Wells, and refined over the life of the project with input from the project's teacher-participants and instructional leaders.

Units - The finished products, web-based instructional units, created by the institute participants. Each unit consisted of on an overview and five lessons. 


\section{Chapter 2 - Review of the Literature}

\section{The Use of Rubrics in Evaluation}

Rubrics are tools that list the criteria for a piece of work, specifying "what counts" in an evaluation, as well as detailing the levels of quality, ranging from poor to excellent (Goodrich, 1997). They can be used to evaluate a broad range of subjects and activities (Moskal, 2000). Rubrics are generally developed by teachers, content experts, or other evaluators as guides for the scoring of students' work. They are particularly useful when judgments of quality might be influenced by an individual evaluator's personal criteria (Brookhart, 1999). By establishing a system in advance for performing a particular evaluation, assessments requiring the use of judgments can be made more objective.

Rubrics use descriptive scales to allow evaluators to categorize the extent to which students have met pre-determined criteria. The scales usually are numbered on a range, with each number in the range reflecting the achievement of a certain level. Besides aiding in and supporting the scoring for the raters, the descriptors can be used before the activity to explain to students what will be required and, after the scoring is complete, what could be improved upon (Moskal, 2000).

Rubrics can be analytic or holistic. Analytic rubrics break down the various criteria for the work into separate parts, each to be evaluated independently of the others (Moskal, 2000). Holistic rubrics combine the different criteria into a single descriptive scale, with the score reflecting the rater's overall impression of the work (Moskal, 2000; Pomplun, Capps, \& Sundbye, 1998). Trek 21’s rubric (Appendix A) was created by Dr. John Wells, the project’s director, and Dr. Deborah Wells. It was refined over the project's three years, using input from project participants and instructional leaders. It was an analytic rubric, with 55 individual items to be scored. 


\section{Reliability of Evaluators}

Trek 21 used the nine instructional leaders from the 2002 institute as reviewers of the participants' completed units. They were trained in the use of the rubric, using discussion-ratingdiscussion. In this method, reviewers first study and practice the applicable criteria and ratings in a group, then rate simulated products individually, and finally, come together again with the group to discuss and compare their ratings. In a study on training for constructed-response items, this method of training resulted in a rater reliability of approximately .90 (Pomplun, Sundbye, \& Kelly, 1996).

Inter-rater reliability refers to the concept of the agreement in scoring between independent evaluators (Moskal, 2000). There has been little research into inter-rater reliability when judgments are required (Frisbie, 1988; Pomplun, Capps, \& Sundbye, 1998). The studies that have been done on this topic usually involve evaluators performing assessment of writing skills. Baume and Yorke (2002) maintain that assessment, in general, suffers from a lack of theoretical research.

In studies throughout the 1980's and 1990's, MacMillan (2000) found that, despite different methods of training and management of the reviewers, variation in scores by reviewers often occurred. The greater the complexity of the object to be scored or the greater the variations between objects, the greater the disparity (Dunbar, Koretz, \& Hoover, 1991; Miller \& Legg, 1993). During an initial experiment in using portfolios to assess students in Vermont, a study by the RAND Corporation compared rater agreement of standardized assessments in writing as opposed to agreement in portfolio scoring (Nidds \& McGerald, 1997). The study found that, while reliability coefficients often reach .70 or higher for standardized writing assessments, the agreement in portfolio scoring in writing and math ranged from 0.33 to 0.43 . Nidds and McGerald state that, at least according to the findings in the Vermont experiment, portfolio 
assessment is valid when there are no specific educational standards, such as in a classroom setting, but that the judging of portfolios is too subjective to be meaningful for purposes of larger scale comparisons. Doolittle (1994) agrees, stating that, in cases where portfolios are used in making decisions concerning teacher certification or advancement, questions have been raised regarding variability in content and lack of agreement on standards.

According to Lam (1995), the major difficulty in performance assessment is ensuring that the resulting scores are compatible. Welch and Miller (as cited in MacMillan, 2000) maintain that, despite different methods of training, a pool of indistinguishable raters is "rarely if ever achieved.”

\section{Influences on Evaluators}

Raforth and Rubin explain that raters do not always use a rubric in the same way (as cited in Pomplun, Capps, \& Sundbye, 1998). Lumley (2002) explains that, while different evaluators often understand the rating categories in the same general way, there is some evidence that they sometimes apply the scale in different ways. The difference is often in the way they apply the scale's descriptors and how they make decisions when they come upon unavoidable conflicts in the wording on the scales and the products they are reviewing.

Rudner (1992) listed some additional threats to validity of scores when produced by judges. These include:

- The halo effect, where impressions formed about an individual on one dimension influences the rater's scoring of the individual on other dimensions.

- Stereotyping, where the impressions the evaluator has about a group to which an individual belongs may influence scoring.

- Perception differences, where the viewpoints and past experiences of the evaluator influence scoring. 
- Leniency/stringency error, where the evaluator doesn’t have enough knowledge, and therefore compensates by giving scores that are higher or lower.

- Scale shrinking, where an evaluator avoids either end of a rating scale.

Raters tend to depend on their own experience, knowledge, and views about what they are scoring even when they are using a rubric (Lumley, 2002; Sadler, 1989).

Most studies on judgments of evaluators have to do with rating written language performance. In a study of evaluators of English as a second language in Africa, Gamaroff (1999) had teachers of English from different African universities grade English essays of two seventh grade students. English was not a native language for either, however, one student's English was learned starting in Grade 1 and considered a "first learned language” while the other’s English was learned starting in Grade 5 and considered a "second learned language.”

No rubric or other instrument was used, as Gamaroff assumed that experienced teachers of English would be looking for the same general constructs when evaluating essays. Gamaroff found a wide variability in the scores for the student with English as a "second learned language.” For the student of English as a “first learned language,” there was less variability, but a wider range of scores. In this study, the negative judgments by the evaluators were compiled. For example, negative judgments of grammar for each student (19\% and 63\%) were almost in reverse of the negative judgments for each student on spelling (69\% and $25 \%$ ). In addition, the evaluators were asked to define their scores by explaining their criteria behind their scoring. For one evaluator, a score of 3 meant "meaningless cloudy” while for another a 3 meant "misspelled many words but not too bad.” Some evaluators scored primarily on spelling, while others concentrated on content. This study demonstrated how different evaluators can score the same product in different ways, however, because of the lack of an evaluation tool such as a rubric, it 
is difficult to determine if the variability in the scores was due to the evaluators' personal criteria or simply because they did not have a normalizing tool to guide them.

In another study of writing assessment, Lumley (2002) examined the ratings of four experienced English as a Second Language (ESL) teachers in Australia of the Special Test of English Proficiency (STEP). First, the teachers rated 12 tests, using a rubric consisting of four elements each rated on a 5-point scale. Then these same teachers evaluated another 12, also using the rubric, but reading the test out loud and describing their evaluating process as they reviewed. During this process, Lumley recorded the teachers, and later had the tapes transcribed. He coded each teacher's comments, and compiled them into categories correlating with the four categories on the rubric. He then added the total number of comments of each type, as well as totals within each type relating specific themes related to them.

Lumley found that the evaluators applied the rubric differently from each other, and sometimes even the same evaluator would apply it differently on different tests. When the evaluators came to an issue that they could not find covered in the rubric, they resorted to other strategies, such as weighing only one aspect of the criteria, or comparing the evaluation with an earlier one.

Lumley’s study gave a good indication of some of the issues that evaluators struggle with when using a rubric to rate something as complex as an essay. He studied the evaluators' thought processes, but did not look into the differences in backgrounds, training, or other characteristics. In addition, while essay products such as the STEP exams are intricate as far as evaluation, the web-based units and lessons created by the Trek 21 Institute participants are different and more complex, requiring a much more extensive rubric and a greater investment of 
time and effort by the evaluators. According to Miller and Legg (1993), the more complex the scoring task, the greater the potential for disparities in ratings.

Pitts, Coles, \& Thomas (1999) compared the ratings of portfolios of students at the Wessex New Trainer Course in 1997. The course took place over 5 days, with about 3-4 weeks between each class. The students were given "loose” guidelines on creating a portfolio during the course to demonstrate their learning.

The raters of the portfolios were eight experienced general practice trainers from the United Kingdom. They were given a training session before the start of the study. The training was designed to introduce, refine, and reinforce six evaluation criteria, while still maintaining awareness of the complexity of professional practice. The evaluation criteria included: evidence of "reflective learning," student self-awareness, recognition of effective teaching behaviors, ability to identify with their prospective learners, awareness of educational resources, and overall reflections on the course and students' own future career development. These criteria ware incorporated into an assessment guide for the raters to use when evaluating the portfolios. The raters evaluated the portfolios two times, with the second assessment taking place about one month after the first. The portfolios were graded based on the criteria on a scale of 0-5. Scores of 0-2 were identified as "refer” and scores of 3-5 were identified as "pass.”

Comparisons of the judges' ratings were performed on the first round of portfolio scores. Of the 12 portfolios evaluated, 10 were judged to have passed the overall assessment by more than half (five or more) of the judges. Only 3 of the 10 were judged as passing unanimously by the judges. Of the 2 portfolios not passed by five or more raters, 1 portfolio was judged as passing by one rater, and the other was passed by two raters. The total number of passes awarded by the raters ranged from 6 to 11. Pitts, Coles, \& Thomas (1999) determined that the 
agreement between the assessors was “slight” to “fair” based on a Kappa statistic. On the second round of evaluations, comparisons were made between each rater's assessments. The consistency of the individual rates from the first evaluation to the second was found to be “moderate” (Pitts, Coles, \& Thomas, 1999).

Pitts, Coles, \& Thomas determined that a group of experienced trainers, well-trained and using valid criteria, only reached a "fair" degree of inter-rater reliability when evaluating the portfolios. They also found differences in individual raters' scores on individual portfolios between one evaluation and the next. They explain this by citing Phillips, who, based on a theory by Thomas Kuhn, stated that all inquirers (or in their case, evaluators) are wrapped in their own individual paradigms based on their own reality, which influences their conceptual frameworks but may be quite different from the realities of others around them (Pitts, Coles, \& Thomas, 1999).

In a similar 1998 study, Pitts, Coles, \& Thomas (2001) compared the ratings of portfolios of trainers learning about learner-centered approaches to education. The raters again were eight experienced general practice trainers in the United Kingdom.

The learners were asked to create portfolios that would demonstrate their progress over the course. Although the portfolios were based on criteria normally used for recertification, in this study, the portfolios were used strictly for the purposes of research, with the students receiving grades through other methods.

The portfolios ranged widely in size, quantity, and intricacy. The evaluators assessed all the portfolios twice, with one month between ratings. The portfolio was rated using six criteria, a global “pass” or "refer” conclusion, and a comparison with a guidance framework that the 
students had been given. The criteria ranged on a scale of $0-5$, with $0-2$ being classified as “refer” and 3-5 classified as "pass.”

The raters judged nine of the thirteen portfolios as pass. Of these nine, four passes were unanimous, four were passed by seven of the eight judges, with the other four judging them as needing referral, and one was passed by six judges and failed by two. The judges marked three portfolios as refer. Of these, three judges passed one, while five graded it as refer, one was passed by two judges and referred by six, and one was passed by one and referred by seven. The final portfolio was tied, with four raters judging it as a pass and four judging it as refer. Agreement between the raters was found to be "slight” to "fair" but better than what would be expected by chance. When the raters reassessed the portfolios, the intra-rater results were found to be "moderate."

Pitts, Coles, \& Thomas concluded that the main issue in portfolio assessment is that, despite defining the criteria and training both the judges and the participants, such assessment is not "trustworthy." They believe that the individual and reflective qualities of a portfolio are part if its value to the student, and that this creates a need for flexibility in evaluation criteria. However, this individuality and flexibility inherently cause problems in reliability and fairness in the evaluations.

The design of the present study was based on a preliminary study I had performed, as a part of the Trek 21 project, to try to determine what might have influenced the instructional leaders’ evaluations (Weigandt \& Wells, 2003). The participants in this study were the Group A and Group C instructional leaders. I compared these two groups because they had the most ingroup diversity among the instructional leaders, and they were also the groups with the largest 
difference in institute participant skills, as the Group A teacher-participants were classified and "beginners” and the Group C teacher-participants were classified as “advanced.”

In this study, I coded the instructional leaders' negative and positive comments about the units on the combined Unit Score Sheets and Unit/Lesson Feedback Sheets into two categories (Pedagogical Issues and Technical Issues). I then divided the comments within these categories into themes. In the Pedagogical Issues category, the themes were: Clarity/Explanations, Assessment/Objectives, and Activities/Motivation. In the Technical Issues category, the themes were: Page Design, Spelling/Grammar, Links, and Copyright Issues. This data, along with their decisions on whether a unit should be posted or not posted, was compared with comments from interviews of the instructional leaders and their scores on the Survey of Computer Use, Principles of Adult Learning Scale, and Stages of Concern Questionnaire. The Survey of Computer Use scores were used to determine levels of computer skills and experience. The Principles of Adult Learning Scale scores were used to determine teaching styles (whether teacher-centered or learner-centered). The Stages of Concern Questionnaire scores were used to determine concerns about technology integration in the classroom.

Certain interesting findings came out of this study. In Group A, the two instructional leaders who were past participants passed less units than the instructional leader who was not a past-participant. In group $\mathrm{C}$, the one past participant passed the middle number of units. I had expected the past participants to be more lenient in their scoring, as they had mentioned during their interviews that they were aware of the pressure put on the institute teacher-participants, and that they had been uncomfortable being judged. The two instructional leaders who were teachers of technology (one college faculty member and one elementary school teacher), as expected, made the most technical suggestions in their respective group. The instructional leader who was 
a technology teacher in an elementary school passed the least units of any instructional leader in any of the groups. This was also not unexpected, as she had the most practical experience in the use of instructional technologies in P-12 teaching, and might be expected to be a more exacting judge of teacher-participants’ work in her field of expertise.

Working outside of a P-12 setting seemed to have an effect, as the college faculty members in both groups passed the highest percentage of units. They made the most overall positive comments in their groups, and the most positive comments about pedagogical issues. These two instructional leaders also scored high on the Survey of Computer Use and the highest on most of the Stages of Concern Questionnaire. The two college faculty members also were the most learner-centered instructional leaders in their respective groups, which may also have had an effect on their scoring. The P-12 teachers, comparatively, made less positive comments about the units’ pedagogical issues. This might have been due to their more teacher-centered learning styles, which was possibly a reflection of their work with younger students. On the other hand, their experience in P-12 settings may have simply made them more knowledgeable as to real needs for pedagogical improvement in P-12 instructional units. This study also showed the possibility of differences in scoring due to leniency/stringency error (where the evaluator does not have knowledge on as advanced a level as the person being evaluated and therefore compensates by giving them scores that are relatively higher or lower) (Rudner, 1992).

This original study led to the present one. I wanted to further investigate, and use some of what I found during the original study to enhance the methodology of this one. The major addition would be adding Group B to balance the findings from the other two groups. I would use the original six completed instructional leader interviews, but I added three questions, so I would be interviewing all the instructional leaders (Group B with all thirteen questions and 
Groups A and C with the additional three questions). I also used information from the original study to make changes in how I would code the combined Unit Score Sheets and Unit/Lesson Feedback Sheets. I had created the original coding for the combined sheets using open and axial coding. As I performed the study, I realized that a new category was required in addition to the Pedagogical and Technical categories. This category was General, to refer to comments that were either too general to classify or unclear to classify with a specific category or theme (such as “Nice PowerPoint” or "Needs work”). I also revised certain themes.

\section{Mixed Method Designs in Research}

Mixed method designs in research include both qualitative and quantitative data collection and analysis. Data collection can be in parallel form (concurrent mixed method design, where qualitative and quantitative data is collected and analyzed simultaneously), in sequential form (sequential mixed method design, where one type of data provides a basis for collection of another type of data), or where the data are converted (from quantitative to qualitative or the reverse) and analyzed again (conversion mixed method design) (Tashakkori \& Teddlie, 2003). Johnson and Onwuegbuzie (2004) maintain that a key characteristic of mixed methods research is its methodological diversity, which frequently results in superior research (compared to single method research). The words and narrative produced in qualitative research can be used to add meaning to the numbers produced in quantitative research, and the numbers can be used to add precision to the words and the narrative. This adds insights and understanding that might be missed when only a qualitative or quantitative method is used, and can provide stronger evidence for a conclusion through the comparison and corroboration of findings. The ability of qualitative data to more fully describe a phenomenon is important not only from the researcher's perspective, but also from the readers', as the information is presented in form that is often more 
familiar and meaningful to readers not experienced in quantitative research methods (Hoepfl, 1997).

\section{The Use of Surveys in Research}

Surveys are instruments used in quantitative research. The purpose of surveys in research is to describe the characteristics of an individual or group (Fraenkel \& Wallen, 2003). Surveys are often descriptive, that is, they are concerned with describing or identifying individual or group characteristics rather than explaining why they are that way. Surveys can be longitudinal or cross-sectional. In longitudinal surveys, information is collected at different points in time to determine changes over time. In cross-sectional surveys, information is obtained reflecting just one point in time. In many cases, a survey is given to just a sample of the population being studied, however, in certain cases, such as this study, the entire group is surveyed. This is known as a census (Fraenkel \& Wallen, 2003).

\section{The Use of Coding in Research}

Coding refers to the qualitative research technique of assigning words, letters, numbers, and/or phrases to data within interviews, field notes from observations, or documents, to describe and assign meaning to the data and to convey interpretations (Merriam, 1997; Miles \& Huberman, 1994). Assigning codes to data allows for meaningful categorization of data and the detection of relationships between the various pieces (Miles \& Huberman, 1994).

Open coding is a phrase used to describe labeling and categorizing of phenomena during data analysis (Merriam, 2002; Strauss \& Corbin, 1990). In open coding, data is broken down into parts and the researcher looks for similarities and differences to emerge which become the basis for the conceptual terms and phrases that will be used as codes (Strauss \& Corbin, 1990). The concepts, themes, and issues that begin to emerge are delineated using inferential (or pattern) codes (Miles \& Huberman, 1994). 
As the data is labeled assigned to categories using open coding, axial coding is used to make connections between categories and subcategories (Strauss \& Corbin, 1990). As described by Strauss and Corbin, axial coding creates subcategories when a category is further reviewed for context (the environment and conditions in which the phenomenon occurs), action/interaction (strategies used for a phenomenon within its context), and consequences (the results of the action/interaction).

\section{The Use of Interviews in Research}

Interviews are a form of qualitative research where individuals or groups are questioned orally (Fraenkel \& Wallen, 2003). Fetterman (as cited in Fraenkel \& Wallen, 2003) maintains that interviewing is the most important data collection technique available to a qualitative researcher. There are four basic types of interviews: structured, semistructured, informal, and retrospective (Fraenkel \& Wallen, 2003). Structured interviews, such as the interviews conducted for this study, are a predetermined series of questions designed to elicit specific answers from the respondents. Semistructured interviews are more informal, with open-ended questions that act as a starting point but allow the conversation to flow more naturally. Informal interviews are less formal that either structured or semistructured interviews, not involving and specific type or sequence of questions, more resembling casual conversation. Retrospective interviews attempt to get a respondent to recall something from the past. Retrospective interviews can be structured, semistructured, or informal. In the case of this study, many of the interviews could be considered retrospective, as they took place more than a year after the instructional leaders evaluated the institute participants’ units. 


\section{Chapter 3 - Methods}

As a part of the 2002 Trek 21 Summer Institute at West Virginia University, 35 P-12 teachers developed five-lesson web-based instructional units for use in their classrooms and for other teachers to use. Nine instructional leaders assisted with the delivery of the institute, and these instructional leaders acted as reviewers of the completed units. The instructional leaders were trained in the use of a rubric, which they used to determine whether each participant's unit was ready to post online, or if it required revisions before it could be posted. Three instructional leaders reviewed each group of units and posting decisions were based on the majority of the three reviews.

As I was compiling the scores to determine which units could be posted, I discovered that the scoring of the units as either passing to be posted online or requiring revisions before posting varied among the three reviewers in each group, sometimes greatly. Through this study, I attempted to determine what might have influenced the instructional leaders to score the units differently from each other.

\section{Research Approach}

I conducted this investigation using a mixed method study of qualitative and quantitative data instruments. This was a causal-comparative study. In this type of research, an attempt is made to determine the cause or the consequences of differences that already exist between or among individuals or groups (Fraenkel \& Wallen, 2003). In this case, I attempted to determine the effects of the instructional leaders' individual characteristics on their evaluations of the Trek 21 web-based units and lessons.

\section{Research Design}

The characteristics of the instructional leaders and their evaluations of the units and lessons were determined through the use of several instruments: the Survey of Computer Use 
(SCU) (Appendix B), the Principles of Adult Learning Scale (PALS) (Appendix C), the Stages of Concern Questionnaire (SoCQ) (Appendix D), ratings of the units based on the Trek 21 rubric (Appendix A) and comments on the combined Unit Score Sheets and Unit/Lesson Feedback Sheets (Appendix A), and commentary during interviews with the instructional leaders (Appendix I).

\section{Instruments}

The Principles of Adult Learning Scale (PALS)

The Principles of Adult Learning Scale (PALS) (Appendix C) was designed by Dr. Gary Conti to measure teaching style. The Principles of Adult Learning Scale instrument is a 44-item, self-reported survey on a six-point modified Likert scale, ranging from "Always" to "Never," where respondents indicate the frequency with which they practice the behavior described in the items. Possible scores range from zero to 220. The average score is 146 with a standard deviation of 20 (Conti, 1990). Scores near 146 reflect an eclectic approach, utilizing both teacher- and learner-centered styles. Those over 146 indicate more of a tendency towards learnercenteredness, while those below 146 reflect a more teacher-centered style. Scores tend to follow the bell curve, with the majority of scores ranging within one standard deviation of the mean (between 126 and 166). As scores move toward the outer edges of the first standard deviation, they indicate a more specific trend toward a specific style. Scores in the second standard deviation of 20 to 40 points different from the mean indicate a strong and consistent support of a definite style.

The Principles of Adult Learning Scale instrument was based on an original study by Conti using a group of 57 participants, producing a valid and reliable 44-item summated rating scale (Conti, 1979, Spoon \& Schell, 1998). A further analysis by Conti of 778 cases in which 
Principles of Adult Learning Scale was used indicated that the descriptive statistics for Principles of Adult Learning Scale are stable, that is, that 146 is an accurate mean and the standard deviation is 20 (Conti, 1979). An analysis of variance showed no significant differences among the various groups tested. This supported the generalizability of Principles of Adult Learning Scale (Conti, 1979; Spoon \& Schell, 1998). Conti performed a factor analysis using the Statistical Package for the Social Sciences (SPSS) Factor Analysis program, which supported the construct validity of Principles of Adult Learning Scale (Conti, 1979).

Although the Principles of Adult Learning Scale was originally designed to determine teaching style in adult basic education settings, it has been widely used in higher education studies to measure teaching style and has been used in several studies to assess the teaching style of distance educators (Dupin-Bryant, 2004). Trek 21 customized the instrument by eliminating two items that were not applicable to the classroom settings of the instructional leaders and teacher-participants.

The Survey of Computer Use (SCU)

The Survey of Computer Use, or SCU (Appendix B), was designed by the Trek 21 project to determine computer experience and skills. The first part of the Survey of Computer Use was based on a questionnaire developed by Kimball (1996) as part of his doctoral dissertation on the subject of the plans to incorporate technology into the California school system. The second part was based on the CODE 77 rubrics developed by Johnson (1998) as a part of a Minnesota school district formal staff development program that trained teachers how to use technology.

In the first part of the Survey of Computer Use, the participants self-report on each factor on the survey, using a scale of 1-4, with 1 meaning "frequently," 2 meaning "rarely," 3 meaning 
"never,” and 4 meaning "not available.” This first part of the Survey of Computer Use consists of four sections. The first section asks for self-ratings on the participant's technology background (such as what types of computers and other technologies used). The second section asks for selfratings on staff-centered technology (such as how often the participant uses certain applications for classroom instruction and management), the third section asks for self-ratings on studentcentered technology (such as how often the participant’s students use certain applications), and the fourth section asks for self-reports on learning strategies (to what extent the participant's students are engaged in certain strategies such as discovery learning and cooperative learning).

The second part of the Survey of Computer Use was based on Doug Johnson’s (1997, 1998) CODE 77 series of rubrics which described what his school district expected a computer using teacher to be able to do after 30 hours of formal computer instruction and 6 to 9 months of practice. CODE 77 was an acronym for "Computers On Desks Everywhere in District \#77," the name of the program. The rubrics primarily address professional productivity.

There are four CODE 77 rubrics: the Beginning CODE 77 Rubrics, the Advanced CODE 77 Rubrics, the Internet CODE 77 Rubrics, and the Administrative CODE 77 Rubrics. The Survey of Computer Use utilized the first three rubrics. The rubrics are based on self-reported levels of achievement in different competencies, with levels ranging from 1-4, with Level 1 reflecting pre-awareness, Level 2 reflecting awareness, level 3 reflecting mastery, and Level 4 reflecting advanced. The first of these rubrics was a self-evaluation of the participant's basic computer use (such as computer operations, file management, and ethics). The second was a self-evaluation of the participant's advanced teacher computer use (such as information literacy skills, individualization of educational programs, and research and evaluation of technology use 
in the classroom). The third was a self-evaluation of the participant's Internet use (such as email use, web page construction, and using the Internet as a teaching tool).

As designed by Trek 21, the Survey of Computer Use was comprised of two parts resulting in two separate scores. For the purposes of this study, because both parts measured general computer use and even had some information overlap, I used the average of the instructional leaders' scores on both sections to create a single Survey of Computer Use score for each instructional leader.

The Stages of Concern Questionnaire (SoCQ)

The Stages of Concern Questionnaire (SoCQ) (Appendix D) was designed measure people's feelings and perceptions about an educational innovation and the changes required for its implementation. Theories regarding change began to emerge in the late 1960's and early 1970's, when Frances Fuller and George Hall both conducted studies on the concerns of teachers toward innovation (Rakes \& Casey, 2002). Frances Fuller found that pre-service teachers were preoccupied with concerns about self, task, and impact. Hall, working with Richard Wallace and W.A. Dosset, discovered those same three sequences of concern were present when in-service teachers faced the implementation of innovations (Rakes \& Casey, 2002). This work resulted in the Concerns Based Adoption Model (CBAM) (Hall \& Loucks, 1978). The CBAM specifies seven stages of concern that an individual progresses through when something new is introduced into the environment. Table 2 lists the seven stages of concern.

Table 2

The Seven Stages of Concern Based on the CBAM

\begin{tabular}{|l|l|}
\hline $\begin{array}{c}\text { Stage 0 } \\
\text { Awareness }\end{array}$ & Little concern or involvement with the innovation. \\
\hline
\end{tabular}




\begin{tabular}{|c|l|}
\hline $\begin{array}{c}\text { Stage 1 } \\
\text { Informational }\end{array}$ & General awareness and interest in the innovation. \\
\hline $\begin{array}{c}\text { Stage 2 } \\
\text { Personal }\end{array}$ & Concerns about personal ability, demands, adequacy, and role. \\
\hline $\begin{array}{c}\text { Stage 3 } \\
\text { Management }\end{array}$ & Concerns that include logistics and efficient use of resources. \\
\hline $\begin{array}{c}\text { Stage 4 } \\
\text { Consequences }\end{array}$ & Concerns related to student outcomes. \\
\hline $\begin{array}{c}\text { Stage 5 } \\
\text { Collaboration }\end{array}$ & Concerns about working with others to implement the innovation. \\
\hline $\begin{array}{c}\text { Stage 6 } \\
\text { Refocusing }\end{array}$ & Concerns about modifications to the innovation. \\
\hline
\end{tabular}

The Stages of Concern Questionnaire consists of 35 statements to which the participants respond on a seven-point scale ranging from "not true of me now" to "very true of me now" to questions such as, "I would like to know what the use of the innovation will require in the immediate future.” While the Stages of Concern Questionnaire was originally design to measure concerns having to do with changes in curricula, Trek 21 used the Stages of Concern Questionnaire to measure attitudes toward instructional technologies, ranging from internal concerns (their own ability to deal with the technology) to external concerns (how their use of the technology affects their students and others). The concerns were identified by seven stages: internal concerns of Awareness, Informational, Personal, and Management, and external concerns of Consequence, Collaboration, and Refocusing.

The Stages of Concern Questionnaire was tested for validity and reliability in 1979 (Hall, George, \& Rutherford). It has been validated numerous times since then, as it has been widely used in many studies over the past 20 years and continues to have solid support in the literature 
(Newhouse, 2001; Rakes \& Casey, 2002). The project reworded the survey slightly (inserting "instructional technologies" into the survey to replace the word "innovation)." Unit Score Sheets

The Unit Score Sheets were based on the Trek 21 Unit/Lesson Assessment Rubric (Appendix A) and consisted of two sections. The first section described the criteria for the overall unit, while the second section described the criteria for the five individual lessons. Using the Unit Score Sheets, the instructional leaders rated each unit and each lesson on a three-point scale. Each instructional leader scored the overall unit based on five separate criteria, and scored each lesson on ten separate criteria. Total unit scores of 0-12 points reflected that revisions were needed, and scores of 13-15 reflected that the unit could be posted without revisions. Lesson scores of 0-24 points reflected that revisions were needed, while scores of 23-30 reflected that the lessons could be posted without revisions. As a note, the ranges on the sheets were listed as 7-24 and 23-30, which was an error; however, none of the instructional leaders mentioned the mistake. Based on the unit overview score and the lesson plans score, the instructional leader made a judgment as to each unit's overall quality, rating it as requiring revisions, acceptable to post as written, or as an exceptional example. In addition, the instructional leaders were asked to add comments and explanations of their scores in spaces next to the scores on the Unit Score Sheets.

\section{Unit/Lesson Feedback Sheets}

The Unit/Lesson Feedback Sheets were designed by Trek 21 to allow the evaluators additional space for comments about the units. These sheets contained two columns: one column for comments on strengths, and the other for comments on weaknesses. The instructional leaders were encouraged to make at least three comments in each column for each unit and each lesson. 
The instructional leaders' comments on each institute participant's Unit/Lesson Feedback Sheet were combined with the instructional leaders' comments on each participant's Score Sheet by Trek 21 personnel into one list of strengths and suggestions from each instructional leader for each unit.

Interviews

For the interviews, the instructional leaders were initially contacted to request an interview and set the date and time (Appendix G). Before the interview, each instructional leader received a letter explaining the voluntary nature of the study and how their privacy would be maintained (Appendix H). The interviews were standardized open-ended interviews (Appendix I). With this method of interviewing, the wording and sequence of the questions are determined in advance with all the interviewees asked the same basic questions in the same order, and the questions are worded in a completely open ended format (Fraenkel \& Wallen, 2003). The interviews were designed to investigate and compare the instructional leaders' thoughts and feelings about their roles as reviewers and about the participants and their units. The interviews consisted of 13 questions. These questions were:

1. Describe the role of instructional leader based on your experiences.

2. From your perspective as an instructional leader, what were the participants in the Trek $21 \mathrm{P}-12$ institute expected to do?

3. Tell me about your role as a unit reviewer - what was that like?

4. Here is the Trek 21 evaluation rubric. How close were the priorities, or the criteria, on this tool to your own priorities, or criteria, for the units?

5. If you were to design a rubric to evaluate the IT enhanced units, what would it be like?

6. Describe your perception of the units you reviewed. 
7. If you were preparing future instructional leaders, what would that preparation be like? How would you prepare them to be reviewers?

8. How would you rate the overall pedagogical expertise of the participants whose units you reviewed in comparison with your own?

9. How would you rate the overall technical expertise of the participants whose units you reviewed in comparison with your own?

10. How do you feel about integrating technology into teaching?

11. Tell me about your professional background (how long have you been teaching, what grades are you teaching and have you taught)?

12. Tell me about any other evaluation experiences you have had that come to mind.

13. Is there anything I haven’t asked you that you think I should know?

\section{Procedure}

\section{Study Participants}

The participants in this study were the nine instructional leaders involved in the delivery of the Trek 212002 P-12 Summer Institute. These instructional leaders also acted as evaluators of the completed institute units. The instructional leaders evaluating Group A consisted of two practicing $3^{\text {rd }}$ grade classroom teachers from different schools who had both been past participants of the Summer Institutes. The other instructional leader in this group was a college faculty member whose specialty was reading instruction, who had been an instructional leader and reviewer the previous year but had never been a participant of the institute. The instructional leaders investigating Group B consisted of three practicing P-12 teachers. One instructional leader from this group was a kindergarten teacher who was a participant in the first year of the project and an instructional leader and reviewer in the second. The two other instructional leaders in this group were a kindergarten teacher and a high school Spanish teacher, both of 
whom were past institute participants, but had never been instructional leaders or reviewers. The instructional leaders evaluating Group C included two practicing elementary school teachers, however, one was a sixth grade teacher and the other was a technology instructor. The sixth grade teacher was a past institute participant but not an instructional leader or reviewer and the technology instructor was previously an instructional leader and reviewer, but not an institute participant. The third instructional leader in this group was a college faculty member, whose specialty was instructional technology integration. This instructional leader had also acted as an instructional leader and reviewer the previous year, but had never been an institute participant.

\section{Data Collection}

The data were collected at various points in time, both before and after the evaluations took place, as follows:

1. The Survey of Computer Use was administered two times by Trek 21 as a part of the institute, before the institute took place and at the end of the cycle of events. As the evaluations took place between pre and post administration of these two surveys, the pre institute scores were used.

2. The Principles of Adult Learning Scale also was administered two times by Trek 21 as a part of the institute, before the institute took place and at the end of the cycle of events. As the evaluations took place between pre and post administration of these two surveys, the pre institute scores were used.

3. The Stages of Concern Questionnaire was administered three times by Trek 21 as a part of the institute: pre-institute, post institute, and at the end of the cycle of events. In order to maintain consistency, the pre institute scores were used, as these Stages of Concern scores were based on surveys completed at the same time 
as the other two surveys (the Survey of Computer Use and the Principles of Adult Learning Scale).

4. After the institute, I examined the instructional leaders' comments from the combined Unit Score Sheets and Unit/Lesson Feedback Sheets (Appendix E) and compiled them for each instructional leader into the following categories: total number of comments, total positive comments, total negative comments, total pedagogical comments, total technical comments, total positive pedagogical comments, total positive technical comments, total negative pedagogical comments, and total negative technical comments. These categories were further divided into the following themes: Clarity/Explanations, Assessment/Objectives, and Activities/Motivation, Page Design, Spelling/Grammar, Links, and Copyright Issues. General comments that could not be categorized (such as "Good site" or “Needs more work”) were coded as Generic Positive and Generic Negative. Appendix F contains the code book I created during coding.

5. Finally, I interviewed each instructional leader. I interviewed the instructional leaders who reviewed Group C approximately 3 months after they evaluated the units, and then contacted them again and asked some additional questions about 17 months later. I interviewed the instructional leaders who reviewed Group A approximately 6 months after their unit evaluations, and then asked some additional questions 14 months later. I interviewed the instructional leaders who reviewed Group B 20 months after the evaluations took place, and was able to ask them the entire set of questions I asked the other two groups in one sitting. I 
recorded the interviews on tape and transcribed them with the help of a professional transcriptionist.

Analysis

In order to determine any patterns that might indicate that a certain instructional leader characteristic had an influence on their scoring, I analyzed the data from the various sources and compared them by group using side-by-side columns on a comparison chart. The data entered on the comparison charts came from various sources.

The first nine rows of the chart contained data about the instructional leader characteristics. The first row contained the total scores for each instructional leader from the Principles of Adult Learning Scale. The second row contained the combined scores for each instructional leader from the Survey of Computer Use. The third row contained a $Y$ or $N$ regarding whether any instructional leader had a second peak in their concerns on the Survey of Computer Use that was an internal, as opposed to an external concern. The fourth row contained the totaled scores for each instructional leader on the Stages of Concern Questionnaire. The fifth row contained a $Y$ or $N$ indicating whether the instructional leader had a position that involved technology. This information came from interview questions 10 and 12 . The sixth row contained a $Y$ or $N$ indicating which instructional leaders considered themselves mentors (as opposed to peers). This information came from interview questions $1,2,3,6,8,9,11$, and 12 . The seventh row contained a $Y$ or $N$ indicating which instructional leader worked with the group being evaluated during the institute's delivery. This information came from project records. The eighth row contained a $Y$ or $N$ indicating whether each instructional leader agreed with the rubric. This information came from interview questions 2, 4, and 5. The ninth row contained a $Y$ or $N$ 
indicating whether the instructional leader was a past participant. This information came from project records.

The next rows contained the findings from analyzing the instructional leaders' combined Unit Score Sheets and Unit/Lesson Feedback Sheets. The first two of these rows included the percent of units passed by each instructional leader and each instructional leader's total number of comments on the units they reviewed. The next rows contained the percents of different types of comments (for example, comments that were pedagogical as opposed to comments that were technical). The last three rows contained the first, second, and third most mentioned theme of each instructional leader. Table 3 shows an example of the comparison chart used to compare instructional leaders within each group.

Table 3

Sample Data Comparison Chart

\begin{tabular}{|l|l|l|l|}
\hline & $\begin{array}{l}\text { First } \\
\text { Instructional } \\
\text { Leader }\end{array}$ & $\begin{array}{l}\text { Second } \\
\text { Instructional } \\
\text { Leader }\end{array}$ & $\begin{array}{l}\text { Third } \\
\text { Instructional } \\
\text { Leader }\end{array}$ \\
\hline Principles of Adult Learning Scale (PALS) & & & \\
\hline Survey of Computer Use (SCU) Combined Scores & & & \\
\hline Stages of Concern (SoC) Second Peak Internal & & & \\
\hline Stages of Concern (SoC) Total Score & & & \\
\hline Position Involving Technology & & & \\
\hline Considers Self a Mentor & & & \\
\hline Agreed with Rubric & & & \\
\hline Past Participant & & & \\
\hline Percent of Units Passed & & & \\
\hline Total Number of Comments & & & \\
\hline Percent of Comments that were Negative & & & \\
\hline Percent of Comments that were Pedagogical & & & \\
\hline Percent of Comments that were Technical & & & \\
\hline Percent of Positive Pedagogical Comments & & & \\
\hline Percent of Negative Pedagogical Comments & & & \\
\hline Percent of Positive Technical Comments & & & \\
\hline Percent of Negative Technical Comments & & & \\
\hline Percent of Generic Positive Comments & & & \\
\hline Percent of Generic Negative Comments & & & \\
\hline Most Mentioned Theme & & & \\
\hline
\end{tabular}




\begin{tabular}{|l|l|l|l|}
\hline & $\begin{array}{l}\text { First } \\
\text { Instructional } \\
\text { Leader }\end{array}$ & $\begin{array}{l}\text { Second } \\
\text { Instructional } \\
\text { Leader }\end{array}$ & $\begin{array}{l}\text { Third } \\
\text { Instructional } \\
\text { Leader }\end{array}$ \\
\hline Second Most Mentioned Theme & & & \\
\hline Third Most Mentioned Theme & & & \\
\hline
\end{tabular}

As an example of how the data was compared within each group, I looked at the scores from a particular instrument, in this case the Principles of Adult Learning Scale, and determined if any instructional leaders had a higher score than the others (i.e., a more learner-centered style). Then I looked at the data in each row from the instructional leaders' evaluations to see if they had the highest or lowest number in any category. For example, I looked to see if the instructional leader with the highest score on the Principles of Adult Learning Scale also passed the most units, if they made the most comments, and so on. I did this in all three groups. If I did find possible relationship in one group (such as, that the instructional leader with the highest Principles of Adult Learning Scale score passed the most units), I would look at the other two groups to see if they demonstrated the same pattern.

In some cases, one instrument provided most of the data for a particular research question, with others acting more as methods of triangulation. In other cases, several instruments were used to answer the question. For example, the first three research questions were addressed primarily through the study's surveys. Research Question 1 was addressed primarily through the Survey of Computer Use. Research Question 2 was primarily addressed through the Principles of Adult Learning Scale. Research Question 3 was primarily addressed though the Stages of Concern Questionnaire. Research Question 4 was primarily addressed through interview questions which asked about the instructional leaders' current professional positions, particularly interview questions 10,11, and 12. Research Question 5 was primarily addressed through interview questions about the instructional leaders' perceptions of their roles and the roles of the 
teacher-participants, particularly interview questions $1,2,3,6,8,9,11$, and 12 , as well as

information on whether the instructional leaders had been teacher-participants during previous

summer institutes. Research Question 6 was primarily answered through interview questions,

particularly questions 2, 4, 5, and 7, as well as the instructional leaders' comments from Unit

Score Sheets and Unit/Lesson Feedback Sheets. Table 4 shows the data sources and their

relationships to the research questions.

Table 4

Data Sources and Relationship to Research Questions

\begin{tabular}{|c|c|c|c|c|c|c|c|c|}
\hline & $\begin{array}{l}\text { Profession } \\
\text { al } \\
\text { Position }\end{array}$ & $\begin{array}{l}\text { Past } \\
\text { Experienc } \\
\text { e in the } \\
\text { Project }\end{array}$ & $\begin{array}{l}\text { Survey of } \\
\text { Computer } \\
\text { Use (SCU) }\end{array}$ & $\begin{array}{l}\text { Principles } \\
\text { of Adult } \\
\text { Learning } \\
\text { Scale } \\
\text { (PALS) }\end{array}$ & $\begin{array}{l}\text { Stages of } \\
\text { Concern } \\
\text { (SoCQ) }\end{array}$ & $\begin{array}{l}\text { Scores } \\
\text { from Unit } \\
\text { Score } \\
\text { Sheets }\end{array}$ & $\begin{array}{l}\text { Combined } \\
\text { Comments } \\
\text { from Unit } \\
\text { Score } \\
\text { Sheets and } \\
\text { Unit/ } \\
\text { Lesson } \\
\text { Feedback } \\
\text { Sheets }\end{array}$ & Interviews \\
\hline $\begin{array}{l}\text { RQ 1. How did the } \\
\text { instructional leaders' personal } \\
\text { computer use skills influence } \\
\text { their evaluations of the web- } \\
\text { based instructional units? }\end{array}$ & $\mathrm{X}$ & & $X$ & & & & $\mathrm{X}$ & $\mathrm{X}$ \\
\hline $\begin{array}{l}\text { RQ 2. How did the } \\
\text { instructional leaders' styles of } \\
\text { teaching influence their } \\
\text { evaluations of the web-based } \\
\text { instructional units? }\end{array}$ & & & & $X$ & & & $\mathrm{X}$ & $\mathrm{X}$ \\
\hline $\begin{array}{l}\text { RQ 3. How did the } \\
\text { instructional leaders' concerns } \\
\text { about Instructional Technology } \\
\text { integration influence their } \\
\text { evaluations of the web-based } \\
\text { instructional units? }\end{array}$ & & & & & $\mathrm{X}$ & & $X$ & $X$ \\
\hline $\begin{array}{l}\text { RQ 4. How did the } \\
\text { instructional leaders' current } \\
\text { professional positions influence } \\
\text { their evaluations of the web- } \\
\text { based instructional units? }\end{array}$ & $X$ & & & & & & $X$ & $\mathrm{X}$ \\
\hline $\begin{array}{l}\text { RQ 5. How did the } \\
\text { instructional leaders' } \\
\text { perceptions of their roles and } \\
\text { the roles of the participants } \\
\text { influence their evaluations of } \\
\text { the web-based instructional } \\
\text { units? }\end{array}$ & & $\mathrm{X}$ & & & & & $X$ & $X$ \\
\hline $\begin{array}{l}\text { RQ 6. How did each } \\
\text { instructional leader's own } \\
\text { criteria for what makes a good } \\
\text { unit/lesson influence his/her } \\
\text { evaluations of the web-based } \\
\text { instructional units? }\end{array}$ & & & & & & $X$ & $\mathrm{X}$ & $\mathrm{X}$ \\
\hline
\end{tabular}




\section{Limitations}

This study was based on the nine instructional leaders from the Trek 212002 P-12 Summer Institute. In order the make the task of carefully reviewing 36 units possible over the summer by nine reviewers, each reviewer only evaluated the units produced by one group: Group A (the Beginner Group), Group B (the Intermediate Group), or Group C (the Advanced Group). Therefore, individual reviewers were studied largely in comparison with the two others who reviewed in the same group.

In addition, because each instructional leader only reviewed a group that had been designated at a certain level of competence, each individual reviewer's potential to evaluate various levels of expertise in different ways could not be examined (For example, a reviewer may have been more or less lenient at different levels of experience or skill). It also was not feasible to compare differences in evaluations of male and female reviewers, as there was only one male in the group of nine instructional leaders.

The three surveys used in this study were administered by the project before the start of this study. One survey (the Survey of Computer Use) was developed by the project through the modification and combination of several other surveys. Neither the original surveys nor the final survey had been tested for validity or reliability. The other two surveys (the Stages of Concern Questionnaire and the Principles of Adult Learning Scale), were successfully tested for reliability and validity in their original forms; however, they were modified to fit the needs of the project. 


\section{Chapter 4 - Results}

As a part of the 2002 West Virginia University Trek 21 Summer Institute, 35 P-12 teachers developed five-lesson web-based instructional units for use in their classrooms the following fall. Nine instructional leaders assisted with the delivery of the institute, and then reviewed the completed units, using a rubric, to determine whether each participant's unit was ready to post online, or if it required revisions before it could be posted. Each group of units (those from Group A, Group B, and Group C) was reviewed by three instructional leaders, and posting decisions were based on the majority of the three reviews.

While reviewing the scores to determine which would be posted, I discovered that the scoring of the units as either passing to be posted online or requiring revisions before posting varied among the three reviewers, sometimes greatly. Through this study, I attempted to determine what might have influenced the instructional leaders to score the units way they did, by comparing the number of units they passed or did not pass, as well as their comments about the units on Trek 21 Rubric-Score Sheet-Unit/Lesson Feedback Sheets (Appendix A), by performing interviews (Appendix I), and by analyzing the results of several surveys [the Survey of Computer Use (SCU) (Appendix B), the Principles of Adult Learning Scale (PALS) (Appendix C), the Stages of Concern Questionnaire (SoCQ) (Appendix D)].

\section{Instructional Leaders Reviewing Group A}

\section{Instructional Leaders’ Backgrounds}

The instructional leaders reviewing the Group A units evaluated 11 institute participants’ units. The Group A instructional leaders consisted of one higher education professor and two elementary school teachers. To protect the instructional leaders’ privacy, their names have been changed. 
Ione. Ione was a college faculty art and instructional technologies instructor, who explained that she had been teaching "for decades” (over 25 years). She had also worked as a school administrator. She was very interested in technology, and felt that her background in art made for a natural transition into technology. She was the only one of the three reviewers of Group A who had been an instructional leader and reviewer for a previous institute, and the only one of the three that had not been a past participant. Ione believed that being a previous reviewer had an effect on her reviews of the 2002 Institute units. She felt that her experience had made it easier for her to do the evaluations relatively quickly and easily. In addition, Ione had a background as an artist, and felt that this made her better equipped to evaluate "creativeness" and “intangibles.” She was very experienced in various types of evaluation and had been involved in the development of the Trek 21 scoring rubric; she felt that this helped, as well.

Felicity. Felicity, a $3^{\text {rd }}$ grade teacher, was a past participant and new to being an instructional leader and reviewer. She had an extensive background in education, including being a special education teacher and an instructor of other special education teachers. She was a major advocate of technology in education. After the institute, she received a grant to direct the incorporation of technology into her elementary school. Having had little experience in evaluation beyond the classroom, she was concerned about being a first-time reviewer, and was very aware of her feelings as a participant during the previous year, particularly her sensitivity to negative comments about her Unit.

Sarah. Sarah, a $3^{\text {rd }}$ grade teacher for 34 years, was, like Felicity, a past participant and new as an instructional leader and reviewer. However, she had a wide variety of experience in evaluating, including assessing the work of children and adults in different contexts. She assisted in the development of the West Virginia “WESTEST,” helping decide whether particular 
questions were relevant and what levels of answers would be accepted to demonstrate "mastery" or other levels of knowledge. Sarah felt that technology was now an integral part of teaching. She explained that she had “been doing it for so long now I don't even think about it as something additional.” Sarah felt the most positive of the three reviewers about the reviewing experience. She recalled feeling discouraged as a participant at the amount of suggestions for her unit and felt that her role was to "find the positives." Sarah was the one instructional leader in the group who had worked closely with Group A participants in the creation of their units.

\section{PALS Scores of Instructional Leaders Reviewing Group A}

Ione's score on the Principles of Adult Learning Scale instrument of 137 was higher than the other two in the group, and the closest to a learner-centered median score of 146 of the three. Ione was the only instructional leader in the group whose Principles of Adult Learning Scale score fell in the first standard deviation, which reflected a style that was mixed teacher- and learner-centered (heading slightly more toward teacher-centered, but not that strongly). Felicity’s score of 118 on Principles of Adult Learning Scale reflected a much more teacher-centered style as it was in the second standard deviation, meaning that she had a committed teacher-centered style. Sarah’s Principles of Adult Learning Scale score of 117 was very close to Felicity’s score, and reflected a style that was similarly teacher-centered.

\section{SCU Scores of Instructional Leaders Reviewing Group A}

Ione's background in the use of instructional technologies is reflected in the highest score of the group on the Survey of Computer Use (89.91). Felicity, who also had a background in technology, although less of one than Ione, fell in the middle of the group with a score of 67.15, a score relatively lower than Ione and closer to that of Sarah’s score of 61.83. Figure 1 compares the Survey of Computer Use scores of the three instructional leaders reviewing Group A. 


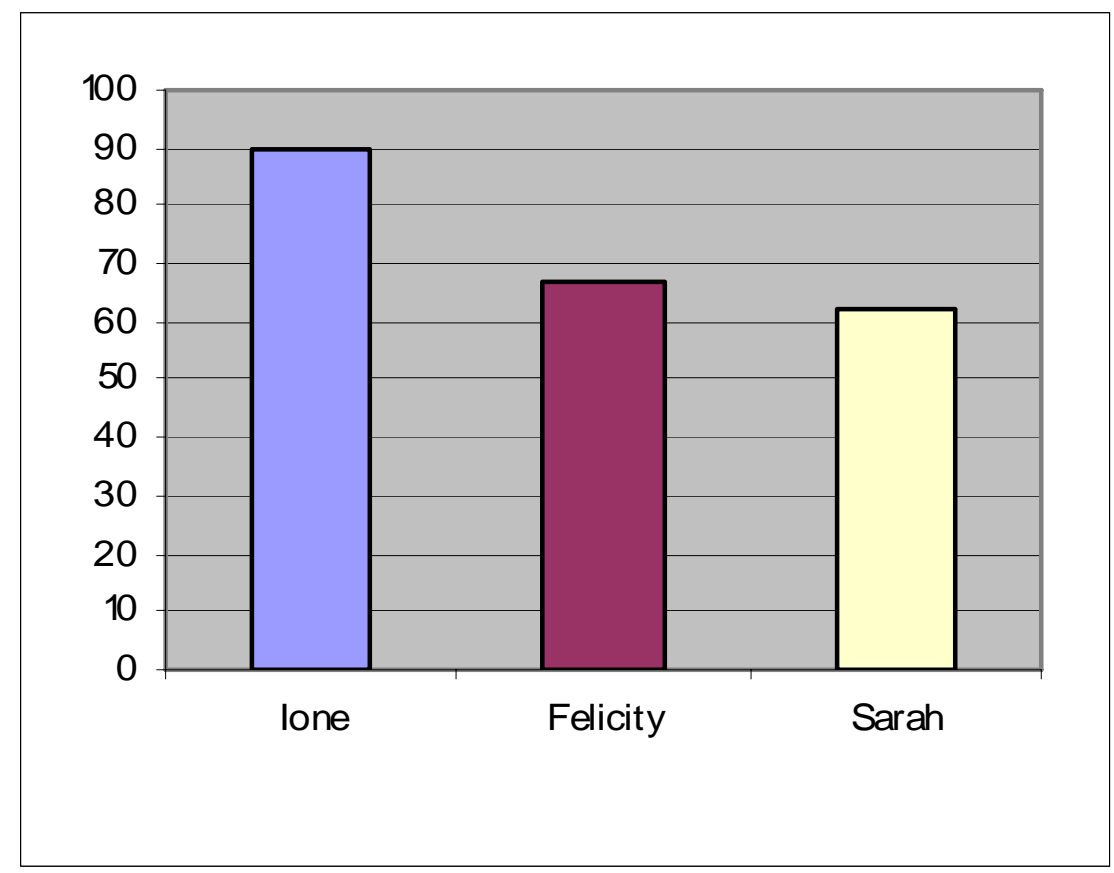

Figure 1. Survey of Computer Use Scores of Instructional Leaders Reviewing Group A SoC Scores of Instructional Leaders Reviewing Group A

The Stages of Concern Questionnaire is often used to measure changes in concerns toward an innovation over time. This study used the Stages of Concern Questionnaire only to measure the instructional leaders' concerns at one point in time. The most commonly used method of analyzing Stages of Concern scores involves comparing the highest score, or peak stage, or the two highest scores, or peaks. This method was somewhat difficult to use in this study, as the peak scores for all the participants were all similar, usually reflecting the most concerns in the last two external stages: Collaboration and Refocusing. In addition, their scores did not reflect a normal Stages of Concern pattern, which is generally s-shaped or bell-curved. This may have been because their positions as instructional leaders during the institute involved not only personally adopting an innovation, but also encouraging others to adopt it. Therefore, their concerns were based largely on external issues. However, in each group, one instructional leader had a second peak score that was in an internal stage, meaning that this instructional 
leader had some high concerns with their personal use of instructional technologies, so I was able to compare these instructional leaders with their counterparts whose concerns were more externally based. I also compared the instructional leader's total scores to see if higher concerns, in general, lead to any differences in scoring.

Ione had very low concerns on the Stages of Concern (SoC) in Awareness, moderately high scores in Informational, and very high scores in all the other stages, with her peak scores reflecting most concern with Refocusing, with a lower peak showing concern with Collaboration. Ione had the highest total score of concerns in the group (526), reflecting higher concerns about instructional technologies. Felicity was the one instructional leader in Group A to have her second peak of concern be an internal issue. Felicity’s Informational score was also very high, her Personal score was lower, and her Management and Consequences scores were quite low, while her Collaboration and Refocusing scores were very high (Collaboration was her peak concern). Felicity’s total score was the middle of the total scores within her group (387). Interestingly, despite her lower levels of technology knowledge, Sarah’s Stages of Concern scores on Awareness, Informational, Personal, and Management were generally lower than the others in the group were, and she had the lowest overall total score on the Stages of Concern Questionnaire (287). Because of her lower skill level, she may have felt less responsible than the others did to pass the knowledge onto others. Her concerns about Consequences were in between the other two instructional leaders' scores, and her peak scores concerned Collaboration and Refocusing. Figure 2 shows the SoC scores of the three instructional leaders reviewing Group A. 


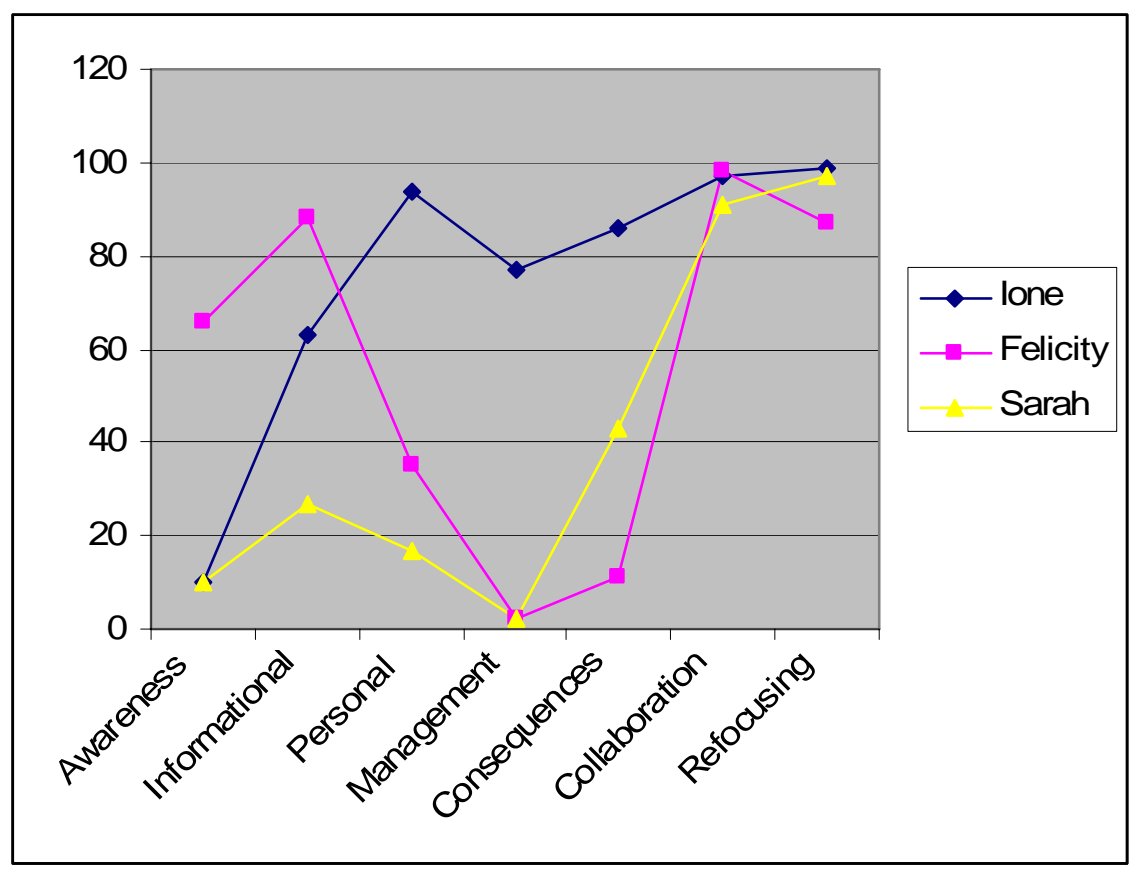

Figure 2. SoC Scores of Instructional Leaders Reviewing Group A

\section{Instructional Leaders’ Reviews of Group A Units}

Ione, Felicity, and Sarah evaluated the eleven Group A units, using the rubric. However, they had reviewed the units differently, as the percentage of units each gave passing scores to were quite different. Ione passed $91 \%$ of the eleven units, Felicity passed $73 \%$ of the units, and Sarah passed only 55\% of the units. Table 5 shows the total number of units passed and not passed in the group by each instructional leader.

Table 5

Instructional Leaders’ Group Total Posting Decisions for Group A Units

\begin{tabular}{|l|l|l|}
\hline & Number of Units Passed & Number of Units Not Passed \\
\hline Ione & 10 & 1 \\
\hline Felicity & 8 & 3 \\
\hline Sarah & 6 & 5 \\
\hline
\end{tabular}


Of the 11 units from Group A, the combined evaluations resulted in 9 approvals and 2 non-approvals. Of those approved, 5 were unanimous decisions and 4 were not unanimous. Of the 2 units not approved, 1 decision was unanimous. The total unanimous decisions in the reviews of Group A units were 6 out of 11. Table 6 shows the differences in the instructional leaders’ decisions for passing each Unit.

Table 6

Instructional Leaders’ Individual Posting Decisions for Group A Units

\begin{tabular}{|l|l|l|l|l|}
\hline Participant Unit & $\begin{array}{l}\text { Felicity's } \\
\text { Posting } \\
\text { Decisions }\end{array}$ & $\begin{array}{l}\text { Ione's } \\
\text { Posting } \\
\text { Decisions }\end{array}$ & $\begin{array}{l}\text { Sarah's } \\
\text { Posting } \\
\text { Decisions }\end{array}$ & $\begin{array}{l}\text { Final Combined } \\
\text { Posting Decision }\end{array}$ \\
\hline $\mathbf{1}$ & Y & Y & N & Y \\
\hline $\mathbf{2}$ & Y & Y & Y & Y \\
\hline $\mathbf{3}$ & Y & Y & Y & Y \\
\hline $\mathbf{4}$ & Y & Y & Y & Y \\
\hline $\mathbf{5}$ & N & Y & Y & Y \\
\hline $\mathbf{6}$ & Y & Y & Y & Y \\
\hline $\mathbf{7}$ & Y & Y & Y & Y \\
\hline $\mathbf{8}$ & N & N & N & N \\
\hline $\mathbf{9}$ & Y & Y & N & Y \\
\hline $\mathbf{1 0}$ & N & Y & N & N \\
\hline $\mathbf{1 1}$ & Y & Y & N & Y \\
\hline
\end{tabular}

The instructional leaders who reviewed Group A also showed marked differences in the total number of comments each instructional leader made on the eleven units. Felicity made 356 comments on the units, Ione made 581, and Sarah made 617 comments. There were also differences in the proportion of negative to positive comments made by the instructional leaders. 
Of Ione’s comments, 34\% were positive and 66\% were negative. Of Sarah’s comments, 27\% were positive and 73\% were negative. Of Felicity's comments, only 19\% were positive and the other $81 \%$ were negative. Table 7 compares the number of negative and positive comments of the instructional leaders.

Table 7

Instructional Leaders' Number of Negative and Positive Comments on Group A Units

\begin{tabular}{|l|l|l|l|}
\hline & Ione & Sarah & Felicity \\
\hline Total Positive Comments & 199 & 168 & 68 \\
\hline Total Negative Comments & 382 & 449 & 288 \\
\hline
\end{tabular}

Additional differences could be found in the types of comments made by the instructional leaders. Of Ione’s comments, 55\% referred to pedagogical issues, while $42 \%$ referred to technical issues, (with 3\% generic comments). Of Sarah’s comments, 55\% referred to pedagogical issues while 43\% referred to technical (with 3\% generic comments). However, 35\% of Felicity’s comments referred to pedagogical issues and 63\% referred to technical issues (with 2\% generic issues). Both Ione and Sarah had a higher percentage of pedagogical comments, while Felicity commented more on technical issues than on pedagogical issues. Table 8 compares the number of pedagogical and technical comments of the instructional leaders.

Table 8

Differences in Pedagogical, Technical, and Generic Comments on Group A Units

\begin{tabular}{|l|l|l|l|}
\hline & Ione & Felicity & Sarah \\
\hline Total Pedagogical Comments & 322 & 126 & 339 \\
\hline Total Technical Comments & 242 & 223 & 265 \\
\hline Total Generic Comments & 17 & 7 & 14 \\
\hline
\end{tabular}


Within the pedagogical and technical comments of these instructional leaders, there was another difference. While Ione and Felicity each made about the same amount of positive pedagogical comments as they made negative pedagogical comments, Sarah made twice as many negative as positive pedagogical comments. As far as technical comments, the instructional leaders percentage of negative and positive comments were very similar, with the numbers of negative comments far outnumbering the positive comments for all three instructional leaders. Table 9 shows the breakdown of pedagogical and technical comments of the instructional leaders.

Table 9

Instructional Leaders' Positive and Negative Pedagogical and Technical Comments on Group A Units

\begin{tabular}{|l|l|l|l|}
\hline & Ione & Felicity & Sarah \\
\hline Total Positive Comments (Pedagogical) & 159 & 62 & 100 \\
\hline Total Negative Comments (Pedagogical) & 163 & 64 & 238 \\
\hline Total Positive Comments (Technical) & 25 & 9 & 58 \\
\hline Total Negative Comments (Technical) & 217 & 214 & 207 \\
\hline
\end{tabular}

Besides differences in the numbers and categories of comments, there were also differences in the themes each instructional leader mentioned. For example, while Ione and Sarah made a similar total number of comments, Ione made 144 comments about Activities/Motivation, while Sarah made only 78 comments on this theme. Figure 3 illustrates the differences in the themes within the instructional leaders' total numbers of comments. 


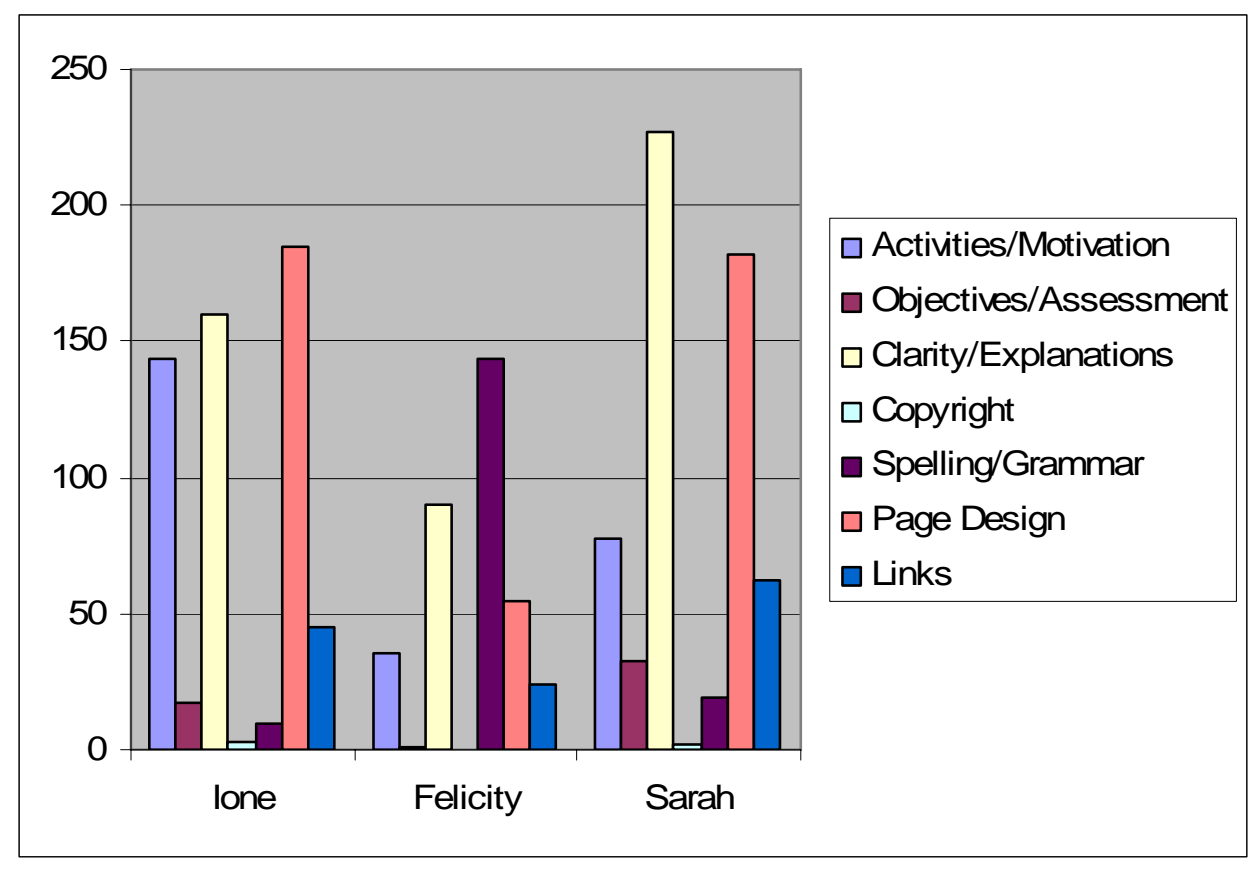

Figure 3. Comparison of Instructional Leaders’ Comment Themes on Group A Units

The majority of Ione's combined comments concerned pedagogical issues, but the largest amount of comments were about technical issues. Her comments emphasized Page Design (185), Clarity/Explanations (160), and Activities/Motivation (144), with a lesser emphasis on Links (45), Objectives/Assessment (17), Spelling/Grammar (10), and Copyright Issues (3). Ione was the only instructional leader in the group with a mixed teacher- and learnercentered style (the other two instructional leaders were committed to teacher-centered styles). She commented more about Clarity/Explanations than about Activities/Motivation; however, the difference between the numbers of these comments was not great. She also passed the greatest number of units.

Ione was experienced in both teaching using technology and teaching about technology, and she stated that she was a strong proponent of the use of technology in education. This was reflected in her Stages of Concern and Survey of Computer Use scores. Ione did not perceive the participants as peers, but saw herself as more of a mentor. This might explain why she passed a 
large number of units, but made a large number of comments and suggestions for improvement. Ione mentioned that she thought the Trek 21 rubric was very good. She had created her own rubric for evaluation of students she teaches that, while very similar, placed a greater emphasis on design. This, along with her background in teaching how to use instructional technologies, was particularly evident in that her most numerous type of negative comments related to technical aspects of the units, with issues relating to Page Design receiving the most comments overall. Another influence could also have been her background in art and design. Her second highest number of comments was based on the need for better Clarity/Explanations, with a somewhat less but still substantial amount of comments about Activities/Motivation. This could possibly reflect Ione's teacher-centered (bordering on learner-centered) teaching style. This style of teaching might also explain her passing units while still making a large number of suggestions.

Felicity made the least comments of the three instructional leaders and the least in each category, except for Spelling/Grammar, where she made many more comments than the other two reviewers did. She was the only instructional leader to make more technical than pedagogical comments. However, these comments were mostly regarding spelling and grammar in one Unit (107 of her 144 comments on that particular unit). While Felicity’s comments concentrated mainly on Spelling/Grammar (144) with a lesser emphasis on Clarity/Explanations (90), she also commented on Page Design (55), Activities/Motivation (35), Links (24), and Objectives/Assessment (1). Felicity had a teacher centered style, reflected in a larger number of comments about Clarity/Explanations and fewer comments about Activities/Motivation.

Felicity’s high internal Stages of Concern scores and fairly high Survey of Computer use scores may be reflected in her suggestions having largely to do with technical issues 
(Spelling/Grammar and to a lesser extent, Page Design). She had also mentioned that, while she felt the institute participants were similar in pedagogical skills to herself, she felt she was stronger technically. Felicity's teacher-centered style is reflected in a greater emphasis on Clarity/Explanation than Activities/Motivation. Felicity expressed the most dissatisfaction in the group about several units that had spelling and grammar errors. Suggestions for corrections regarding a large amount of spelling and grammar errors in one unit, in particular, accounted for more than half of her total negative comments for the entire group. She, like Ione, felt that some of the participants did not "put a lot into it." However, she felt that most of the institute participants did well, particularly at integrating various instructional technologies. She felt that they had achieved a great deal considering their beginner status, a possibility that a stereotyping effect may have occurred, i.e., where the impressions the evaluator has about a group to which an individual belongs influences the rater’s scoring (Rudner, 1992).

Sarah, a third-grade teacher, despite describing feeling as though her role was to find the positives, and mentioning how uncomfortable she was being judged when she was a participant, actually passed the fewest units, made the most overall comments, and made the largest number of suggestions for improvement in the group. While Felicity made proportionately more negative comments to total comments, these were mostly for the one unit with the large number of Spelling/Grammar errors. When taking these comments for that one unit into account, in general, Sarah made the largest percentage of negative comments in the group. Sarah had a teacher-centered style, based on the Principles of Adult Learning Scale, reflected in an emphasis on Clarity/Explanations (227), and less on Activities/Motivation (78). She also discussed Page Design (182), Links (62), Objectives/Assessment (33), and Spelling/Grammar (19), and Copyright (2). 
Sarah's Principles of Adult Learning Scale score indicated a style that was the most teacher-centered of the group. The emphasis on pedagogical as opposed to technical issues may also have been influenced by Sarah's lower levels of technology knowledge, as shown in her Survey of Computer Use score. Interestingly, despite her lower levels of technology knowledge, Sarah’s Stages of Concern scores on Awareness, Informational, Personal, and Management showed lower concerns about these issues than the others in the group did. Her concerns about Consequences were in between the other two instructional leaders' scores, and her Collaboration and Refocusing scores were, similar to the other two instructional leaders in the group, high.

While Ione passed the largest number of units in the group of three reviewers, she also commented that she believed the participants should have integrated more student activities and felt they could have "pushed themselves just a little further." Sarah believed that most of the units were good, especially because of the limited time the participants had to create them, but also felt that many of the participants had "stuck to the minimum” as far as Instructional Technology integration, a possible explanation for her large amount of comments about Page Design. Ione, like all the instructional leaders, made more negative than positive comments. In Ione's case, the negative comments were almost double the positive comments; however, the other two reviewers in this group had even higher percentages of negative to positive comments.

All three instructional leaders in this group felt that the rubric was very good, only Ione mentioned that she might have added more emphasis on web-design. The three reviewers of the Group A found the reviewing process to be hard and sometimes disheartening, but also somewhat fun and very educational. They felt they learned a great deal from the units they reviewed as well as from participating in the evaluation process. Table 10 shows the main findings for the instructional leaders reviewing Group A. 
Table 10

Major Findings for the Instructional Leaders Reviewing Group A Units

\begin{tabular}{|c|c|c|c|}
\hline & Ione & Felicity & Sarah \\
\hline Principles of Adult Learning Scale (PALS) & 137 & 118 & 117 \\
\hline Survey of Computer Use (SCU) Combined Scores & 89.9 & 67.15 & 61.83 \\
\hline Stages of Concern (SoC) Second Peak Internal & No & Yes & No \\
\hline Stages of Concern (SoC) Total Score & 526 & 387 & 287 \\
\hline Position Involves Technology & Yes (official position) & $\begin{array}{r}\text { Yes (unofficial } \\
\text { "guru') }\end{array}$ & No \\
\hline Considers Self a Mentor & Yes & No & No \\
\hline Worked with Group Evaluated & No & No & Yes \\
\hline Agreed with Rubric & Yes (add more design) & Yes & Yes \\
\hline Past Participant & No & Yes & Yes \\
\hline Percent of Units Passed & $91 \%$ & $73 \%$ & $55 \%$ \\
\hline Total Number of Comments & 581 & 356 & 617 \\
\hline Percent of Comments that were Negative & $66 \%$ & $81 \%$ & $71 \%$ \\
\hline Percent of Comments that were Pedagogical & $55 \%$ & $35 \%$ & $55 \%$ \\
\hline Percent of Comments that were Technical & $42 \%$ & $63 \% *$ & $43 \%$ \\
\hline Percent of Positive Pedagogical Comments & $27 \%$ & $17 \%$ & $16 \%$ \\
\hline Percent of Negative Pedagogical Comments & $28 \%$ & $18 \%$ & $39 \%$ \\
\hline Percent of Positive Technical Comments & $4 \%$ & $3 \%$ & $9 \%$ \\
\hline Percent of Negative Technical Comments & $37 \%$ & $60 \% *$ & $34 \%$ \\
\hline Percent of Generic Positive Comments & $3 \%$ & $1 \%$ & $2 \%$ \\
\hline Percent of Generic Negative Comments & $0 \%$ & $1 \%$ & $1 \%$ \\
\hline Most Mentioned Theme & Page Design & Spelling & Clarity \\
\hline Second Most Mentioned Theme & Clarity & Clarity & Page Design \\
\hline Third Most Mentioned Theme & Activities & Page Design & Activities \\
\hline \multicolumn{4}{|c|}{ * Felicity's relatively large percent of technical comments had to do with spelling errors in one unit } \\
\hline
\end{tabular}

\section{Instructional Leaders Reviewing Group B}

The three instructional leaders reviewing Group B units evaluated 10 institute

participants’ units.

\section{Instructional Leaders’ Backgrounds}

Farrah. Farrah had been teacher of high school Spanish teacher for 38 years. She was a

past participant of the summer institutes, and a first-time instructional leader and reviewer for the 2002 institute. Farrah described attending “any training the county offered teachers” in technology for the previous eight or nine years. She also participated in web-design courses. 
Despite her extensive background in computer use, she was very modest about her computer skills, explaining that she felt she needed to learn computers because her students and student teachers were becoming more proficient. She also was very complimentary toward the institute participants' units, with the exception of one that she found to be disappointing. Due to her perception of the teaching and technology skills of the participants, Farrah appeared to feel that she was more like a peer than a mentor.

Farrah was very enthusiastic about the use of technology in the classroom. She felt the use of computers were highly motivating for students. Farrah stated that "some of the best projects/assignments that my students have done have been things that they have done on the Internet, or, at least, used the computers for.” During her interview, she demonstrated a project her students were working on that incorporated a Spanish web-site on room design. Her only reservation about technology was the concern that technology might be added without a legitimate purpose. Her main experience with evaluation, besides the Trek 21 project, was in the classroom.

Elizabeth. Elizabeth had been a kindergarten teacher for 14 of her 23 years of teaching. Before teaching kindergarten, she was an elementary school teacher of several different grade levels. Elizabeth explained that she always had a "knack" with computers. She described having taken some early programming courses, and had felt that working with computers came naturally to her. After those initial programming courses, Elizabeth often received technology training through online training courses and summer training programs. She had some experience with writing assessment, but not much other evaluation experience beyond her classroom. Elizabeth was a past institute participant, and this had been her first experience as an instructional leader and reviewer. She seemed to feel that the institute participants were at about 
the same level, making her feel like more of a peer than a mentor. She was a strong proponent of technology in the classroom, and mentioned several times that she wished there was a continuation of the Trek 21 program.

Nancy. Nancy was a kindergarten teacher in her fortieth year of teaching. She had taught every elementary grade: 1st through 8th. Nancy had participated in several different workshops about integrating technology into teaching. She also worked with the faculty in her school and helping them develop their own web pages for a state educational site. She was a past institute participant, but new to the role of instructional leader and reviewer. Another strong proponent of technology in teaching, she felt that it might be the only way to teach certain subjects or reach certain students. She found the units she reviewed to be at about the same level or only slightly lower than her own, and she seemed to express herself as more of a mentor than as a peer, possible because of her many years of teaching and her strong technology background.

\section{PALS Scores of Instructional Leaders Reviewing Group B}

Elizabeth, with a Principles of Adult Learning Scale score of 146, was the only reviewer in Group B to have a teaching style in the in the mixed teacher- and learner-centered style. Elizabeth’s score of 146 is actually the median Principles of Adult Learning Scale score, reflecting an exact combination of both styles. Nancy’s score of 120 on Principles of Adult Learning Scale (in the second standard deviation) reflected a much more teacher-centered style, while Farrah’s Principles of Adult Learning Scale score of 116 (also in the second standard deviation) reflected a style that was the most teacher-centered of the group.

\section{SCU Scores of Instructional Leaders Reviewing Group B}

Nancy had more of a background in technology than the others in her group, and her Survey of Computer Use score of 65.90 reflects this. Farrah and Elizabeth had lower scores that 
were essentially the same (46.10 for Farrah and 46.97 for Elizabeth). Figure 4 compares the Survey of Computer Use scores of the three instructional leaders reviewing Group B.

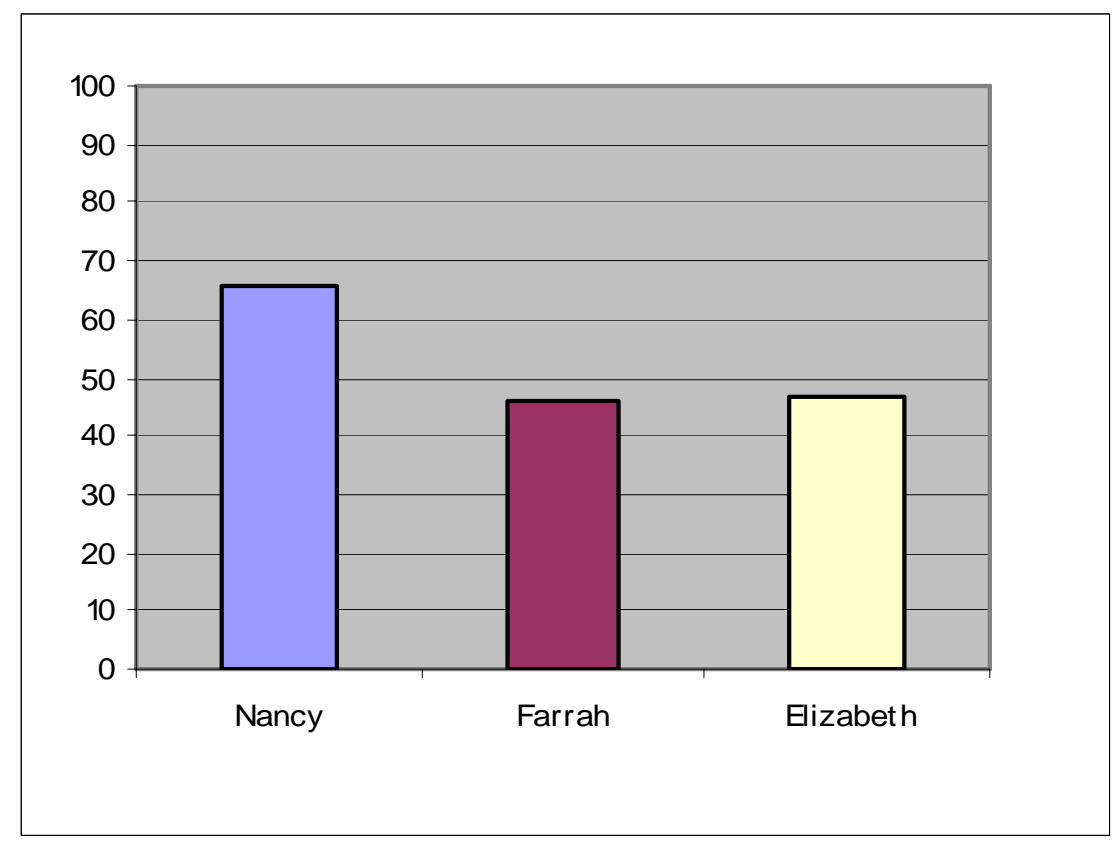

Figure 4. Survey of Computer Use Scores of Instructional Leaders Reviewing Group B SoC Scores of Instructional Leaders Reviewing Group B

Nancy had a fairly high score on Awareness, and the highest score of the group on Informational concerns (her second peak concern). Her Personal, Management, Consequences, and Collaboration scores were all low, and her Refocusing score was her first peak, and the highest of the group. Elizabeth's concerns about Awareness and Informational were fairly high, and her Personal, Management, and Consequences were very low. Her concerns about Collaboration were her peak concerns, and her Refocusing concerns were her second peak. Farrah had the lowest Awareness and Informational concerns. Her Personal and Management concerns, while fairly low, were the highest in the group, and her concerns with Consequences were also low. Her Refocusing and Collaboration and Refocusing scores were quite high (her first and second peak concerns). All three instructional leaders in this group had similar total 
scores: Nancy had a total score of 393, Elizabeth had a total score of 389, and Farrah had a total score of 375. Figure 5 shows the Stages of Concern scores for the instructional leaders reviewing Group B.

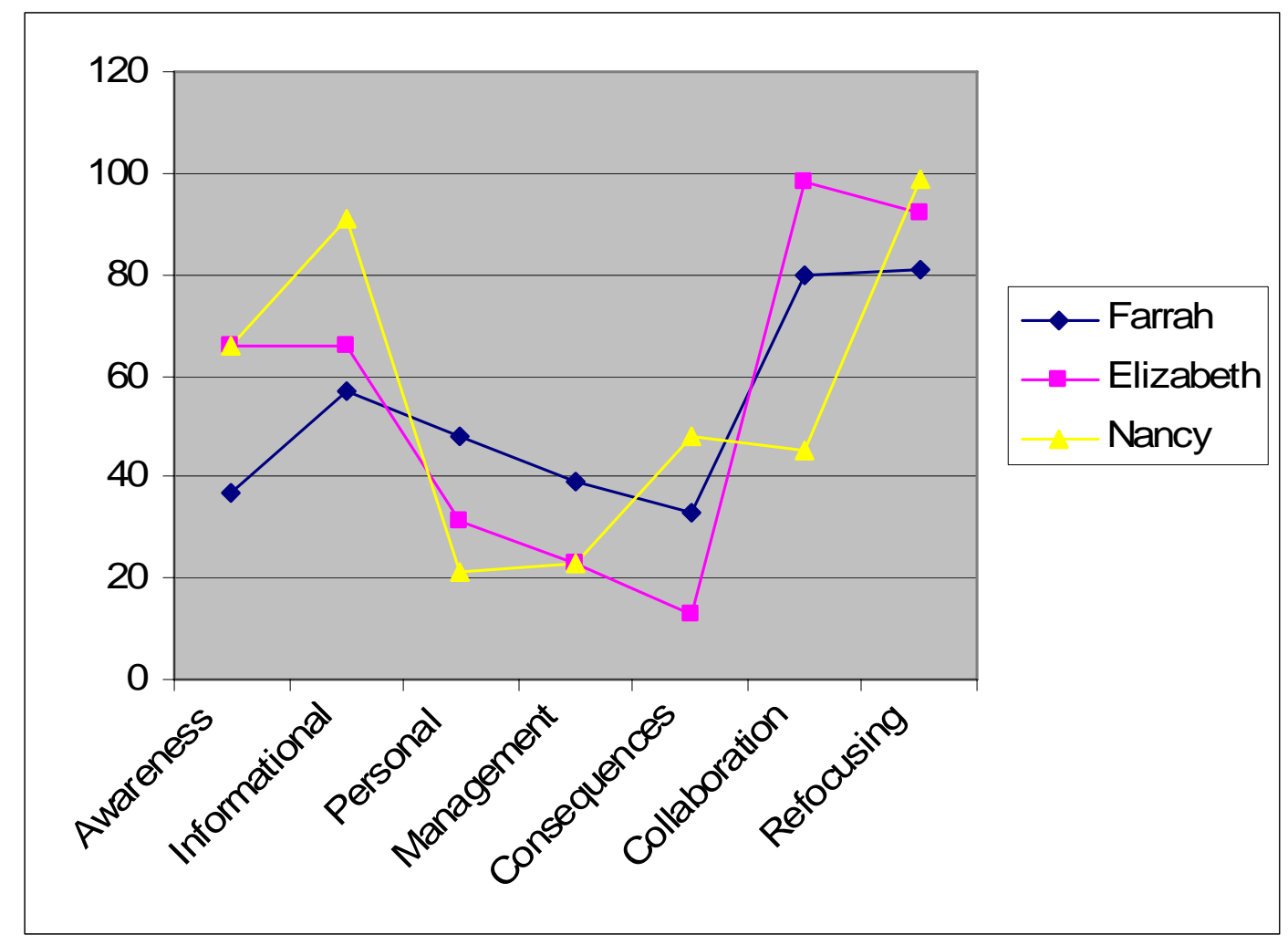

Figure 5. SoC Scores of Instructional Leaders Reviewing Group B Instructional Leader's Reviews of the Group B Units

Farrah, Elizabeth, and Nancy evaluated the ten Group B units, using the same rubric. However, the percentage of units each gave passing scores to were quite different. Elizabeth passed $100 \%$ of the units, while Farrah passed $90 \%$ of the units and Nancy passed only $50 \%$ of the units. Table 11 shows the differences in the numbers of units the instructional leaders passed and did not pass. 
Table 11

Instructional Leaders’ Group Total Posting Decisions for Group B Units

\begin{tabular}{|l|l|l|}
\hline & Number of Units Passed & Number of Units Not Passed \\
\hline Elizabeth & 10 & 0 \\
\hline Farrah & 9 & 1 \\
\hline Nancy & 5 & 5 \\
\hline
\end{tabular}

Of the 10 units from Group B, the combined evaluations resulted in 9 approvals and 1 non-approval. Of the 9 approvals, 5 units were unanimously approved, and 4 were "split decisions.” The 1 non-approved unit was also not unanimous. This made for a total of 5 unanimous decisions and 5 "split decisions.” Table 12 shows the differences in the instructional leaders’ decisions for passing each Unit.

Table 12

Instructional Leaders' Individual Posting Decisions for Group B Units

\begin{tabular}{|c|c|c|c|c|}
\hline Participant Unit & $\begin{array}{l}\text { Elizabeth's } \\
\text { Posting } \\
\text { Decisions }\end{array}$ & $\begin{array}{l}\text { Farrah's } \\
\text { Posting } \\
\text { Decisions }\end{array}$ & $\begin{array}{l}\text { Nancy's } \\
\text { Posting } \\
\text { Decisions }\end{array}$ & $\begin{array}{l}\text { Final Combined } \\
\text { Posting Decision }\end{array}$ \\
\hline $\mathbf{1}$ & $\mathrm{Y}$ & $\mathrm{Y}$ & $\mathrm{Y}$ & $\mathrm{Y}$ \\
\hline $\mathbf{2}$ & $\mathrm{Y}$ & $\mathrm{N}$ & $\mathrm{N}$ & $\mathrm{Y}$ \\
\hline $\mathbf{3}$ & $\mathrm{Y}$ & $\mathrm{Y}$ & $\mathrm{N}$ & $\mathrm{Y}$ \\
\hline $\mathbf{4}$ & $\mathrm{Y}$ & $\mathrm{Y}$ & $\mathrm{Y}$ & $\mathrm{Y}$ \\
\hline $\mathbf{5}$ & $\mathrm{Y}$ & $\mathrm{Y}$ & $\mathrm{Y}$ & $\mathrm{Y}$ \\
\hline $\mathbf{6}$ & $\mathrm{Y}$ & $\mathrm{Y}$ & $\mathrm{N}$ & $\mathrm{Y}$ \\
\hline $\mathbf{7}$ & $\mathrm{Y}$ & $\mathrm{Y}$ & $\mathrm{Y}$ & $\mathrm{Y}$ \\
\hline $\mathbf{8}$ & $\mathrm{Y}$ & $\mathrm{Y}$ & $\mathrm{Y}$ & $\mathrm{Y}$ \\
\hline $\mathbf{9}$ & $\mathrm{Y}$ & $\mathrm{Y}$ & $\mathrm{N}$ & $\mathrm{N}$ \\
\hline $\mathbf{1 0}$ & $\mathrm{Y}$ & $\mathrm{Y}$ & & $\mathrm{N}$ \\
\hline
\end{tabular}


The instructional leaders reviewing Group B also showed marked differences in the total number of comments each instructional leader made on the ten units. Elizabeth made a total of 235 comments on the units, and Farrah made about the same amount at 238, but Nancy made 415 comments. There were also differences in the proportion of negative to positive comments made by the instructional leaders. Of Elizabeth’s comments, 37\% were positive and 63\% were negative. Of Farrah’s comments, 45\% were positive and 55\% were negative. Of Nancy’s comments, $27 \%$ were positive and $73 \%$ were negative. Table 13 compares the number of negative and positive comments of the instructional leaders.

Table 13

Instructional Leaders’ Number of Negative and Positive Comments on Group B Units

\begin{tabular}{|l|l|l|l|}
\hline & Farrah & Elizabeth & Nancy \\
\hline Total Positive Comments & 107 & 87 & 111 \\
\hline Total Negative Comments & 131 & 148 & 304 \\
\hline
\end{tabular}

Additional differences could be found in the types of comments made by the instructional leaders. Of Farrah’s comments, 74\% referred to pedagogical issues, while 25\% referred to technical issues, (with 1\% generic comments). Of Elizabeth’s comments, 57\% referred to pedagogical issues, while 39\% referred to technical issues, (with $4 \%$ generic comments). Of Nancy’s comments, 68\% referred to pedagogical issues and 30\% referred to technical issues (with $2 \%$ generic issues). All three instructional leaders had higher percentage of pedagogical comments compared to technical comments. Table 14 compares the number of pedagogical, technical, and generic comments of the instructional leaders. 
Table 14

Differences in Pedagogical, Technical, and Generic Comments on Group B Units

\begin{tabular}{|l|l|l|l|}
\hline & Farrah & Elizabeth & Nancy \\
\hline Total Pedagogical Comments & 175 & 134 & 282 \\
\hline Total Technical Comments & 60 & 91 & 124 \\
\hline Total Generic Comments & 3 & 10 & 9 \\
\hline
\end{tabular}

Within the pedagogical and technical comments of these instructional leaders, there was another difference. While Farrah made a similar amount of positive versus negative pedagogical comments, Elizabeth and Nancy made a greater proportion of negative pedagogical comments. As far as technical comments, Farrah and Nancy made very few positive comments about technical issues, with most technical comments being negative. This was particularly true of Nancy, who made 122 negative comments about technical issues, and only 2 positive technical comments. Table 15 shows the breakdown of pedagogical and technical comments of the instructional leaders.

Table 15

Instructional Leaders’ Positive and Negative Pedagogical and Technical Comments on Group B Units

\begin{tabular}{|l|l|l|l|}
\hline & Farrah & Elizabeth & Nancy \\
\hline Total Positive Comments (Pedagogical) & 92 & 49 & 105 \\
\hline Total Negative Comments (Pedagogical) & 83 & 85 & 177 \\
\hline Total Positive Comments (Technical) & 12 & 29 & 2 \\
\hline Total Negative Comments (Technical) & 48 & 62 & 122 \\
\hline
\end{tabular}


Besides differences in the numbers and categories of comments, there were also differences in the themes each instructional leader mentioned. Figure 6 illustrates the differences in the three instructional leaders' themes within their total numbers of comments.

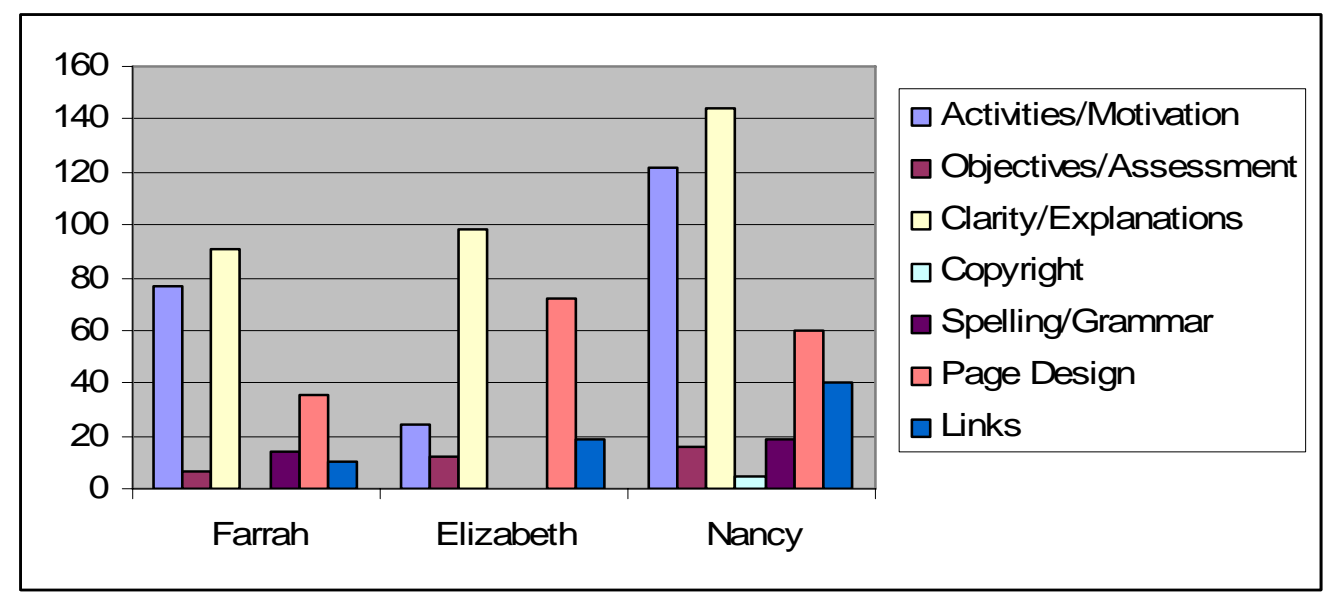

Figure 6. Comparison of Instructional Leaders' Comment Themes on Group B Units

Elizabeth felt that her job as an instructional leader was "to be supportive.” She was also learner-centered as opposed to the two other reviewers in her group who were teacher-centered. Her comments during her interview supported this, as she mentioned that in reviewing she would "tread softly" as the units were "their (the individual teacher's) view.” This is reflected in Elizabeth passing all of the units she reviewed. Interestingly, despite her high learnercenteredness, her comments were not as involved with activities/motivation as might have been suspected. The largest number of her comments had to do with Clarity/Explanations (98), with other comments having to do with Page Design (72), Activities/Motivation (24), Links (19), and Objectives/Assessment (12).

Nancy, the only instructional leader in the group who considered herself a mentor rather than a peer, had a higher percentage of negative comments to positive comments. Nancy, like Elizabeth, made the most comments about Clarity/Explanations (144), followed closely by Activities/Motivation (122). This was interesting coming from a teacher with a style that was 
more teacher-centered than Elizabeth's style, who made proportionately less comments about Activities/Motivation. She also commented on Page design (60), Links (40), Spelling/Grammar (19), Objectives/Assessment (16), and Copyright (5).

Farrah, the high school Spanish teacher, like the other two instructional leaders reviewing Group B, made the most comments about Clarity/Explanations (91). She was the least learnercentered, yet like Nancy, made proportionately more comments about Activities/Motivation (77), than the learner-centered Elizabeth made. Farrah also made comments about Page Design (36), Spelling/Grammar (14), Links (10), and Objectives/Assessment (7).

All three instructional leaders felt the rubric was good, but Elizabeth did mention that she disliked rubrics in general, and Nancy said that she would have widened the range from 1-3 to 15. Like the Group A reviewers, the Group B reviewers enjoyed the reviewing process. All three mentioned that, in general, they found the completed units to be impressive. Table 16 shows the main findings for the instructional leaders reviewing Group B.

Table 16

Major Findings for the Instructional Leaders Reviewing Group B Units

\begin{tabular}{|c|c|c|c|}
\hline & Elizabeth & Nancy & Farrah \\
\hline Principles of Adult Learning Scale (PALS) & 146 & 120 & 116 \\
\hline Survey of Computer Use (SCU) Combined Scores & 46.97 & 65.9 & 46.1 \\
\hline Stages of Concern (SoC) Second Peak Internal & No & Yes & No \\
\hline Stages of Concern (SoC) Total Score & 389 & 393 & 375 \\
\hline Position Involving Technology & No & No & No \\
\hline Considers Self a Mentor & No & Yes & No \\
\hline Worked with Group Evaluated & Yes & No & No \\
\hline Agreed with Rubric & $\begin{array}{r}\text { Yes (but generally } \\
\text { dislikes rubrics) }\end{array}$ & $\begin{array}{r}\text { Yes (but enlarge } \\
\text { range) }\end{array}$ & Yes \\
\hline Past Participant & Yes & Yes & Yes \\
\hline Percent of Units Passed & $100 \%$ & $90 \%$ & $50 \%$ \\
\hline Total Number of Comments & 235 & 415 & 238 \\
\hline Percent of Comments that were Negative & $62 \%$ & $73 \%$ & $55 \%$ \\
\hline Percent of Comments that were Pedagogical & $57 \%$ & $68 \%$ & $74 \%$ \\
\hline
\end{tabular}




\begin{tabular}{|c|c|c|c|}
\hline & Elizabeth & Nancy & Farrah \\
\hline Percent of Comments that were Technical & $39 \%$ & $30 \%$ & $25 \%$ \\
\hline Percent of Positive Pedagogical Comments & $21 \%$ & $25 \%$ & $39 \%$ \\
\hline Percent of Negative Pedagogical Comments & $36 \%$ & $43 \%$ & $35 \%$ \\
\hline Percent of Positive Technical Comments & $12 \%$ & $0 \%$ & $5 \%$ \\
\hline Percent of Negative Technical Comments & $26 \%$ & $29 \%$ & $20 \%$ \\
\hline Percent of Generic Positive Comments & $4 \%$ & $1 \%$ & $1 \%$ \\
\hline Percent of Generic Negative Comments & $0 \%$ & $1 \%$ & $0 \%$ \\
\hline Most Mentioned Theme & Clarity & Clarity & Clarity \\
\hline Second Most Mentioned Theme & Page Design & Activities & Activities \\
\hline Third Most Mentioned Theme & Activities & Page Design & Page Design \\
\hline
\end{tabular}

\section{Instructional Leaders Reviewing Group C}

Three instructional leaders evaluated 14 units developed by the participants in Group C.

\section{Instructional Leaders’ Backgrounds}

Sam. Sam, a $6^{\text {th }}$ grade teacher, was a past participant and was new to being an instructional leader. He had been a teacher for 23 years, starting with two years teaching remedial math, then 21 years teaching $6^{\text {th }}$ grade, as well as eight grade science classes. Sam had been part of a project that promoted “democratic” ways of teaching. In addition, he had participated in Phase 9, a project to assist teachers in integrating technology into teaching, and had, through his experiences with technology, become the unofficial “technology person” at his school. As such, he was a strong advocate of technology in the classroom. Sam had been part of a discussion group on assessment of teacher intern portfolios, but had not done any actual evaluating of them. He considered his evaluation of the Trek 21 units as his main experience in evaluation, with the exception of regular classroom evaluations. Sam viewed himself more of a peer then a mentor during the institute. Sam spoke of being very aware of how difficult it was to complete a unit and said that evaluating other teachers on some factors where they were equal to or even stronger than himself was sometimes "very difficult." Sam was the one evaluator in the 
group who had worked closely during the institute with the participants whose units he subsequently reviewed.

Theresa. Theresa, an elementary school technology teacher, had not been a past participant, but had previously been an instructional leader. She had been teaching for 25 years, including kindergarten, first grade, and second grade, as well as Spanish, English as a Second Language, and Curriculum and Instruction, all in higher education. In addition, she taught International Society for Technology in Education (ISTE) Tech Standards classes and was an instruction specialist for WVU Forestry's Environment and Education workshop. She assisted WVU student teachers in the creation of electronic portfolios. She explained that she was very much in favor of integrating technology into teaching. Theresa described herself as quite experienced in evaluation, having evaluated student teachers, student teacher portfolios, office personnel “wayyyy back when,” elementary students, and novice teachers.

Maria. Maria, a college faculty reading specialist, like Theresa, had not been past participant, but had previously been an instructional leader. In addition to her background in as a college professor, Maria had spent many years as teaching middle school and working in adult training, totaling about 24 years of teaching. She had gotten involved in using technology in the classroom because her students were so interested in it. Maria had some past experience in evaluation, particularly in evaluating trainers. Since that experience entailed merit pay and other rewards, she felt that they were extremely high pressure compared to the Trek 21 evaluations. She also talked about being evaluated each semester as a university instructor. She believed that her various experiences helped make her a fair evaluator. Maria was also a strong proponent of technology in education. She believed that "education was moving in that direction.” She also 
felt that "the kids sometimes know more than the teachers," and that some teachers tend to "drag their feet."

\section{PALS Scores of Instructional Leaders Reviewing Group C}

Maria was the only instructional leader reviewing Group C to reflect a learner-centered teaching style score. In fact, her score of 167 fell into the second standard deviation, making her a committed learner-centered teacher. Theresa's score of 122.5 and Sam's score of 118 (both in the second standard deviation) reflected a style that was highly teacher-centered.

\section{SCU Scores of Instructional Leaders Reviewing Group C}

All three instructional leaders reviewing Group C had similarly very high scores on the Survey of Computer Use, reflecting high levels of experience using computers. Theresa's score was 80.04, Sam’s score was 79.47, and Maria’s score was 75.26. Figure 7 compares the Survey of Computer Use scores of the three instructional leaders reviewing Group C.

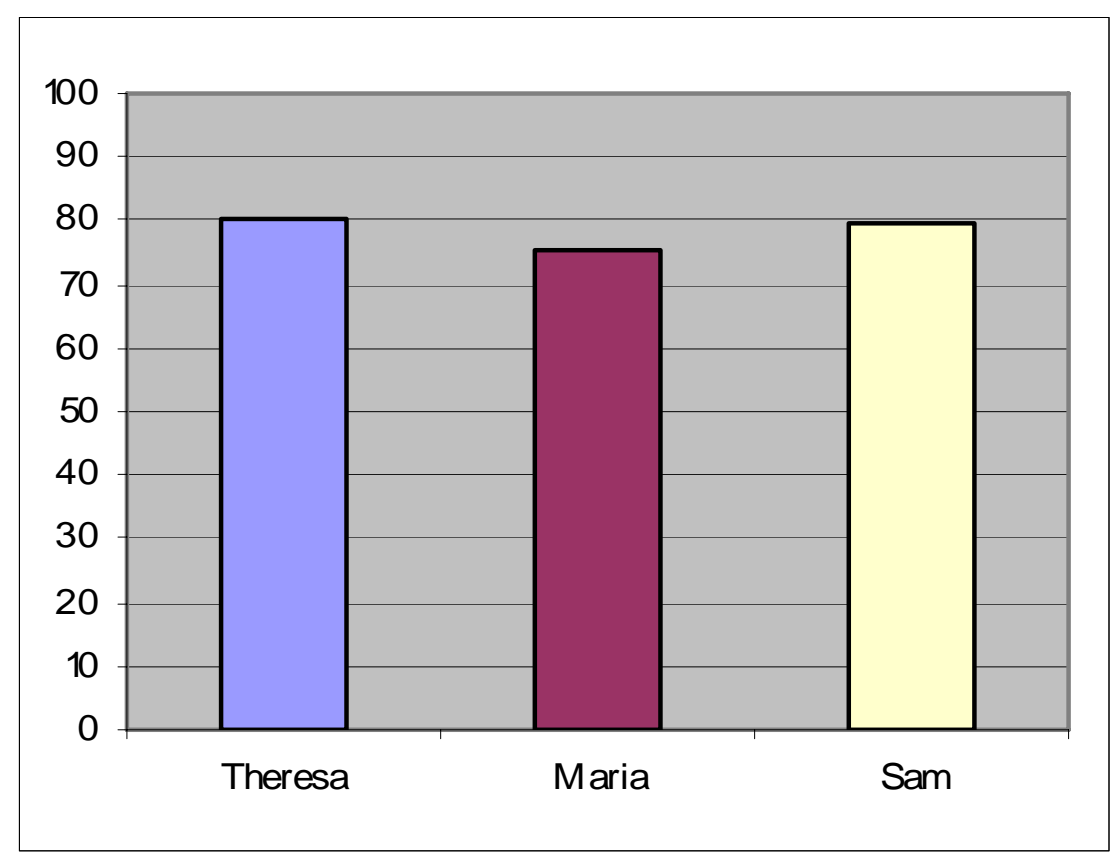

Figure 7. Survey of Computer Use Scores of Instructional Leaders Reviewing Group C 
SoC Scores of Instructional Leaders Reviewing Group C

Theresa, the technology teacher, scored quite high on all the concerns on the Stages of Concern Questionnaire, with the exception of Awareness, on which she scored quite low. Her peak scores were on Refocusing and Collaboration. Maria also scored very high on all stages, with tied peak scores on Refocusing and Collaboration. Sam's scores varied a bit more. His scores on Awareness, Informational, and Personal were all quite high, his Management and Consequences scores were somewhat lower, and his scores on Collaboration and Refocusing were very high. While Sam's highest peak was in the external concern of Refocusing, he was the only instructional leader in this group the have a second peak in an internal concern. In Sam's case, his second peak was in the Informational stage. Like the instructional leaders who reviewed Group B, these instructional leaders had similar total Stages of Concern scores: Theresa's total was 543, Maria's total was 569, and Sam's total was 570. Figure 8 shows the SoC scores of the three instructional leaders reviewing Group C.

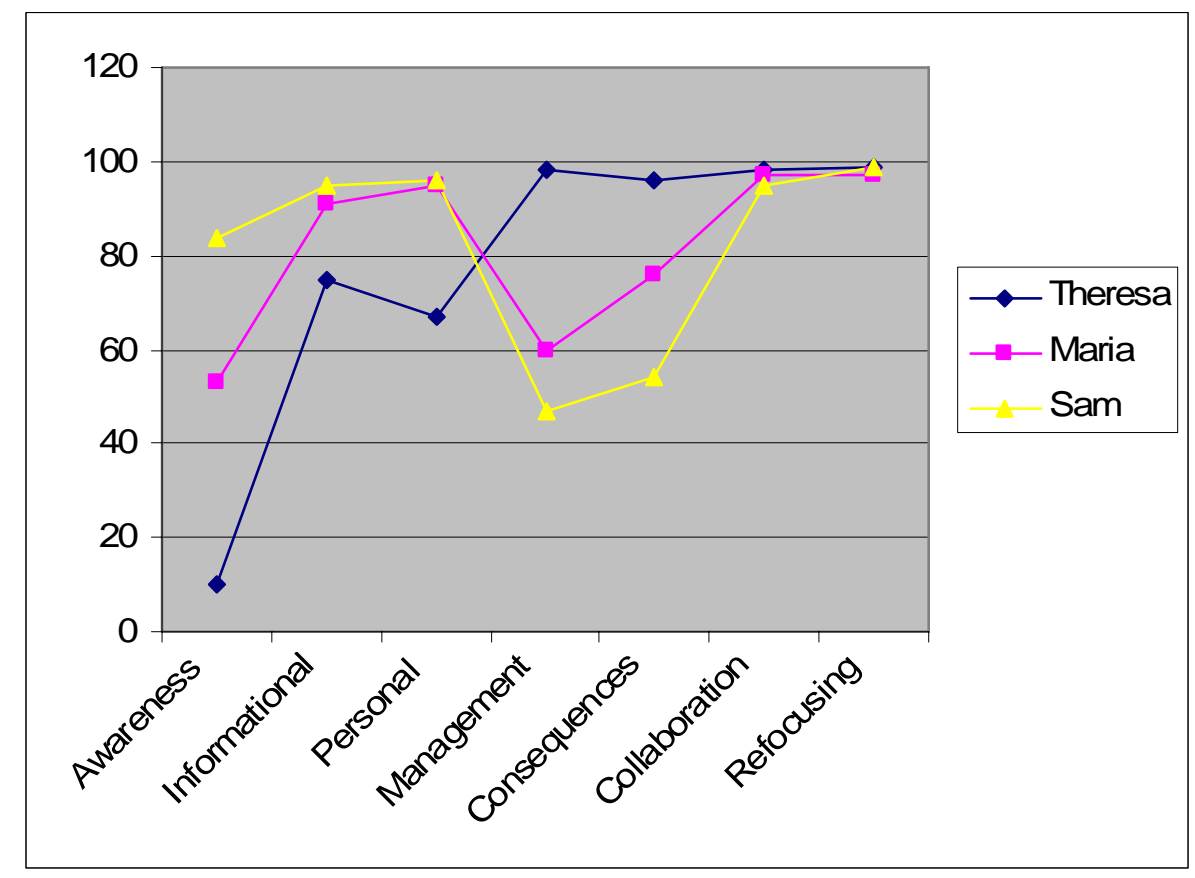

Figure 8. SoC Scores of Instructional Leaders Reviewing Group C 
Instructional Leaders' Reviews of Group C Units

Maria, Sam, and Theresa evaluated the 14 Group C units, using the same rubric.

However, these instructional leaders, like those in the other two groups, reviewed the units differently, as the percentage of units each gave passing scores to were quite different. Maria passed $64 \%$ of the 14 units, Sam passed $43 \%$ of the units, and Theresa passed only $21 \%$ of the units. Table 17 shows the total number of units passed as well as not passed in the group by each instructional leader.

Table 17

Instructional Leaders’ Group Total Posting Decisions for Group C Units

\begin{tabular}{|l|l|l|}
\hline & Number of Units Passed & Number of Units Not Passed \\
\hline Maria & 9 & 5 \\
\hline Sam & 6 & 8 \\
\hline Theresa & 3 & 11 \\
\hline
\end{tabular}

Of the 14 units from Group C, the combined evaluations resulted in six units being approval and eight not being approved. Of those units approved, 3 were unanimous decisions and 3 were not unanimous. Of the 8 units not approved, 5 decisions were unanimous and 3 were not unanimous. The total unanimous decisions in the reviews of Group C units were 8 out of 14 . Table 18 shows the differences in the instructional leaders' decisions for passing each Unit.

Table 18

Instructional Leaders' Individual Posting Decisions for Group C Units

\begin{tabular}{|l|l|l|l|l|}
\hline $\begin{array}{l}\text { Participant } \\
\text { Unit }\end{array}$ & $\begin{array}{l}\text { Theresa's } \\
\text { Posting } \\
\text { Decisions }\end{array}$ & $\begin{array}{l}\text { Sam's } \\
\text { Posting } \\
\text { Decisions }\end{array}$ & $\begin{array}{l}\text { Maria's } \\
\text { Posting } \\
\text { Decisions }\end{array}$ & $\begin{array}{l}\text { Final Combined } \\
\text { Posting Decision }\end{array}$ \\
\hline $\mathbf{1}$ & $\mathrm{N}$ & $\mathrm{N}$ & $\mathrm{N}$ & $\mathrm{N}$ \\
\hline
\end{tabular}




\begin{tabular}{|l|l|l|l|l|}
\hline $\begin{array}{l}\text { Participant } \\
\text { Unit }\end{array}$ & $\begin{array}{l}\text { Theresa's } \\
\text { Posting } \\
\text { Decisions }\end{array}$ & $\begin{array}{l}\text { Sam's } \\
\text { Posting } \\
\text { Decisions }\end{array}$ & $\begin{array}{l}\text { Maria's } \\
\text { Posting } \\
\text { Decisions }\end{array}$ & $\begin{array}{l}\text { Final Combined } \\
\text { Posting Decision }\end{array}$ \\
\hline $\mathbf{2}$ & N & N & Y & N \\
\hline $\mathbf{3}$ & N & N & N & N \\
\hline $\mathbf{4}$ & N & N & Y & N \\
\hline $\mathbf{5}$ & N & Y & Y & Y \\
\hline $\mathbf{6}$ & Y & Y & Y & Y \\
\hline $\mathbf{7}$ & Y & Y & Y & Y \\
\hline $\mathbf{8}$ & N & Y & Y & Y \\
\hline $\mathbf{9}$ & N & N & N & N \\
\hline $\mathbf{1 0}$ & N & N & Y & N \\
\hline 11 & N & N & N & N \\
\hline 12 & N & Y & Y & Y \\
\hline 13 & N & N & N & N \\
\hline 14 & & & & \\
\hline
\end{tabular}

The instructional leaders reviewing Group C also showed marked differences in the total number of comments each instructional leader made on the 14 units. Sam made 568 comments on the units, Theresa made 754, and Maria made 912 comments. There were also differences in the proportion of negative to positive comments made by the instructional leaders. Of Sam's comments, $45 \%$ were positive and 55\% were negative. Of Theresa's comments, 32\% were positive and $68 \%$ were negative. Of Maria's comments, only $29 \%$ were positive and $71 \%$ were negative. Table 19 compares the number of negative and positive comments of the instructional leaders. 
Table 19

Instructional Leaders' Number of Negative and Positive Comments on Group C Units

\begin{tabular}{|l|l|l|l|}
\hline & Theresa & Maria & Sam \\
\hline Total Positive Comments & 245 & 266 & 256 \\
\hline Total Negative Comments & 509 & 646 & 312 \\
\hline
\end{tabular}

Additional differences could be found in the types of comments made by the instructional leaders. Of Theresa's comments, $60 \%$ referred to pedagogical issues, while $38 \%$ referred to technical issues, (with 2\% generic comments). Of Maria’s comments, $76 \%$ referred to pedagogical issues and $21 \%$ referred to technical issues (with $2 \%$ generic issues). Os Sam’s comments, $82 \%$ referred to pedagogical issues, while only $15 \%$ referred to technical issues, (with $2 \%$ generic comments). Table 20 compares the number of pedagogical and technical comments of the instructional leaders.

Table 20

Differences in Pedagogical, Technical, and Generic Comments on Group C Units

\begin{tabular}{|l|l|l|l|}
\hline & Theresa & Maria & Sam \\
\hline Total Pedagogical Comments & 452 & 694 & 467 \\
\hline Total Technical Comments & 285 & 194 & 88 \\
\hline Total Generic Comments & 18 & 21 & 13 \\
\hline
\end{tabular}

Within the pedagogical and technical comments of these instructional leaders, there was another difference. Sam's negative and positive comments were divided fairly evenly, making about the same amount of positive pedagogical comments and negative pedagogical comments, and exactly the same amount of negative and positive technical comments. However, Theresa's pedagogical comments were divided between about 30\% positive and $70 \%$ negative, and she made close to double the amount of negative technical comments as she made positive technical 
comments. Maria’s pedagogical comments were similar to Theresa, divided between 25\% positive and $75 \%$ negative, with her technical comments divided between $41 \%$ positive and $59 \%$ negative. Table 21 shows the breakdown of pedagogical and technical comments of the instructional leaders.

Table 21

Instructional Leaders’ Negative and Positive Pedagogical and Technical Comments on Group C Units

\begin{tabular}{|l|l|l|l|}
\hline & Theresa & Maria & Sam \\
\hline Total Positive Comments (Pedagogical) & 131 & 172 & 204 \\
\hline Total Negative Comments (Pedagogical) & 320 & 523 & 263 \\
\hline Total Positive Comments (Technical) & 98 & 81 & 44 \\
\hline Total Negative Comments (Technical) & 187 & 115 & 44 \\
\hline
\end{tabular}

Besides differences in the numbers and categories of comments, there were also differences in the themes each instructional leader mentioned. Figure 9 illustrates the differences in the three instructional leaders' themes within their total numbers of comments.

Sam mentioned that he felt his strengths were in technical issues, not in organizing lesson plans, so he felt less comfortable judging pedagogical issues. Interestingly, he made many more pedagogical comments than technical comments. While number of units he passed fell in the middle of the group, he made the least comments overall and while he made about the same amount of positive comments as Theresa and Maria, he made much fewer negative comments.

Sam had a teacher-centered style; however, he felt that his particular interest was in making the units more engaging and “child-centered.” Most of his comments reflected these two aspects, as they largely had to do with Clarity/Explanations (232) and Activities/Motivation 
(182). To a lesser extent, Sam commented on Page Design (71), Objectives/Assessment (53), Spelling/Grammar (11), Links (5), and Copyright (1).

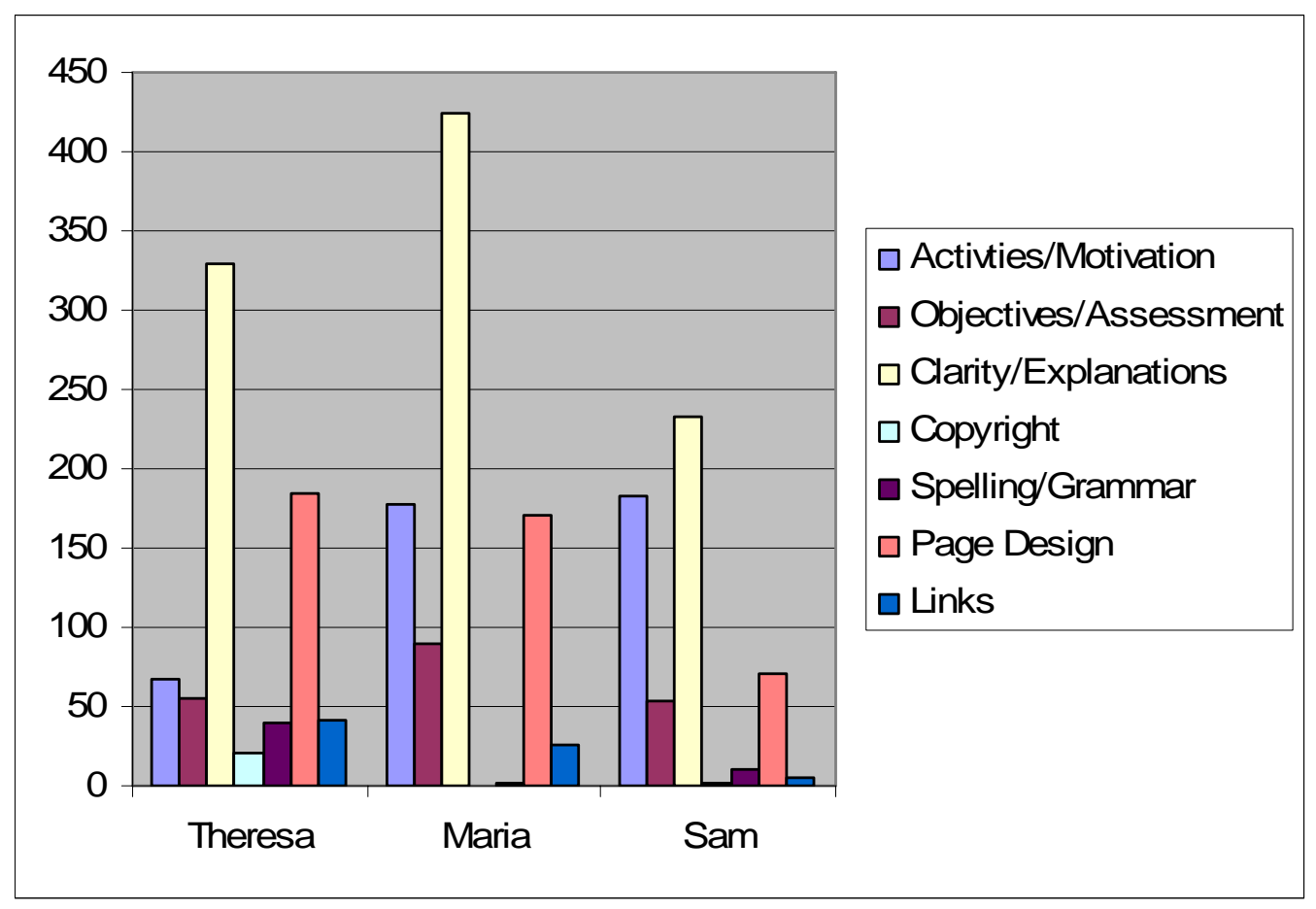

Figure 9. Comparison of Instructional Leaders’ Comment Themes on Group C Units

Maria, while passing the most units for posting, made the most comments overall, including the most suggestions for improvement. Maria’s comments were largely based on Clarity/Explanations (425). She also commented on Activities/Motivation (178), Page Design (170), Objectives/Assessment (90), Links (26), and Spelling/Grammar (2). While she had made the most suggestions for improvement, Maria explained that she was very concerned about comments that the reviewers during the previous institute rated too critically. This seemed to be reflected in a combination of passing the most units while still making the most suggestions for improvement.

Maria, the only learner-centered teacher in the group, passed the greatest number of units. This was similar to Elizabeth, whose style was the most learner-centered in Group B, and Ione, 
the most learner-centered in Group A. Each of these three instructional leaders passed the most units in their groups. As the only learner-centered teacher in the group, I expected that she would have made a greater percentage of comments on Activities/Motivation. However, Sam, who had a teacher-centered style, actually made proportionately higher amount of Activities/Motivation comments to Clarity/Explanation comments.

Theresa, as expected from a technology teacher, made more comments about technical issues than the other two instructional leaders. Overall, Theresa made the most comments about Clarity/Explanations (329), with a lesser emphasis on Page Design (184 comments). Other comments included Activities/Motivation (67), Objectives/Assessment (55), Links (41), Spelling/Grammar (40), and Copyright (20). Theresa made the most comments about Copyright within the group, and in fact, much more than all of the instructional leaders (20 comments, where the others all made 5 or less). Theresa was also teacher/centered, and, as expected, made much less comments about Activities/Motivation than she made about Clarity/Explanations. Theresa was the most vocal about feeling disappointed in some of the units, both for pedagogical and technical reasons. She felt that some people in the group simply did not try very hard. While all three instructional leaders reviewing Group C felt their main role was to offer support with teaching issues, Theresa, in particular, felt that she was called upon more for technical support.

The three instructional leaders reviewing Group C had strong feelings about the group they reviewed. Sam had worked closely with the group during the institute, and had helped them develop their units. He felt that, because the Group C participants were identified during the institute as the Advanced Group, many had behaved arrogantly, explaining that they seemed to feel that they did not desire or need any guidance. He admitted that he had to work particularly hard not to let his feelings influence his reviews. He suggested finding another title for the 
Advanced Group, to eliminate any possible "Pygmalion-type” effects. The other two instructional leaders had not worked as closely with Group C, but Maria and Theresa also expressed that they had fairly high expectations of this group, as they were the Advanced Group. Maria was generally positive about the units in the group, and only mentioned that a few were disappointing. Theresa said that she expected more "Wow!" as far as technology. She felt like some of the Group C participants did the minimum possible work to fulfill their obligation to the project. This is reflected in Maria passing more units than Sam and Theresa.

Maria felt, like Sam, that some of the participants were more skilled than she was at certain tasks (Maria was more impressed with their technical skills, Sam with their pedagogical skills). This also might have led to both of them passing more units than Theresa, due to leniency/stringency error, i.e., where the evaluator does not feel knowledgeable enough and therefore compensates by giving scores that are higher (or lower) than they would normally give (Rudner, 1992).

The three instructional leaders reviewing Group C thought the rubric was good; however, each had a suggestion to improve it. Sam liked the detail but found it to be very long. Theresa said she would add a "zero" score to reflect items that were missing. Maria was the most positive in the group, but did say that she would have preferred a scale of 1-5 as opposed to 1-3. All the instructional leaders from this group mentioned enjoying being instructional leaders, except for the reviewing process, which all three remembered as a very negative experience. They felt it was too long, difficult, and somewhat disappointing. This was interesting, as the other two groups found it difficult but enjoyable. Table 22 shows the main findings for the instructional leaders reviewing Group A. 
Table 22

Major Findings for the Instructional Leaders Reviewing Group C Units

\begin{tabular}{|c|c|c|c|}
\hline & Maria & Theresa & Sam \\
\hline Principles of Adult Learning Scale (PALS) & 167 & 122.5 & 118 \\
\hline Survey of Computer Use (SCU) Combined Scores & 75.26 & 80.04 & 79.47 \\
\hline Stages of Concern (SoC) Second Peak Internal & No & No & Yes \\
\hline Stages of Concern (SoC) Total Score & 569 & 543 & 570 \\
\hline Position Involving Technology & No & $\begin{array}{r}\text { Yes (official } \\
\text { position) }\end{array}$ & Yes (unofficial "guru") \\
\hline Considers Self a Mentor & Yes & No & No \\
\hline Worked with Group Evaluated & No & No & Yes \\
\hline Agreed with Rubric & Yes (but extend range) & Yes (but add zeros ) & Yes (but very long) \\
\hline Past Participant & No & No & Yes \\
\hline Percent of Units Passed & $64 \%$ & $21 \%$ & $43 \%$ \\
\hline Total Number of Comments & 912 & 754 & 568 \\
\hline Percent of Comments that were Negative & $71 \%$ & $66 \%$ & $55 \%$ \\
\hline Percent of Comments that were Pedagogical & $77 \%$ & $60 \%$ & $82 \%$ \\
\hline Percent of Comments that were Technical & $21 \%$ & $38 \%$ & $16 \%$ \\
\hline Percent of Positive Pedagogical Comments & $19 \%$ & $17 \%$ & $36 \%$ \\
\hline Percent of Negative Pedagogical Comments & $57 \%$ & $42 \%$ & $46 \%$ \\
\hline Percent of Positive Technical Comments & $9 \%$ & $13 \%$ & $8 \%$ \\
\hline Percent of Negative Technical Comments & $13 \%$ & $25 \%$ & $8 \%$ \\
\hline Percent of Generic Positive Comments & $1 \%$ & $2 \%$ & $2 \%$ \\
\hline Percent of Generic Negative Comments & $1 \%$ & $0 \%$ & $1 \%$ \\
\hline Most Mentioned Theme & Clarity & Clarity & Clarity \\
\hline Second Most Mentioned Theme & Activities & Page Design & Activities \\
\hline Third Most Mentioned Theme & Page Design & Activities & Page Design \\
\hline
\end{tabular}




\section{Chapter 5 - Conclusion}

During the 3-week 2002 West Virginia University Trek 21 Summer Institute, 35 P-12 teacher-participants developed five-lesson web-based instructional units for use in their classrooms. Trek 21 recruited nine Instructional leaders who assisted with the delivery of the institute and reviewed the completed units, using a rubric. As a graduate assistant working for Trek 21, I compiled the final scoring of the units by the instructional leaders. While reviewing the scores, I discovered that the scoring of the units as either passing to be posted online or requiring revisions before posting varied, sometimes greatly. Through this study, I attempted to determine what might have influenced the instructional leaders to score the units way they did, through the use of several instruments: the Survey of Computer Use (SCU) (Appendix B), the Principles of Adult Learning Scale (PALS) (Appendix C), the Stages of Concern Questionnaire (SoCQ) (Appendix D), comparisons of instructional leader ratings of the units based on the Trek

21 rubric and comments on the combined Unit Score Sheets and Unit/Lesson Feedback Sheets (Appendix A), and commentary during interviews with the instructional leaders (Appendix I).

\section{Research Questions}

Research Question 1. How did the Trek 21 instructional leaders’ personal computer use skills influence their evaluations of the teacher-participants’ web-based instructional units?

There did not appear to be a relationship between the instructional leaders’ computer skills as measured by the Survey of Computer Use and their reviews of the participants' units. I had expected to find that instructional leaders who scored higher in use and comfort with computers concentrated more on technical issues, either negative or positive, in the participants' units. However, this was not the case. In all three groups, the instructional leaders made more pedagogical comments than technical comments overall (except for in the case of one instructional leader, and that was because she noted many spelling errors in one unit). 
I had expected, within their comments addressing technology, a trend toward more either negative or more positive comments from instructional leaders who scored higher on the Survey of Computer Use, but this also was not the case. While two groups did have slightly higher percentages of negative comments about technical issues from their higher Survey of Computer Use scorers, the third group had an even higher percentage of negative comments from their instructional leader with the Survey of Computer Use score that was between the two others' scores.

Research Question 2. How did the instructional leaders’ styles of teaching influence their evaluations of the teacher-participants’ web-based instructional units?

There appeared to be a possible relationship between styles of teaching, based on the Instructional Leader's scores on the Principles of Adult Learning Scale (PALS), and the number of units passed for posting by the Instructional Leaders. Principles of Adult Learning Scale scores of 146 reflect a style that is a combination of teacher- and learner-centeredness. As scores move above 146, they reflect a teacher's style that is to act more as a facilitator than as an instructor, as opposed to scores that move below 146, which reflect a style that is more teachercentered. Each group had one instructional leader that had a style that was either mixed style or was highly learner-centered, and two instructional leaders that were committed to a teachercentered style. In all three groups, the mixed or learner-centered instructional leader passed the largest number of units in each group. From there the results were less clear. Among the teachercentered instructional leaders, having a Principles of Adult Learning Scale score that reflected a higher or lower degree of teacher-centeredness did not clearly reflect any pattern. In two groups, a slightly more learner-centered score correlated with more units being passed, but in the other, the more learner-centered instructional leader passed the fewest units. 
I had expected the more learner-centered teachers to have a higher percentage of comments regarding Activities/Motivation than other types of comments, but this was not the case. Seven out of nine instructional leaders made the most comments about Clarity/Explanations, and the other two put Clarity/Explanations second after technical comments, but still before Activities/Motivation. It appears that, to the instructional leaders, the most important factor was clarity, mostly for the teachers who might use the unit, but also for students who might use the site as part of a class. This still fits with a learner-centered teaching style, as even a learner-centered project must have clear enough goals, objectives, and instructions to allow the student to succeed.

From the comparisons between the Principles of Adult Learning Scale scores and the instructional leader reviews, it appeared that the learner-centered instructional leaders passed more units because the nature of a learner-centered teacher is to act as a facilitator in a process where the learner is in charge of their own learning. In this case, the more learner-centered instructional leaders might have felt that their role was to help the participants create whatever units they felt were required based on their own experience in the classroom, while the teachercentered instructional leaders might have felt more of a need to guide the participants in creating units according to established specifications (either their own or those on the rubric).

Research Question 3. How did the instructional leaders’ concerns about Instructional Technology integration influence their evaluations of the Institute participants’ web-based instructional units?

There appeared to be an interesting relationship between instructional leader concerns as reflected on the Stages of Concern peak scores and their evaluations. All the instructional leaders had a main peak concern in the external stages of either Collaboration or Refocusing. However, 
one instructional leader in each group had a second peak (which was lower than the first) that was in an internal stage as opposed to another external stage. With the main peak for all instructional leaders reflecting concerns on working with others using instructional technologies and putting it into practice in different ways, these instructional leaders did show some concerns with their own use of instructional technologies. The instructional leaders with a second peak in an internal stage passed the middle amount of units within their groups, and made the least comments that were positive about technical issues. The fact that they made the least positive comments about technology may have been due to their own feelings of concern with their own use of it. Why they would pass the middle amount of units seems less clear. Possibly, this was also due to their ambivalence about their own use of technology; however, it seems more likely that they passed the middle number of units in their groups for other reasons.

A more interesting, and potentially more useful finding, was that the instructional leader in each group who had the lowest total score on the Stages of Concern Questionnaire passed the lowest percent of the units in their group. Possibly, feeling less concerned (and therefore more personally confident) about the use of instructional technology and its implications made these instructional leaders feel more comfortable about making negative judgments about the webbased units, where the instructional leaders with more concerns about their own use did not feel qualified to make similar judgments. This could be a reflection of a leniency/stringency error (Rudner, 1992), where the instructional leaders who were more concerned about their own levels of instructional technology use would score others' use of technology relatively higher.

Research Question 4. How did the instructional leaders' current professional positions influence their evaluations of the Institute participants’ web-based instructional units? 
In two of the three groups of reviewers, the instructional leaders' technical roles in their schools varied. In each of these two groups, there was one instructional leader whose job officially involved being a leader in instructional technology use, as well as one who was their schools' unofficial “technical guru.” In these groups, while there was no apparent association between an instructional leader having a technical position and the amount of units passed or whether they made more comments about technical issues or pedagogical issues, there was an interesting trend in how the instructional leaders commented on the units. The instructional leaders with the least technical positions made the most comments in their groups about the units overall, as well as the most negative comments referring to pedagogical issues. It does seem possible that these instructional leaders were concentrating more on pedagogical issues, so a greater percentage of their issues they felt needed attention were pedagogical. However, why they made the most comments overall is not as obvious. This may have been an effect of another factor. The instructional leaders with the informal technical positions made the fewest comments overall in their groups, and the least positive comments about technical issues. The findings regarding the instructional leaders with informal technical positions were similar. That they made the lowest percentage of positive comments in their group could have been due to their somewhat technical positions, but why they made the fewest comments overall is not clear. These trends were only observed in two out of the three groups, as the third group had no instructional leaders that held technical positions in their schools.

Two groups also had two instructional leaders who were P-12 teachers and one member who was not. The two non-P-12 instructional leaders both passed the most units in their groups. Their positions in higher education may have made them perceive themselves more as mentors than as peers. They also were more learner-centered. These factors may have been reflected in 
their relatively more generous scores. On the other hand, the instructional leaders who were teaching in the public school system may have had more realistic views of what is required in the classroom, and this might have led to their (legitimately) scoring the units lower.

Research Question 5. How did the instructional leaders' perceptions of their roles and the roles of the participants influence their evaluations of the Institute participants' web-based instructional units?

Each group had one instructional leader who perceived themselves as more of a mentor to the participants than the other two instructional leaders, who perceived themselves more as peers. However, there did not seem to be any clear effect of instructional leaders feeling like a mentor as opposed to a peer. In two groups, the mentors made the middle number of pedagogical comments. In the third group, the mentor made the same amount of comments as one of the members who considered themselves a peer. This again seems to demonstrate that some other factor was involved.

An interesting finding concerned the instructional leaders who had been past participants. Although several instructional leaders who were past participants mentioned how they had felt pressure to perform and anxiety during the evaluations of their own units, this did not appear to have an effect (either positive or negative) on their evaluations of the units. Group A and Group $\mathrm{C}$ both had a mixture of reviewers who had been past participants and who had not been past participants. When reviewing Group A, the instructional leaders who had been previous participants passed fewer units and made higher percentages of negative comments than the instructional leader who had not been a past participant. The previous participant who reviewed Group C passed the middle number of units in the group and made the lowest percentage of negative comments. It appears that past experience as a participant does not make for reviewers 
that are either "easier” or "tougher.” It might have been that the past participants were reacting in different ways to the same phenomenon. While these three past participants all had felt uncomfortable about being judged when they were participants, the two past participants in Group A may have felt obligated to evaluate the units the same way they perceived their units to have been evaluated (stringently), while the past participant in Group C may have evaluated more leniently as a response to his past experience of feeling that the judging had been too stringent. It would have been easier to make a more of a distinction if there had been an instructional leader who had not been a past participant in Group B.

Research Question 6. How did each instructional leader's personal criteria for what makes a good unit or lesson influence his or her evaluations of the Institute participants’ web-based instructional units?

All nine instructional leaders seemed to feel comfortable working with the rubric, and said that the objectives on the rubric matched what they would have looked for themselves. Three instructional leaders did say that they prefer a rubric with a wider range of scores (scores ranging from one to five as opposed to from one to three), and one mentioned that a range of scores that included zero would be better, in order to appropriately score when items are missing. Only one instructional leader did not like working with rubrics, in general. She felt they were too "general" and that sometimes the performance of a participant falls between the allotted numeric scores on the rubric. However, she, like the other instructional leaders, thought the rubric worked well for helping the instructional leaders review the units. They all expressed that the goals for the participants based on the rubric were close to their own goals for the participants. 
In looking into the most mentioned themes, no clear differentiation in what the instructional leaders were looking for in the units was evident. Seven of the nine instructional leaders mentioned issues of Clarity the most, and the other two mentioned it the second most.

The instructional leaders all stated that they agreed with the rubric, and appeared to be looking for similar issues in the units (mostly Clarity, Page Design, and Activities). This is interesting because they still scored the units differently, therefore at least some must not have been totally agreeing with the ratings categories on the rubric. Lumley (2002) explains that, even when different evaluators understand the rating categories in the same way, they sometimes apply the scale in different ways. This includes the importance they give to various components of the scale's descriptors and how they make decisions when interpreting the wording on the scales.

\section{Other Findings}

An interesting issue became evident during the interviews with the instructional leaders. All the instructional leaders enjoyed their roles during the institute, but only the instructional leaders who reviewed Groups A and B enjoyed the reviewing process. The reviewers of Group C described reviewing the units as "hell," "harrowing," and "horrible.” This was fascinating because they were so negative while the reviewers of the other groups used terms like “enjoyable” “educational,” and “fun.” Since the Group C instructional leaders had all, coincidentally, used words that began with an " $h$ " to describe their feelings about reviewing the units, I asked the instructional leaders in the other groups to use an "h" word, and they came up "helpful,” "hilarious," "happy,” and "hard (but worth it!)”. All the reviewers felt that the reviewing process was very time-consuming, and the Group C reviewers were aware that they had the most units to review (14 units as opposed to 10 and 11 in the other groups). However, the fact that they had more to do did not appear to be the main reason they disliked the process so 
much (although it did appear to make them even more unhappy about it). It seems as though reviewing the group that was known as the “Advanced Group” had an effect on the reviewers. The reviewers of this group passed relatively fewer units, which was particularly interesting, as this advanced group may have actually created better units. However, there appears to have been two factors at work, both having to do with the group being identified as “advanced.” One factor was that the reviewers did appear to expect more from the group identified as "advanced.” While the instructional leaders from all three groups occasionally mentioned that several participants seemed to be "not really trying," the Group C reviewers mentioned this the most. In additions, the one reviewer from Group $\mathrm{C}$ who was in the room working with the participants during the institute mentioned that some of these participants had been "arrogant” because they felt they were too knowledgeable to be guided. He talked about thinking of this when evaluating those units. It appears that the instructional leaders who evaluated Group C were more dissatisfied with the reviewing process for both of these reasons. They felt that the group had been more difficult to deal with than the other groups, and did not live up to the instructional leaders’ expectations for an advanced group.

Because each group had one instructional leader who had worked more closely with the group being evaluated than the others, I thought this might have some effect on the scoring. Perhaps the more familiar instructional leader in the group might judge the units more favorably, because this evaluator would feel some “ownership” of the units (having helped to create them), an example of “perception differences” (Rudner, 1992) However, only one group’s evaluator who had worked with the group as an instructional leader passed the most units in their group. The others passed the middle amount and the least amount in their groups. 


\section{Implications}

While a diverse group of instructors or mentors can assist teachers in achieving pedagogically and technically well-developed instructional units, it is important to be aware that this diversity can also influence their individual evaluations. Reviewers are often chosen specifically because of their experience and knowledge, but this expertise may cause them have individual reactions, thoughts, and feelings about what they are scoring (Lumley, 2002; Sadler, 1989). Instruments such as rubrics can help minimize inconsistencies in scoring due to different reviewers or different content (Brookhart, 1999; Goodrich, 1997); however, even a welldeveloped, well-explained rubric may be interpreted and applied in different ways (Lumley, 2002). This can affect not only instruction, but also interpretation and application of assessment instruments.

In case such at the Trek 21 Summer Institutes, having diverse evaluations, where reviewers noted and commented on different issues, was not problematic. The project director decided that all of the participants' units could be posted, and any necessary changes could be made at a continuity meeting held several months after the institutes. None of the participants were held back from posting or using their unit, and no participant was ever aware that some units had not “passed.” The Trek 21 teacher-participants benefited from the different reviewers characteristics, which offered them different perspectives on their work without any consequences.

In the case of more "high stakes" testing, this may not be the case. In high stakes testing, there are consequences based on the evaluations. These tests might include evaluations of items such as portfolios for graduation or advancement, web-based courses or other projects, or any product that requires judgment to "pass.” It is critical, in the name of fairness and accuracy, to have reviewers apply the same standards to all test-takers. As this is difficult to achieve when 
using humans as judges, other safeguards may be beneficial. These include the use of rubrics, training in the use of the rubric, and using several reviewers and averaging their scores. However, in cases of large numbers of tests, where the same reviewers cannot score all of the tests, the characteristics of the reviewers may need to be taken into account.

When using experts for training and evaluation, it is exactly their expertise that is of the most value. After I described this research to one of the instructional leaders, and we discussed training evaluators to make their evaluations more similar, she asked, "Would you really want that?” This is an important question. Nevertheless, when choosing, training, and assigning of evaluators, consideration should be given as to how individual characteristics, however valuable they may be, may affect their evaluations.

The difficulty is in determining what characteristics may influence an evaluator's judgment and what characteristics have no real effect. This study has established a few possibilities. The instructional leaders, who, according to the Principles of Adult Learning Scale, had teaching styles that were more "learner-centered,” or who had a mix of "learner-centered” and "teacher-centered" teaching styles, passed the most units in their respective groups. The instructional leaders who, according to the Stages of Concern Questionnaire, had the lowest concerns overall about technology passed the least units. The two instructional leaders from higher education who were not in similar P-12 positions as the participants passed more, while the instructional leader whose job it was to teach technology in the public school system passed the least units of any instructional leader.

Besides these possible relationships, the characteristics that effected the evaluations became less clear. Possibly the best information came from the instructional leaders interviews. The instructional leader who mentioned several times that her role was to support the participants 
passed $100 \%$ of the units, the most in her group. The instructional leader who said that she had been told in the past that the reviewers judged too harshly passed the most units in her group. The instructional leader who said it was not fair to for her to judge the teacher-participants' units according to her own standards, because she was much more experienced, passed the second largest amount of all the instructional leaders. Determining whether an instructional leader/reviewer feels that their job is to more offer support or to offer guidance appears to be a factor.

An additional implication concerns the effect of labeling groups being reviewed. The group that was labeled as “advanced” appeared to have been judged more harshly than the other two groups, and the highest scores appeared to go to the group identified as “intermediate.” This may have indicated a possible effect of "stereotyping” of all the groups (Rudner, 1992). The expectations for the beginners were low, so their scores were fairly high, and the expectations for the advanced group were very high, so their scores were relatively lower. The intermediate group scored the best, as they probably best met the expectations of the reviewers.

In all, this study often tended to feel like nine separate case studies. The instructional leaders did evaluate differently, but each may have had his or her own, different reasons for doing so. One theory of why this may be has been highlighted by Phillips, who quoted Thomas Kuhn, staining that, “in a sense, all inquirers are trapped within their own paradigms; they will judge certain things as being true (for them) that other inquirers will judge as being false (for them)” (Pitts, Coles, \& Thomas, 1999).

\section{Suggestions for Further Study}

In this study, I attempted to answer the question of why reviewers, trained in the use of a rubric, evaluated the same web-based units in different ways. To do this, I looked at the 
characteristics of the nine reviewers of the thirty-five units completed during the Trek 212002 Summer Institute. A few possible reasons appeared to stand out in all three groups, some only appeared in two out of three, and some only appeared in one. When a possible relationship appeared to be the same across all three groups, I felt it was clear that, at least, a trend was evident. When only two groups appeared to show a relationship, the ability to identify a trend became more difficult. Using a "best two out of three" when there are only three reviewers in each group, and only ten, eleven, or fourteen units being reviewed, seemed a bit too confident. The same was true if one group showed something very clearly, while the other two did not. Was this an actual lack of an effect of reviewer characteristics, or were there simply not enough reviewers or items to be reviewed to identify a possible relationship?

One way to make such possible relationships clearer would be to have all the reviewers evaluate all of the finished products. This would make for not only more reviewers and more products, but eliminate the question of whether or not evaluating the units from the "advanced group” had a different effect than evaluating the units from the "intermediate group" or the units from the "beginner's group.” By having all the reviewers evaluate all the units, the questions of differences in the evaluations becomes even more a matter of the reviewers' characteristics, and less of a matter of the individual differences in the units themselves, or in the reviewers' perceptions that some units should have been more advanced than others.

Other suggestions for further study might be to investigate other characteristics of the reviewers. For example, reviewers' characteristics of personality-type (such as introverted or extroverted, or confrontational or non-confrontational) or motivation (internal or external) could have an effect on how they judge. In addition, the group of instructional leaders in this study consisted on eight females and one male. It was not possible to determine if gender may have 
had any effect on the evaluations. A study that included more males might show some interesting differences in scoring and comments. Finally, it would be interesting to see if evaluators who had grown up surrounded by much of the technology used in the classroom today, such as younger teachers, evaluate the use of technology differently than the teachers in this study, who learned to incorporate the current instructional technologies into their teaching after teaching for many years without it. 


\section{References}

Atkins, N. E., \& Vasu, E. S. (2000). Measuring knowledge of technology usage and stages of concern about computing: A study of middle school teachers. Journal of Technology and Teacher Education, 8(4), 279-302.

Baume, D., \& Yorke, M. (2002). The reliability of assessment by portfolio on a course to develop and accredit teachers in higher education [Electronic version]. Studies in Higher Education, 27(1), 7-25.

Brennan, R. (1995). Generalizability of performance assessments [Electronic version]. Paper presented at the annual meeting of the National Council of Measurement in Education.

Brookhart, S. M. (1999). The art and science of classroom assessment: The missing part of pedagogy [Electronic version]. ASHE-ERIC Higher Education Report, 27(1), 1-102.

Conti, G. (1979). Principles of adult learning scale: Follow-up and factor analysis. Ann Arbor, MI: Adult Education Research Conference. (ERIC Document Reproduction Service No. ED 228 424).

Conti, G. J. (1982). The principles of adult learning scale. Adult literacy and basic education, 6, 135-150.

Conti, G. J. (1990). Identifying your teaching style. In M.W. Galbraith (Ed.), Adult Learning Methods (pp. 79-96). Malabar, FL: Robert E. Krieger Publishing Co, Inc.

Doolittle, P. (1994). Teacher portfolio assessment. ERIC/AE Digest. Washington, DC: ERIC Clearinghouse on Assessment and Evaluation. Retrieved August 1, 2005, from http://searcheric.org/scripts/seget2.asp?db=ericft\&want=http://searcheric.org/ericdb/ED3 85608.htm 
Dunbar, S. B., Koretz, D. M., \& Hoover, H. D. (1991). Quality control in the development and use of performance assessments. Applied Measurement in Education, 4(4), 289-303.

Dupin-Bryant, P. A. (2004). Teaching styles of interactive television instructors: A descriptive study [Electronic Version]. The American Journal of Distance Education, 18(1), 39-50.

Fraenkel, J. R., \& Wallen, N. E. (2003). How to design and evaluate research in education. New York: McGraw-Hill.

Frisbie, D. A. (1988). Reliability of scores from teacher-made tests. Educational Measurement: Issues and Practice, 7(1), 25-35.

Gamaroff, R. (1999). Rater reliability in language assessment: The bug of all bears [Electronic version]. System, 28, 31-53.

Goodrich, H. (1997). Understanding rubrics [Electronic version]. Educational Leadership, 54 (4), $14-17$.

Hall, G. E., George, A., \& Rutherford, W. (1979). Measuring stages of concern about the innovation: A manual for the use of the SoC questionnaire (Report No. 3032). Austin: The University of Texas, Research and Development Center for Teacher Education (ERIC Document Reproduction Service No. ED 147 342).

Hall, G. E., \& Loucks, S. F. (1978). Teacher concerns as a basis for facilitating and personalizing staff development. Teachers College Record, 80, 36-53.

Hoepfl, M. C. (1997). Choosing qualitative research: A primer for technology education researchers. Journal of Technology Education, 9(1). Retrieved November 22, 2004, from http://scholar.lib.vt.edu/ejournals/JTE/v9n1/hoepfl.html 
Holahan, P. J., Jurkat, M. P., \& Friedman, E. A., (2000). Evaluation of a mentor teacher model for enhancing mathematics instruction through the use of computers. Journal of research in computing in education, 32(3).

Hout, B. A. (1990). Reliability, reliability, and holistic scoring; What we know and what we need to know [electronic version]. College Composition and Communication, 41, 201213.

Ingwerson, D. (1997). A model for technology training: The Los Angeles County Office of Education's Technology for Training Initiative, T H E Journal, 25, 4.

Johnson, D. (1997). What does it look like? Part 1: The code 77 rubrics. Technology Connection. Retrieved October 9, 2002, from http://www.doug-johnson.com/dougwri/Rubbeg.HTM

Johnson, D. (April, 1998). Rubrics to gauge your staff's computer literacy. The School Administrator. Retrieved April, 2005, from http://www.aasa.org/publications/sa/1998_04/Johnson_side_rubrics.htm

Johnson, R. L., McDaniel, F., \& Willeke, M. J. (2000). Using portfolios in program evaluation: An investigation of interrater reliability [Electronic Version]. American Journal of Evaluations, 21(1), 65-80.

Johnson, R. B., \& Onwuegbuzie, A. J. (2004) Mixed methods research: A research paradigm whose time has come [Electronic Version] Educational Researcher, 33(7), 14-26.

Kimball, C. (1996). Technology planning in California schools: Planning for success or doomed for failure? Unpublished doctoral dissertation. Los Angeles: University of Southern California.

Lam, T. (1995). Fairness in Performance Assessment. ERIC Digest. 
Lumley, T. (2002). Assessment criteria in a large-scale writing test: what do they really mean to the raters? [Electronic version] Language Testing, 19(3), 246-276.

MacMillan, P. D. (2000). Classical, generalizability, and multifaceted Rasch detection of interrater variability in large, sparse data sets [electronic version]. Journal of Experimental Education, 68(1), 167-192.

Merriam, S. B. (1997). Qualitative research and case study applications in education. San Francisco: Jossey-Bass.

Merriam, S. B. (Ed.). (2002). Qualitative research in practice: Examples for discussion and analysis. San Francisco: Jossey-Bass.

Miles, M. B., \& Huberman, A. M. (1994). Qualitative data analysis: An expanded sourcebook ( $2^{\text {nd }}$ Ed.). Thousand Oaks, CA: Sage.

Miller, M. D., \& Legg, S. M. (1993). Alternative assessment in a high-stakes environment [Electronic version]. Educational Measurement: Issues and Practice, 12(2), 9-15.

Moskal, B. M. (2000). Scoring rubrics: What, when and how? [Electronic version] Practical Assessment, Research \& Evaluation, 7(3). Retrieved March 1, 2002 from http://pareonline.net/getvn.asp?v=7\&n=3

Newhouse, C. P. (2001). Applying the Concerns-Based Adoption Model to research on computers in classrooms. Journal of Research on Technology in Education, 33(5). Retrieved May 12, 2005, from http://www.iste.org/inhouse/publications/jrte/33/5/newhouse.cfm?Section=JRTE_33_5

Nidds, J., \& McGerald, J. (1997). How functional is portfolio assessment anyway? [Electronic version]. Education Digest, 62(5), 47-50. 
Pitts, J., Coles, C., \& Thomas, P. (1999). Educational portfolios in the assessment of general practice trainers: Reliability of assessors [Electronic version]. Medical Education, 33, 515-520.

Pitts, J., Coles, C., \& Thomas, P. (2001). Enhancing reliability in portfolio assessment: "shaping” the portfolio [Electronic version]. Medical Teacher, 23(4), 351-356.

Pomplun, M., Capps, L., \& Sundbye, N. (1998). Criteria teachers use to score performance items [Electronic version]. Educational Assessment, 5(2), 95-110.

Pomplun, M., Sundbye, N., \& Kelley, J. (1996). Gender format differences: Relevant or irrelevant? Paper presented at the annual meeting of the American Educational Research Association, New York.

Rakes, G. C., \& Casey, H. B. (2002). An analysis of teacher concerns toward instructional technology. International Journal of Educational Technology, 3(1). Retrieved May 12, 2005, from http://www.ao.uiuc.edu/ijet/v3n1/rakes/index.html

Riel, M., \& Becker, H. (2000). The beliefs, practices, and computer use of teacher leaders. Paper presented at the American Educational Research Association, New Orleans, April 26, 2000.

Rudner, L. M. (1992). Reducing errors due to the use of judges. ERIC/TM Digest. Washington, DC: ERIC Clearinghouse on Tests Measurement and Evaluation. Retrieved August 1, 2005, from http://www.ericdigests.org/1993/judges.htm

Sadler, D. R. (1989). Formative assessment and the design of instructional systems, Instructional Science, 18, 119-141.

Sibley, P., \& Kimball, C. (1994). The Technology Maturity Model. EDmin.com, Inc. 
Spoon, J. C., \& Schell, J. W. (1998). Aligning student learning styles with instructor teaching styles. Journal of Industrial Teacher Education, 35(2), 41-56.

Strauss, A. L., \& Corbin, J. (1990). Basics of qualitative research: Grounded theory procedures and techniques. Newbury Park, CA: Sage.

Tashakkori, A., \& Teddlie, C. (2003). Handbook of mixed methods in the social and behavioral research. Thousand Oaks, CA: Sage.

Weigandt, C. M., \& Wells, J. (2003). Evaluating the evaluators: Variations in instructional leaders' assessments of instructional technology integration. Paper presented at the 2003 National Educational Computing Conference, Seattle, WA.

Wells, J. (1999). Trek 21 - Educating Teachers as Agents of Technological Change. Proposal document for PT3 Grant Program, U. S. Department of Education. 
Appendices 
Appendix A

Trek 21 Rubric-Score Sheet-Unit/Lesson Feedback Sheet 
Participant Code \#

Trek 21 Unit/Lesson Assessment Rubric 2002

\begin{tabular}{|c|c|c|c|}
\hline \multirow{2}{*}{\multicolumn{2}{|c|}{$\begin{array}{ll}\text { 1. } & \text { Unit Title: } \\
\text { 2. } & \text { Targeted Grade Level(s): }\end{array}$}} & \multicolumn{2}{|c|}{ Unit Authored by: } \\
\hline & & \multicolumn{2}{|c|}{ Subject(s) Addressed: } \\
\hline \multicolumn{4}{|c|}{ 3. Date Unit Created: $\quad$ Date Unit Last Modified (if applicable): } \\
\hline \multicolumn{4}{|c|}{$\begin{array}{l}\text { For } 4-18 \text { below, use the scale below to determine the option that best describes the extent to which each item is completed in the } \\
\text { unit/lessons. Score the unit/lessons on the score sheet. }\end{array}$} \\
\hline & Accomplished (3 points) & Developing (2 points) & Vague (1 point) \\
\hline \multicolumn{4}{|l|}{ UNIT OVERVIEW } \\
\hline 4. Unit Summary & $\begin{array}{l}\text { Summary is clearly stated and includes the } \\
\text { content knowledge and skills students } \\
\text { should be able to do. It is concise and clear. }\end{array}$ & $\begin{array}{l}\text { Summary is clearly stated, but lacks } \\
\text { complete information students should } \\
\text { know. }\end{array}$ & $\begin{array}{l}\text { Summary is unclear, too general, or not } \\
\text { present. }\end{array}$ \\
\hline $\begin{array}{l}\text { 5. Unit Time } \\
\text { Required }\end{array}$ & $\begin{array}{l}\text { Approximate number of class periods or } \\
\text { sessions is clearly indicated, and the length } \\
\text { of time specified for each. }\end{array}$ & $\begin{array}{l}\text { Approximate number of class periods or } \\
\text { sessions is clearly indicated, but the length } \\
\text { of time for each not specified. }\end{array}$ & $\begin{array}{l}\text { Time required is not clear, or is not } \\
\text { apparent. }\end{array}$ \\
\hline $\begin{array}{l}\text { 6. Major Unit } \\
\text { Goals }\end{array}$ & $\begin{array}{l}\text { A minimum of one major goal for each } \\
\text { lesson is clearly stated, and correlates with } \\
\text { lesson objectives. }\end{array}$ & $\begin{array}{l}\text { A minimum of one major goal for each } \\
\text { lesson is clearly stated, but not all } \\
\text { correlate with objectives. }\end{array}$ & $\begin{array}{l}\text { A major goal for each lesson is not clearly } \\
\text { stated or apparent. }\end{array}$ \\
\hline $\begin{array}{l}\text { 7. Unit Design } \\
\text { (layout, font, color) }\end{array}$ & $\begin{array}{l}\text { Unit layout is uncluttered/navigable, no } \\
\text { more than two font styles are used, and } \\
\text { color selection provides good contrast for } \\
\text { easy reading. }\end{array}$ & $\begin{array}{l}\text { Unit layout is uncluttered/navigable, no } \\
\text { more than two font styles are used, but } \\
\text { color selection provides poor contrast. }\end{array}$ & $\begin{array}{l}\text { Unit layout is cluttered/non-navigable, } \\
\text { more than two font styles are used, and } \\
\text { color selection provides poor contrast. }\end{array}$ \\
\hline 8. IT Integrations & $\begin{array}{l}\text { A minimum of one instructional technology } \\
\text { and one telecom activity is integrated as } \\
\text { part of the unit. }\end{array}$ & $\begin{array}{l}\text { A minimum of one instructional } \\
\text { technology is integrated as part of the unit, } \\
\text { but telecom activity not included. }\end{array}$ & $\begin{array}{l}\text { One instructional technology or telecom } \\
\text { activity is not clearly part of the unit. }\end{array}$ \\
\hline \multicolumn{4}{|l|}{ LESSON PLANS } \\
\hline 9. Title & $\begin{array}{l}\text { The lesson title is brief, and creatively } \\
\text { summarizes the theme of the lesson. }\end{array}$ & $\begin{array}{l}\text { The lesson title is brief, but does not } \\
\text { capture the theme of the lesson. }\end{array}$ & $\begin{array}{l}\text { The title is too long, and does not capture } \\
\text { the theme of the lesson. }\end{array}$ \\
\hline 10. Objectives & $\begin{array}{l}\text { Action verbs used to clearly specify } \\
\text { observable student outcomes. Stated to } \\
\text { measure high order thinking/learning skills. }\end{array}$ & $\begin{array}{l}\text { Action verbs specify observable student } \\
\text { outcomes, but not stated to measure high } \\
\text { order thinking/learning skills. }\end{array}$ & $\begin{array}{l}\text { Observable student outcomes not clear, } \\
\text { and not stated to measure high order } \\
\text { thinking and learning skills. }\end{array}$ \\
\hline 11. Assessment & $\begin{array}{l}\text { Each objective has at least one assessment } \\
\text { item that describes how the student } \\
\text { behavior will be evaluated. }\end{array}$ & $\begin{array}{l}\text { Each objective has at least one assessment } \\
\text { item, but not all describe how the student } \\
\text { behavior will be evaluated. }\end{array}$ & $\begin{array}{l}\text { Not all objectives have an assessment } \\
\text { items, and not all describe how the student } \\
\text { behavior will be evaluated. }\end{array}$ \\
\hline $\begin{array}{l}\text { 12. WV } \\
\text { IGOs/CSO's }\end{array}$ & $\begin{array}{l}\text { A minimum of one IGO/CSO is connected } \\
\text { to each objective, and the outcome number } \\
\text { is tied to the proper subject. IGO/CSO is } \\
\text { hyperlinked to WV State DoE web site. }\end{array}$ & $\begin{array}{l}\text { Minimum of one IGO/CSO for each } \\
\text { objective, and tied to proper subject. } \\
\text { IGO/CSO not hyperlinked to WV State } \\
\text { DoE web site. }\end{array}$ & $\begin{array}{l}\text { IGO/CSO not connected to each objective, } \\
\text { and not tied to proper subject. IGO/CSO } \\
\text { not hyperlinked to WV State DoE web } \\
\text { site. }\end{array}$ \\
\hline $\begin{array}{l}\text { 13. Materials and } \\
\text { Resources }\end{array}$ & $\begin{array}{l}\text { All items, supplies, and equipment needed to } \\
\text { complete lesson are listed. All } \\
\text { relevant/necessary information sources listed. }\end{array}$ & $\begin{array}{l}\text { All items, supplies, and equipment needed } \\
\text { for lesson are listed, but relevant } \\
\text { information sources are not. }\end{array}$ & $\begin{array}{l}\text { Incomplete listing of items, supplies, } \\
\text { equipment, and relevant information sources } \\
\text { needed to complete lesson. }\end{array}$ \\
\hline $\begin{array}{c}\text { 14. Instructional } \\
\text { Strategies } \\
\end{array}$ & $\begin{array}{l}\text { Teaching approaches are stated and } \\
\text { explained. }\end{array}$ & $\begin{array}{l}\text { Teaching approaches stated, but not } \\
\text { explained. }\end{array}$ & $\begin{array}{l}\text { Teaching approaches not clear, and no } \\
\text { explanation. }\end{array}$ \\
\hline $\begin{array}{l}\text { 15. Teacher } \\
\text { Preparation }\end{array}$ & $\begin{array}{l}\text { Sufficient details provided for teacher to } \\
\text { run the lesson. Essential background } \\
\text { information explained. }\end{array}$ & $\begin{array}{l}\text { Sufficient details provided to run lesson, } \\
\text { but essential background information not } \\
\text { explained. }\end{array}$ & $\begin{array}{l}\text { Insufficient details to run lesson, and } \\
\text { essential background information not } \\
\text { explained. }\end{array}$ \\
\hline $\begin{array}{l}\text { 16. Teacher } \\
\quad \text { Procedure } \\
\text { (Introduction, Concept } \\
\text { Development, Closure, } \\
\text { Hints) } \\
\end{array}$ & $\begin{array}{l}\text { Time required, motivating introduction, } \\
\text { step-by-step concept development, closure } \\
\text { summarizing concepts, and additional } \\
\text { suggestions provided. }\end{array}$ & $\begin{array}{l}\text { Time required, introduction, and concept } \\
\text { development provided, but closure not } \\
\text { stated. }\end{array}$ & $\begin{array}{l}\text { Time required and introduction provided, } \\
\text { but not concept development or closure. }\end{array}$ \\
\hline $\begin{array}{l}\text { 17. Student } \\
\quad \text { Procedure } \\
\text { (Introduction, Concept } \\
\text { Development, Closure, } \\
\text { Hints) } \\
\end{array}$ & $\begin{array}{l}\text { Time required, motivating introduction, } \\
\text { step-by-step details of activity, closure } \\
\text { steps, and additional suggestions provided. }\end{array}$ & $\begin{array}{l}\text { Time required, motivating introduction, } \\
\text { step-by-step details of activity, and helpful } \\
\text { hints provided, but closure steps are } \\
\text { absent. }\end{array}$ & $\begin{array}{l}\text { Time required and motivating introduction } \\
\text { provided, but step-by-step details of } \\
\text { activity are unclear and closure steps are } \\
\text { absent. }\end{array}$ \\
\hline 18. Extensions & $\begin{array}{l}\text { More than one activity is included to extend } \\
\text { lesson addressing diverse learners AND } \\
\text { other curricular areas. }\end{array}$ & $\begin{array}{l}\text { At least one activity is included to extend } \\
\text { lesson addressing diverse learners OR } \\
\text { other curricular areas, but not both. }\end{array}$ & $\begin{array}{l}\text { Extension activities are not clear or not } \\
\text { found. }\end{array}$ \\
\hline
\end{tabular}




\section{SCORE SHEET}

Score each element of the lesson (3,2,1 point) using the scale provided.

\begin{tabular}{|c|c|c|c|c|}
\hline UNIT & $\begin{array}{c}\text { Accomplished } \\
\text { (3) }\end{array}$ & $\begin{array}{l}\text { Developing } \\
\text { (2) }\end{array}$ & $\begin{array}{c}\text { Vague } \\
(1)\end{array}$ & Suggestions \\
\hline \multicolumn{4}{|l|}{ 4. Init Summary } & \\
\hline \multicolumn{4}{|l|}{ 5. Unit Time required } & \\
\hline \multicolumn{4}{|l|}{ 6. Major I'nit Goals } & \\
\hline \multicolumn{4}{|c|}{ 7. ('nit Design (layout, navigation, font, color, etc) } & \\
\hline \multicolumn{4}{|l|}{ 8. IT Integrations } & \\
\hline \multicolumn{4}{|c|}{ Total $=$} & \\
\hline LESSON 1 & $\begin{array}{c}\text { Accomplished } \\
\text { (3) }\end{array}$ & $\begin{array}{l}\text { Developing } \\
\text { (2) }\end{array}$ & $\begin{array}{l}\text { Vague } \\
\text { (1) }\end{array}$ & Suggestions \\
\hline \multicolumn{4}{|l|}{ 9. Title } & \\
\hline \multicolumn{4}{|l|}{ 10. Objectives } & \\
\hline \multicolumn{4}{|l|}{ 11. Assessment } & \\
\hline \multicolumn{4}{|l|}{ 12. WV IGOs/CSOs } & \\
\hline \multicolumn{4}{|c|}{ 13. Materials \& Resources } & \\
\hline \multicolumn{4}{|c|}{ 14. Instructional Strategies } & \\
\hline \multicolumn{4}{|c|}{ 15. Teacher Preparation } & \\
\hline \multicolumn{4}{|l|}{ 16. Teacher Procedure } & \\
\hline \multicolumn{4}{|c|}{ 17. Student Procedure } & \\
\hline \multicolumn{4}{|l|}{ 18. Extensions } & \\
\hline \multicolumn{4}{|c|}{ Total $=$} & \\
\hline
\end{tabular}

\begin{tabular}{|c|c|c|c|c|}
\hline LESSON 2 & $\begin{array}{c}\text { Accomplished } \\
\text { (3) }\end{array}$ & $\begin{array}{l}\text { Developing } \\
\text { (2) }\end{array}$ & $\begin{array}{c}\text { Vague } \\
\text { (1) }\end{array}$ & Suggestions \\
\hline \multicolumn{4}{|l|}{ 9. Title } & \\
\hline \multicolumn{4}{|l|}{ 10. Objectives } & \\
\hline \multicolumn{4}{|l|}{ 11. Assessment } & \\
\hline \multicolumn{4}{|l|}{ 12. WV IGOs/CSOs } & \\
\hline \multicolumn{4}{|c|}{ 13. Materials \& Resources } & \\
\hline \multicolumn{4}{|c|}{ 14. Instructional Strategies } & \\
\hline \multicolumn{4}{|c|}{ 15. Teacher Preparation } & \\
\hline \multicolumn{4}{|c|}{ 16. Teacher Procedure } & \\
\hline \multicolumn{4}{|c|}{ 17. Student Procedure } & \\
\hline \multicolumn{4}{|l|}{ 18. Extensions } & \\
\hline \multicolumn{4}{|c|}{ Total $=$} & \\
\hline LESSON 3 & Accomplished & $\begin{array}{l}\text { Developing } \\
\text { (2) }\end{array}$ & $\begin{array}{c}\text { Vague } \\
\text { (1) }\end{array}$ & Suggestions \\
\hline \multicolumn{4}{|l|}{ 9. Title } & \\
\hline \multicolumn{4}{|l|}{ 10. Objectives } & \\
\hline \multicolumn{4}{|l|}{ 11. Assessment } & \\
\hline \multicolumn{4}{|l|}{ 12. WV IGOs/CSOs } & \\
\hline \multicolumn{4}{|c|}{ 13. Materials \& Resources } & \\
\hline \multicolumn{4}{|c|}{ 14. Instructional Strategies } & \\
\hline \multicolumn{4}{|c|}{ 15. Teacher Preparation } & \\
\hline \multicolumn{4}{|c|}{ 16. Teacher Procedure } & \\
\hline \multicolumn{4}{|c|}{ 17. Student Procedure } & \\
\hline \multicolumn{4}{|l|}{ 18. Extensions } & \\
\hline \multicolumn{4}{|c|}{ Total $=$} & \\
\hline
\end{tabular}




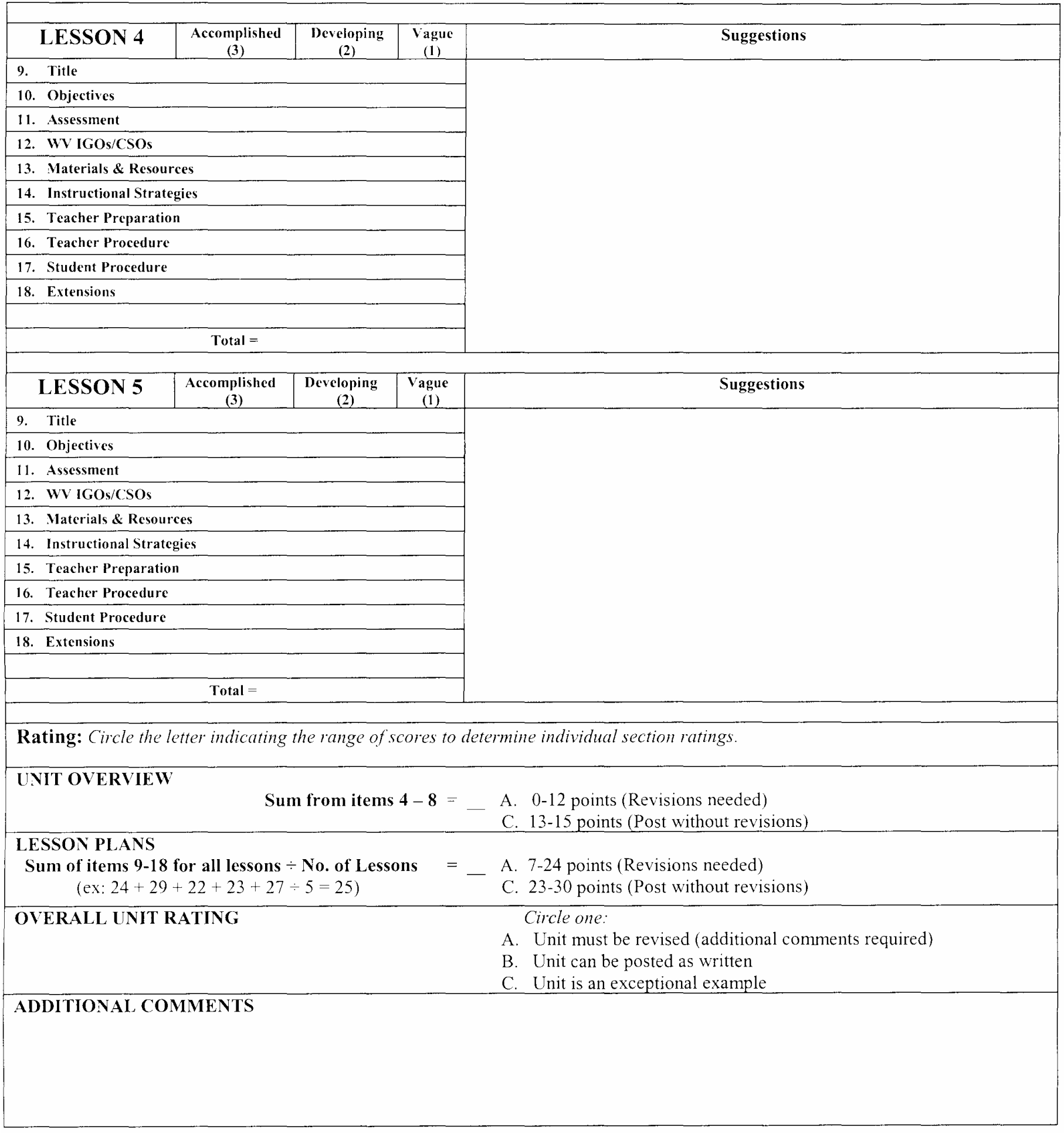




\begin{tabular}{|c|c|}
\hline \multicolumn{2}{|c|}{$\begin{array}{l}\text { Unit/Lesson Feedback Sheet } \\
\text { te unit/lessons, use this sheet to indicate what you see as the major strengths } \\
\text { for improvement (give } 3 \text { ). }\end{array}$} \\
\hline \multicolumn{2}{|c|}{ Unit Overview } \\
\hline $\begin{array}{l}\text { Strengths } \\
1 . \\
2 . \\
3 .\end{array}$ & $\begin{array}{l}\text { Suggestions } \\
\quad 1 . \\
2 . \\
3 .\end{array}$ \\
\hline \multicolumn{2}{|c|}{ Lesson 1} \\
\hline $\begin{array}{l}\text { Strengths } \\
\quad 4 . \\
5 . \\
6 .\end{array}$ & $\begin{array}{l}\text { Suggestions } \\
4 . \\
5 . \\
6 .\end{array}$ \\
\hline \multicolumn{2}{|c|}{ Lesson 2} \\
\hline $\begin{array}{l}\text { Strengths } \\
1 . \\
2 . \\
3 .\end{array}$ & $\begin{array}{l}\text { Suggestions } \\
1 . \\
2 . \\
3 .\end{array}$ \\
\hline \multicolumn{2}{|c|}{ Lesson 3} \\
\hline $\begin{array}{l}\text { Strengths } \\
1 . \\
2 . \\
3 .\end{array}$ & $\begin{array}{l}\text { Suggestions } \\
\quad 1 . \\
2 . \\
3 .\end{array}$ \\
\hline \multicolumn{2}{|c|}{ Lesson 4} \\
\hline $\begin{array}{c}\text { Strengths } \\
1 . \\
2 . \\
3 .\end{array}$ & $\begin{array}{l}\text { Suggestions } \\
1 . \\
2 . \\
3 .\end{array}$ \\
\hline \multicolumn{2}{|c|}{ Lesson 5} \\
\hline $\begin{array}{c}\text { Strengths } \\
1 . \\
2 . \\
3 .\end{array}$ & $\begin{array}{c}\text { Suggestions } \\
1 . \\
2 . \\
3 .\end{array}$ \\
\hline
\end{tabular}


Appendix B

Survey of Computer Use (SCU)

Permission to use the CODE 77 rubrics for non-profit use is granted by the author, Doug Johnson, on his web-site:

http://www.doug-johnson.com/dougwri/rubrics2002.html 


\section{Survey of Computer Use}

Participant Code:

Directions: Complete sections A-D of the survey by checking $(\checkmark)$ the appropriate response.

\section{Part A: Your Technology Background}

How often have you used the following technologies?

$$
\text { CODE: } \quad 1=\text { frequently } \quad 2 \text { = rarely } 3=\text { never } \quad 4=\text { not available }
$$

\begin{tabular}{|c|c|c|c|c|c|}
\hline Applications & 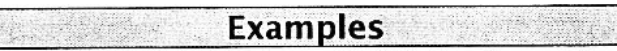 & 1 & 2 & 3 & 4 \\
\hline 1. IBM Compatible computer & Windows 3.11 , Windows $95 / 98$, Windows NT & & & & \\
\hline 2. Apple Macintosh computer & Performa, Quadra, PowerMac, G3, G4 & & & & \\
\hline 3. Other Computer & DOS, Apple Ile, UNIX, etc. & & & & \\
\hline 4. VCR & Recorder, player & & & & \\
\hline 5. Laserdisc Player or DVD Player & & & & & \\
\hline 6. Video Camcorder & & & & & \\
\hline 7. Digital Camera & & & & & \\
\hline 8. LCD Panel or Computer Projector & & & & & \\
\hline 9. Internet Web Browser/Online Service & Netscape, Internet Explorer, AOL, etc. & & & & \\
\hline 10. Fax Machine & & & & & \\
\hline 11. Modem & & & & & \\
\hline 12. CD-ROM & & & & & \\
\hline 13. Scanner & & & & & \\
\hline 14. Network File/Print Sharing & & & & & \\
\hline
\end{tabular}

\section{Part B: Staff-Centered Technology}

How often have you used the following applications?

$$
\text { CODE: } \quad 1=\text { frequently } \quad 2=\text { rarely } \quad 3=\text { never } \quad 4=\text { not available }
$$

\begin{tabular}{|c|c|c|c|c|c|}
\hline Applications & 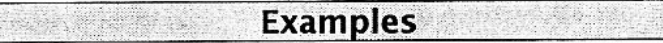 & 1 & 2 & 3 & 4 \\
\hline 1. Student Management Systems & Grading/attendance/assessment programs & & & & \\
\hline 2. Student Information Systems & Student records, discipline, health systems & & & & \\
\hline 3. School Management Systems & Budget, personal scheduling/calendar & & & & \\
\hline 4. Word Processing & Word, WordPerfect, ClarisWorks, Microsoft Works & & & & \\
\hline 5. Spreadsheets/Databases & Excel, Lotus 1-2-3, Filemaker Pro, Access & & & & \\
\hline 6. Desktop Publishing & Pagemaker, QuarkXpress, Print Shop Deluxe & & & & \\
\hline 7. Authoring/Multimedia & Hyerstudio, Authorware, Director & & & & \\
\hline $\begin{array}{l}\text { 8. Instructional } \\
\text { Demonstration/Tutorial }\end{array}$ & PowerPoint, Persuasion & & & & \\
\hline 9. Informational Retrieval & Infrotrac, SIRS, Library Circulation & & & & \\
\hline $\begin{array}{l}\text { 10. Audio/Video Capture or } \\
\text { Digitizing }\end{array}$ & Premiere, Videoshop & & & & \\
\hline
\end{tabular}


Part B: Continued....

\begin{tabular}{|l|l|l|l|l|}
\hline 11. Art/Graphic Development & Photoshop, Painter, Illustrator, Canvas, Draw & & & \\
\hline 12. Computerized Testing & Microtest & & & \\
\hline 13. Internet/Online Service Access & Netscape, Internet Explorer, AOL, Compuserv & & & \\
\hline 14. Web Page Development & FrontPage, HomePage, Pagemill, BB Edit & & & \\
\hline 15. E-mail & Eudora, Outlook, Exchange, Emailer & & \\
\hline
\end{tabular}

\section{Part C: Student-Centered Technology}

In your classes, how often do you have students use the following applications?

$$
\text { CODE: } \quad 1=\text { frequently } \quad 2 \text { = rarely } \quad 3 \text { = never } \quad 4=\text { not available }
$$

\begin{tabular}{|c|c|c|c|c|c|}
\hline Applications & 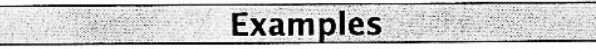 & 1 & 2 & 3 & 4 \\
\hline \multicolumn{6}{|l|}{ 1. CAI: Drill \& Practice/Tutorial } \\
\hline 2. Simulation/Educational Games & Sim City, Sim Life, Civilization & & & & \\
\hline 3. Word Processing & Word, WordPerfect & & & & \\
\hline \multicolumn{6}{|l|}{ 4. Informational Retrieval } \\
\hline \multicolumn{6}{|l|}{ 5. Internet Searches } \\
\hline \multicolumn{6}{|l|}{ 6. E-mail } \\
\hline \multicolumn{6}{|l|}{ 7. Bulletin Boards, Listserves } \\
\hline 8. MUD/MOO & Multi User Domains & & & & \\
\hline $\begin{array}{l}\text { 9. Authoring/Multimedia } \\
\text { Development }\end{array}$ & Hyperstudio, Authorware, Director & & & & \\
\hline 10. Desktop Publishing & Pagemaker, QuarkXpress, Publisher, etc. & & & & \\
\hline 11. Electronic Presentations & PowerPoint, Persuasion & & & & \\
\hline \multicolumn{6}{|l|}{ 12. Video Development } \\
\hline \multicolumn{6}{|l|}{ 13. Open Lab Access } \\
\hline 14. Web Page Development & . & & & & \\
\hline
\end{tabular}

\section{Part D: Learning Strategies}

In your current classes, to what extent are students engaged in the following?

$$
\text { CODE: } \quad 1=\text { frequently } \quad 2 \text { = rarely } \quad 3=\text { not engaged }
$$

\begin{tabular}{|l|l|l|}
\hline $\begin{array}{l}\text { 1. Problem-Solving: The application of principles to the solution of a problem that is new to } \\
\text { the student. }\end{array}$ & $\mathbf{3}$ & \\
\hline $\begin{array}{l}\text { 2. Task Analysis: The process used for identifying the step-by-step procedures needed to } \\
\text { accomplish something. }\end{array}$ & & \\
\hline $\begin{array}{l}\text { 3. Discovery Learning: The student must induce concepts or principles fairly } \\
\text { independently, but may be guided by the teacher. }\end{array}$ & \\
\hline $\begin{array}{l}\text { 4. Critical Thinking: Evaluating the credibility of information, distinguishing relevant from } \\
\text { irrelevant, recognizing bias, and deciding what to do by reasoning from the available } \\
\text { evidence. }\end{array}$ & $\begin{array}{l}\text { 5. Concept Scaffolding: Seeing the larger picture into which a new experience will fit, using } \\
\text { imagery, pictorial representation, a diagram, or other organization to facilitate relationships } \\
\text { within the knowledge structure. }\end{array}$ & \\
\hline
\end{tabular}


Part D: Continued...

\begin{tabular}{|l|l|}
\hline $\begin{array}{l}\text { 6. Higher-order Thinking: Challenging students to interpret, analyze, or manipulate } \\
\text { information in response to a question or problem that cannot be resolved through routine } \\
\text { application of previously learned knowledge. }\end{array}$ & \\
\hline $\begin{array}{l}\text { 7. Metacognition: The mental processes whereby one monitors one's cognitive processes in } \\
\text { thinking, learning, and remembering self-understanding and regulation. }\end{array}$ & \\
\hline $\begin{array}{l}\text { 8. Computer-Assisted Instruction: Instruction mediated by a computer which presents } \\
\text { content, asks questions, and reacts to responses. }\end{array}$ & \\
\hline $\begin{array}{l}\text { 9. Cooperative Learning: An approach to learning, arranged by the teacher, that requires two } \\
\text { or more students to work together to achieve an educational objective, as opposed to } \\
\text { individual learning. }\end{array}$ & \\
\hline $\begin{array}{l}\text { 10. Constructivist Learning: Emphasis on student development of new knowledge through } \\
\text { active engagement processes that link new knowledge to prior understanding. }\end{array}$ & \\
\hline 11. Intrinsic Motivation: Motivation due to satisfaction that is inherent in performing activity. & \\
\hline $\begin{array}{l}\text { 12. Conceptual Change: Construction of new understandings that involves abandoning or } \\
\text { revising some of one's existing conceptions, not just adding new ones. }\end{array}$ & \\
\hline
\end{tabular}

Directions: For sections E-G of the survey please judge your level of achievement in each of the following competencies. Circle the number which best reflects your current level of skill attainment (Level 3 is considered mastery.)

\section{Part E: Self Evaluation of Basic Computer Use}

\section{Basic computer operation}

Level 1 I do not use a computer.

Level 2 I can use the computer to run a few specific, preloaded programs. It has little effect on either my work or home life. I am somewhat anxious I might damage the machine or its programs.

Level 3 I can set-up my computer and peripheral devices, load software, print, and use most of the operating system tools like the scrapbook, clock, note pad, find command, and trash can (recycling bin). I can format a data disk.

Level 4 I can run two programs simultaneously and have several windows open at the same time. I can customize the look and sounds of my computer. I use techniques like shift-clicking to work with multiple files. I look for programs and techniques to maximize my operating system. I feel confident enough to teach others some basic operations.

\section{File management}

Level 1 I do not save any documents I create using the computer.

Level 2 I save documents I've created but I cannot chose where they are saved. I do not back-up my files.

Level 3 I have a filing system for organizing my files, and can locate files quickly and reliably. I back-up my files to floppy disk or other storage device on a regular basis.

Level 4 I regularly run a disk-optimizer on my hard drive and use a back-up program to make copies of my files on a weekly basis. I have a system for archiving files which I use on a regular basis to conserve my computer's hard drive space.

\section{Word processing}

Level 1 I do not use a word processor, nor can I identify any uses or features it might have which would benefit the way I work.

Level 2 I occasionally use the word processor for simple documents which I know I will modify and use again. I generally find it easier to hand write or type most written work I do.

Level 3 I use the word processor for nearly all my written professional work: memos, tests, worksheets, and home communication. I can edit, spell check, and change the format of a document. I can arrange the pages, preview and print my work. I feel my work looks professional.

Level $4 \quad$ I use the word processor not only for my work, but have used it with students to help them improve their own communication skills. 


\section{Spreadsheet use}

Level 1 I do not use a spreadsheet, nor can I identify any uses or features it might have which would benefit the way I work.

Level 2 I understand the use of a spreadsheet and can navigate within one. I can create a simple spreadsheet which adds a column of numbers.

Level 3 I use a spreadsheet for several applications. These spreadsheets use labels, formulas and cell references. I can change the format of the spreadsheets by changing column widths and text style. I can use the spreadsheet to make a simple graph or chart.

Level $4 \quad$ I use the spreadsheet not only for my work, but have used it with students to help them improve their own data keeping and analysis skills.

\section{Database use}

Level I I do not use a database, nor can I identify any uses or features it might have which would benefit the way I work.

Level 2 I understand the use of a database and can locate information within one which has been pre-made. I can add or delete data in a database.

Level 3 I use databases for a personal applications. I can create an original database - defining fields and creating layouts. I can find, sort and print information in layouts which are clear and useful to me.

Level $4 \quad$ I can use formulas with my database to create summaries of numerical data. I can use database information to mail merge in a word processing document. I use the database not only for my work, but have used it with students to help them improve their own data keeping and analysis skills.

\section{Graphics use}

Level I I do not use graphics in my word processing or presentations, nor can I identify any uses or features they might have which would benefit the way I work.

Level 2 I can open and create simple pictures with the painting and drawing programs. I can use programs like PrintShop or SuperPrint.

Level 3 I use both pre-made clip art and simple original graphics in my word processed documents and presentations. I can edit clip art, change its size, and place it on a page. I can purposefully use most of the drawing tools, and can group and un-group objects. I can use the clipboard to take graphics from one application for use in another. The use of graphics in my work helps clarify or amplify my message.

Level $4 \quad$ I use graphics not only for my work, but have used it with students to help them improve their own communications. I can use graphics and the word processor to create a professional looking newsletter.

\section{Hypermedia use}

Level 1 I do not use hypermedia (HyperStudio), nor can I identify any uses or features it might have which would benefit the way I work.

Level 2 I can navigate through a pre-made hypermedia program.

Level 3 I can create my own hypermedia stacks for information presentation. These stacks use navigation buttons, sounds, dissolves, graphics, and text fields. I can use an LCD projection device to display the presentation to a class.

Level $4 \quad$ use hypermedia with students who are making their own stacks for information keeping and presentation.

\section{Network use}

Level 1 I do not use the on-line resources available in my building, nor can I identify any uses or features they might have which would benefit the way I work.

Level 2 I understand that there is a large amount of information available to me as a teacher which can be accessed through networks, including the Internet. With the help of the media specialist, I can use the resources on the network in our building.

Level 3 I use the networks to access professional and personal information from a variety of sources including networked CD-ROM reference materials, on-line library catalogs, the ERIC database, and the World Wide Web. I have an e-mail account that I use on a regular basis.

Level 4 Using telecommunications, I am an active participant in on-line discussions, can download files and programs from remote computers. I use telecommunications with my students. 


\section{Student Assessment}

Level I I do not use the computer for student assessment.

Level 2 I understand that there are ways I can keep track of student progress using the computer. I keep some student produced materials on the computer, and write evaluations of student work and notes to parents with the word processor.

Level 3 I effectively use an electronic grade book to keep track of student data and/or I keep portfolios of student produced materials on the computer. I use the electronic data during parent/teacher conferences.

Level 4 I rely on the computer to keep track of outcomes and objectives individual students have mastered. I use that information in determining assignments, teaching strategies, and groupings.

\section{$X$. Ethical use understanding}

Level 1 I am not aware of any ethical issues surrounding computer use.

Level 2 I know that some copyright restrictions apply to computer software.

Level 3 I clearly understand the difference between freeware, shareware, and commercial software and the fees involved in the use of each. I know the programs for which the district or my building holds a site license. I understand the school board policy on the use of copyrighted materials. I demonstrate ethical usage of all software and let my students know my personal stand on legal and moral issues involving technology. I know and enforce the school's technology policies and guidelines, including its Internet Acceptable Use Policy. I have a personal philosophy I can articulate regarding the ethical use of technology in education.

Level 4 I am aware of other controversial aspects of technology use including data privacy, equitable access, and free speech. I feel comfortable talking about these issues.

\section{Part F: Self-Evaluation for Advanced Teacher Computer Use}

\section{Instructional software use}

Level 1 I do not use instructional software as a part of my instructional program, nor am I aware of any titles which might help my students meet their learning goals.

Level 2 I use a few computer programs as an instructional supplement, as a reward, or with special needs children.

Level 3 I use several programs (drill and practice, simulations, tutorials, etc.) chosen by my department or grade level to help all my students meet specific learning objectives. The software allows me teach and/or reinforce concepts more effectively than traditional methods. When it is available, I use the software's management system to help assess individual student performance. I use technological resources to meet the needs of students who do not respond to traditional methods of instruction.

Level 4 I seek out new programs for evaluation and adoption. I know sources of software reviews and keep current on new developments in computer technologies through professional reading and conference attendance. I share my findings with other professionals.

\section{Information literacy skills}

Level 1 I am not familiar with the term information literacy, nor do I know why such skills are important.

Level 2 As a part of my curriculum, I have library research projects and I support the library skills taught by the media specialist. I am aware that there are electronic resources available to my students.

Level 3 My curriculum includes multiple projects that have an information literacy component. These are team taught with the media specialist. I understand the Big Six or a similar information literacy process and design student projects so that they require higher level thinking skills, use electronic information sources, require the use of computer productivity software, and are authentically assessed. I guide my students in accessing, evaluating and using information and experts from world-wide sources through the Internet and video conferencing.

Level 4 I am involved in curriculum planning teams and advocate the use of multidisciplinary activities which require-information literacy skills. I share successful units with others through print, electronic publishing, presentations and workshops. 
III. Modification of instructional delivery

Level I I have one or two effective methods of teaching content to my students. I do not use technology which requires that I change my instructional methodology.

Level 2 I have tried units or projects that are student-directed, use small groups, or are highly individualized, but I primarily use teacher-directed, whole group instruction.

Level 3 I use a variety of instructional delivery methods and student grouping strategies routinely throughout the year. I can design activities and approaches which best fit the learning objectives and the availability of the technology available to me. I can use small groups working cooperatively or in rotation to take advantage of student to equipment ratios of greater than one to one. I modify instructional methods to take advantage of the learning styles of individual students.

Level 4 I continuously try new approaches suggested by research or observation to discover the most effective means of using technology to engage my students and meet curricular goals.

I work with a team of fellow teachers to create, modify and improve my practices in this area.

\section{Assessment of student performance}

Level 1 I evaluate my students using objective tests only.

Level 2 I evaluate some student performances or projects using subjective criteria. I save some student work for cumulative folders and parent conferences, and print some electronically produced student work.

Level 3 I use a wide range of assessments to evaluate student projects and performances. I can create assessment tools like checklists, rubrics and benchmarks which help the student assess his own performance and allow me to objectively determine the quality of student work. I ask students to keep both a physical and electronic portfolio of their work. Students and their parents have the means to continuously access the recorded progress students are making toward their learning goals through networked grade books and portfolios. Students are given the opportunity to demonstrate skills through performance to a wide audience via data and video networks. I have means of aggregating performance data for my class which I use to modify my teaching activities and strategies.

Level $4 \quad$ I continuously try new approaches suggested by research or observation to discover the most effective means of using technology to help assess student learning. I work with a team of fellow teachers to create, modify and improve my work in this area.

\section{Individualization of the educational program}

Level 1 I modify my curriculum or instructional methods only for students with identified special needs.

Level 2 I occasionally give students the choice of assignments in my class, but all class members (unless they are in special education) must meet the same learning objectives within the same time frame. Skill remediation is done during summer school or informally during or after school.

Level 3 With the assistance of the student, parents and appropriate specialists, I create an individualized learning plan for each of my students. I track the accomplishment of learning goals in the plan using a computerized tool. I use this tool during parent conferences and for school or state reporting. Students and their parents have networked access to this tool for continuous monitoring of progress and plan modification.

Level 4 I provide suggestions about the content and design of the individualized computerized planning and report tools.

\section{Professional growth and communication}

Level I I do not use electronic resources for professional growth or communication.

Level 2 I can find lesson plans and research in on-line data bases. I correspond with parents and other teachers using e-mail.

Level 3 I use the Internet and other on-line resources to obtain research findings, teaching materials and information related to the content of my classes. I read electronic newsletters and journals to keep current on educational practices. I participate in electronic discussion groups and chat rooms which are related to my area of education, and contribute to and use the best practices discussed there. I use a computerized presentation program when giving workshops or speaking at conferences. I use technology to take part in distance learning opportunities for my own professional development.

Level 4 I organize professional growth opportunities for other teachers and feel comfortable teaching other staff members about the use of technology. 
VII. Research and evaluation of technology use

Level 1 I have not attempted to determine whether the use of instructional technology has made a difference in my students' learning or classroom climate.

Level 2 I gather, use and share anecdotal information and observations about student use of technology in my classroom.

Level 3 I use action research and aggregated data to accurately determine whether the technology and methodology I am using has an impact on how well my students learn and on school climate.

Level 4 I participate in formal studies of the impact of technology on student learning conducted by professional groups and academics. I have designed such studies as part of my own professional education. I report electronically and in print the findings of my research to other professionals.

\section{Part G: Self-Evaluation for Teacher Internet Use}

\section{Internet basics}

Level 1 I do not understand how networks work, nor can I identify any personal or professional uses for networks, including the Internet. I do not have an account on any network nor would I know how to get one.

Level 2 I can identify some personal or professional uses for networks, and understand the potential value to my students and me. I've read some articles about the Internet in the popular press. I can directly use network access to a library catalog or CD-ROM.

Level 3 I can describe what a computer network does and how it can be useful personally and professionally. I can distinguish between a local area network, a wide area network, and the Internet and can describe educational uses for each. I have personal access to the Internet that allows me to receive and send email, download files, and access the World Wide Web. I know that I must protect my password, and should restrict access by others to my account.

Level $4 \quad$ I use networks on a daily basis to access and communicate information. I can serve as an active participant in a school or organizational planning group, giving advice and providing information about networks. I can recommend several ways of obtaining Internet access to others.

\section{Email and electronic mailing lists}

Level 1 I do not use email.

Level 2 I understand the concept of email and can explain some administrative and educational uses for it.

Level 3 I use email regularly and can:

- read and delete messages

- send, forward and reply to messages to

- create address books, mailing lists, and a signature file

- send and receive attachments

- use electronic mailing lists and understand the professional uses of them

- read and contribute to a professional electronic mailing list

Level 4 I can send group mailings and feel confident that I could administer an electronic mailing list. I use activities that require email in my teaching. I can locate lists of subject oriented mailing lists.

\section{The World Wide Web}

Level 1 I do not use the World Wide Web.

Level 2 I am aware that the World Wide Web is a means of sharing information on the Internet. I can browse the Web for recreational purposes.

Level 3 I can use a Web browser like Explorer or Netscape to find information on the World Wide Web, and can list some of the Web's unique features. I can explain the terms: hypertext, URL, $\mathrm{http}$, and html. I can write web pages to share information locations with others. I can use Web search engines to locate specific information and can create bookmarks to Web sites of educational value.

Level 4 I can configure my web browser with a variety of helper applications. I understand what "cookies" do and whether to keep them enabled. I can speak about the security issues of online commerce and data privacy. 


\section{Search tools}

Level 1 I cannot locate information on the Internet.

Level 2 I can occasionally locate useful information on the Internet.

Level 3 I can conduct an efficient search of Internet resources using directories likeYahoo or search engines like Excite, Lycos,or Infoseek. I can use advanced search commands to specify and limited the number of hits I get.

Level 4 I can identify some specialized search tools for finding software and email addresses. I can speculate on future developments in on-line information searching including know-bots and other kinds of intelligent search agents.

\section{Newsgroups, gophers and telnet}

Level 1 I have no knowledge of newsgroups, gophers, or telnet functions.

Level 2 I know that there are resources in a variety of formats available on the Internet, but can not confidently access them.

Level 3 I read the newsgroups that interest me on a regular basis, and I can contribute to newsgroups. I understand the use of gophers and can locate several that help me. I can write directions for locating a gopher so that others can find it as well. I can access a remote computer through the telnet command, including remote library catalogs. I can find the help screens when emulating remote computers and can log off properly.

Level 4 I know how to find, configure, and use the specialized tools for newsgroups, gophers, and telnet access. I use the resources found in these areas with my students.

\section{Obtaining, decompressing, and using files}

Level 1 I cannot retrieve files from remote computers.

Level 2 I know that documents and computer programs that are useful to my students and me are stored on computers throughout the world. I can retrieve these files.

Level 3 I understand the concept and netiquette of "anonymous FTP" sites. I can transfer files and programs from remote locations to my computer, and can use programs or plug-ins that help me do this. I can extract compressed files, and know some utilities that help me view graphics and play sounds and movies. I understand the nature and danger of computer viruses, and know how to minimize my risk of contracting a computer virus.

Level 4 I use information I have retrieved as a resource for and with my students. I understand the concept of a network server, and the functions it can serve in an organization. I can use an $\mathrm{ftp}$ client to upload files to a server.

\section{Real-time and push technologies}

Level 1 I use only static documents and files I retrieve from the Internet.

Level 2 I have some information sent to me on a regular basis through e-mail and I check some sites on a regular basis for information.

Level 3 I use chat-rooms and customized news and information feeds. I can listen to audio streamed from the web. I know the hardware and software requirements for web-based videoconferencing.

Level 4 I can use real-time applications to design a "virtual" classroom or interactive learning experience. My students use videoconferencing for communication with experts and project collaboration with other students.

\section{Web page construction}

Level 1 I can not create a web page.

Level 2 I can save text I have created as an html file with a command in my word processor. I know a few, simple html commands.

Level 3 Using hand-coded html or a web page authoring tool, I can:

- view web pages as a source documents

- create a formatted web page that uses background color, font styles and alignment, graphics, and tables

- include links to other parts of my document or other Internet sites in my page

- know basic guidelines for good web page construction and the district's web policies

Level 4 I can use the web as an interface to databases. When appropriate, I can register my pages with search engine sites. I can help write web creation policies for design, content, and use. 


\section{Learning opportunities using the Internet}

Level $1 \quad$ I am not aware of any ways the Internet can be used with students in my classroom.

Level 2 I occasionally allow my students to use the Internet to find information.

Level 3 I know a variety of projects and activities that effectively use the Internet to instruct and involve students. I know a source for collaborative projects, can direct students to on-line tutorials and learning resources, and encourage a variety of key-pal activities.

Level 4 I can design and implement an Internet project or maintain an educational Internet site.

IX. Netiquette, On-line Ethics, and Current Issues Surrounding Internet Use in K-12 Schools

Level 1 I am not aware of any ethics or proprieties regarding the Internet nor am I aware of any issues dealing with Internet use in a school setting.

Level 2 I understand a few rules that my students and I should follow when using the Internet. I understand that the Internet is sometimes a controversial resource that many educators and parents do not understand.

Level 3 I have read a guideline for Internet use such as Rinaldi's "The Net: User Guidelines and Netiquette" or other source, and follow the rules outlined. I know and read the FAQ files associated with sources on the Internet. I am aware that electronic communication is a new communications medium that may require new sensitivities. I can identify printed and online resources that speak to current Internet issues like:

- censorship/site blocking software

- copyright

- legal and illegal uses

- data privacy

- security I can list some of the critical components of a good Acceptable Use Policy and know and use our district's.

Level 4 I can use my knowledge of the Internet to write good school policies and activities that help students develop good judgment and good information skills.

Please add any additional comments or concerns that you would like to share:

Thank you for your participation in Trek 21! 


\section{Appendix C \\ Principles of Adult Learning Scale (PALS)}

Permission to reprint the Principles of Adult Learning Scale was obtained by the author, Gary J. Conti (see below):

$\begin{array}{ll}\text { From: } & \text { "Gary J. Conti" < } \\ \text { To: } & \text { "Chris Weiganti@earthlink.net> } \\ \text { Date: } & 4 / 26 / 2005 \text { 12:41:55 AM } \\ \text { Subject: } & \text { Re: Permission to reprint PALS in dissertation }\end{array}$

Chris:

It's great to hear that you are finding use for PALS. By all means, you have permission to reproduce PALS and to use it as you see fit. If you need a more formal response, I have published a permission release on page 91 of my chapter in Adult Learning Methods (3rd edition) by Michael Galbraith. Good luck with your study...

--- Gary 
Trek 21 Participant Code:

\section{Learning Strategies Survey}

The following survey contains several things that a teacher might do in a classroom. You may personally find some of them desirable and find others undesirable. For each item, respond to the way you most frequently practice the action described by circling the appropriate number as given below:

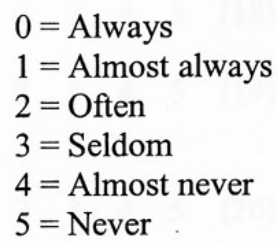

$\begin{array}{lllllll}0 & 1 & 2 & 3 & 4 & 5 & \text { (1) I allow students to participate in developing the criteria for evaluating their }\end{array}$ performance in class.

$\begin{array}{lllllll}0 & 1 & 2 & 3 & 4 & 5 & \text { (2) I use disciplinary action when it is needed. }\end{array}$

$\begin{array}{lllllll}0 & 1 & 2 & 3 & 4 & 5 & \text { (3) I allow some students more time to complete assignments when they need }\end{array}$ it.

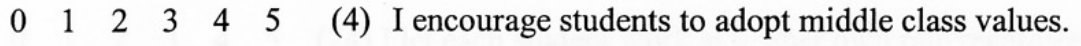

$\begin{array}{llllllll}0 & 1 & 2 & 3 & 4 & 5 & \text { (5) } \text { I help students diagnose the gaps between their goals and their present }\end{array}$ level of performance.

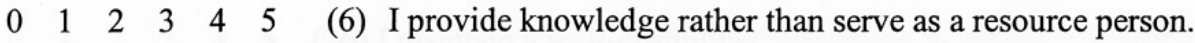

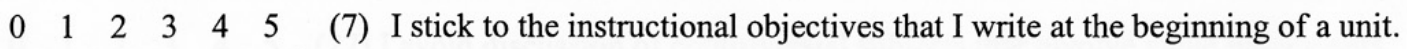

$\begin{array}{llllllll}0 & 1 & 2 & 3 & 4 & 5 & \text { (8) I participate in the informal counseling of students. }\end{array}$

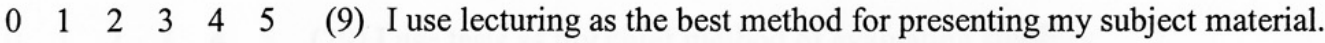

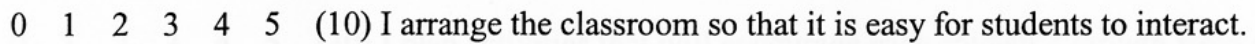

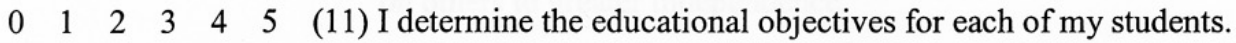

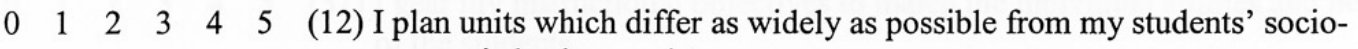
economic backgrounds.

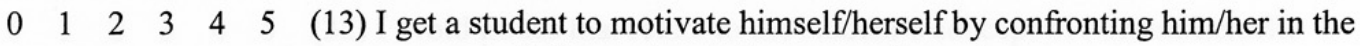
presence of classmates during group discussions.

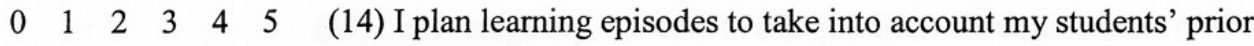
experiences. 
$\begin{array}{lllllll}0 & 1 & 2 & 3 & 4 & 5 & \text { (15) I allow students to participate in making decisions about the topics that will }\end{array}$ be covered in class.

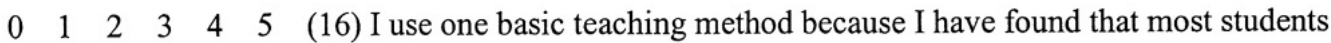
have a similar style of learning.

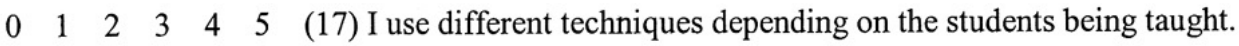

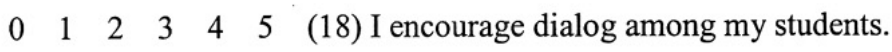

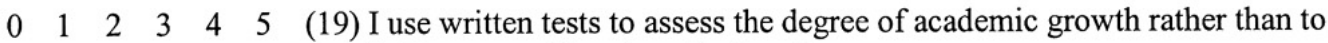
indicate new directions for learning.

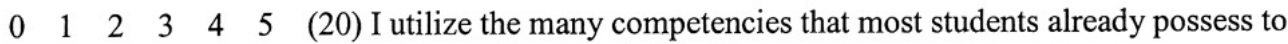
achieve educational objectives.

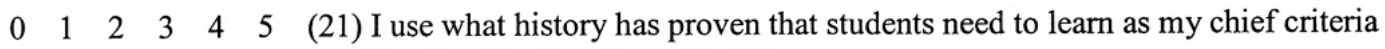
for planning learning episodes.

$\begin{array}{lllllll}0 & 1 & 2 & 3 & 4 & 5 & \text { (22) I accept errors as a natural part of the learning process. }\end{array}$

$\begin{array}{lllllll}0 & 1 & 2 & 3 & 4 & 5 & \text { (23) I have individual conferences to help students identify their educational }\end{array}$ needs.

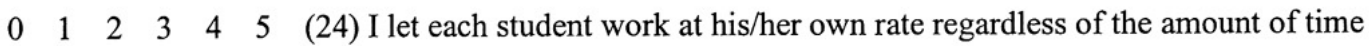
it takes him/her to learn a new concept.

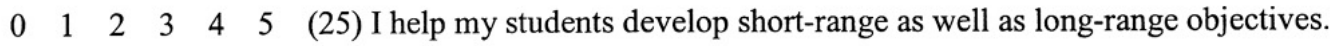

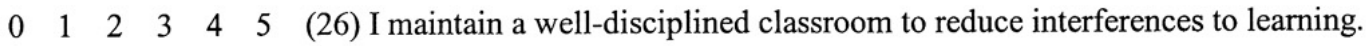

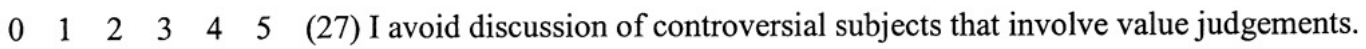

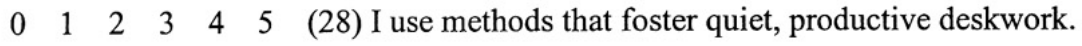

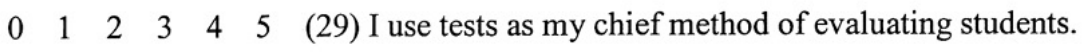

$\begin{array}{lllllll}0 & 1 & 2 & 3 & 4 & 5 & \text { (30) I plan activities that will encourage each student's growth from dependence }\end{array}$ on others to greater independence.

$\begin{array}{lllllll}0 & 1 & 2 & 3 & 4 & 5 & \text { (31) I gear my instructional objectives to match the individual abilites and needs }\end{array}$ of the students.

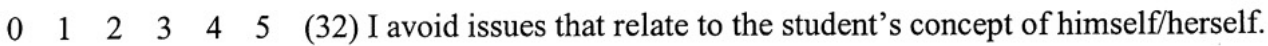

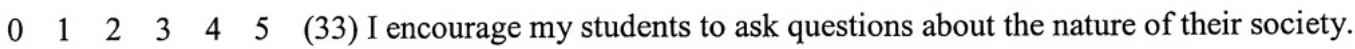




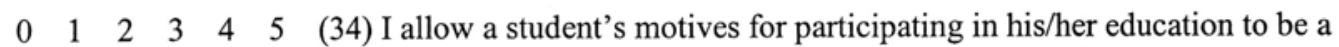
major determinant in the planning of learning objectives.

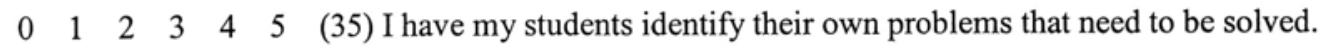

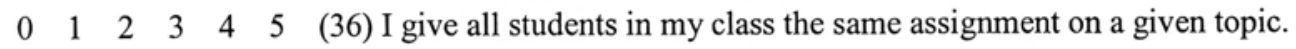

$\begin{array}{lllllll}0 & 1 & 2 & 3 & 4 & 5 & \text { (37) I organize learning episodes according to the problems that my students }\end{array}$ encounter in everyday life.

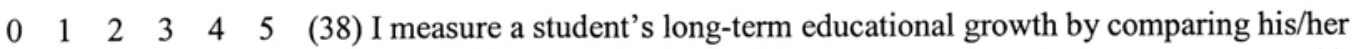
total achievement in class to his/her expected performance as measured by national norms from standardized tests.

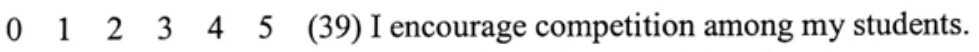

$\begin{array}{lllllll}0 & 1 & 2 & 3 & 4 & 5 & \text { (40) I use different materials with different students. }\end{array}$

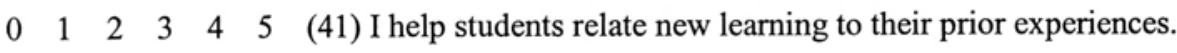

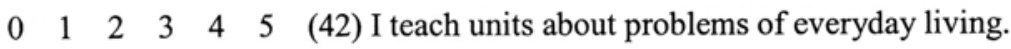




\section{Appendix D \\ Stages of Concern Questionnaire (SoCQ)}

Reprinted with permission from the Southwest Educational Development Laboratory, Austin, Texas (see below):

From: $\quad$ Joyce Pollard <jpollard@sedl.org>

To: $\quad$ "Chris Weigandt" <Chris.Weigandt@mail.wvu.edu>

Date: $\quad$ 4/28/2005 6:18:24 PM

Subject: $\quad$ Re: SoCQ Questionnaire Request

Dear Ms. Weigandt:

Yes, indeed, I recall your study and initial request. In the interest of time, I'm pleased to grant permission for you to reproduce the Stages of Concern Questionnaire in the appendix of your dissertation. As with the previous license, you must duplicate the questionnaire only for this purpose and you must include the credit line at the bottom of the first page: "Reprinted with permission of the Southwest Educational Development Laboratory, Austin, Texas."

Please let me know if you have questions or if you need additional paperwork.

Best wishes,

Joyce Pollard 
Trek 21 Participant Code:

\section{Stages of Concern Instrument}

\section{ATTITUDES TOWARD INSTRUCTIONAL TECHNOLOGY}

DIRECTIONS: Answer as completely and truthfully as you possibly can when thinking how each of the following statements applies to your PRESENT attitude toward integrating instructional technology. Circle the number that best reflects your present attitude. The higher the number, the better the statement reflects your present attitude.

$\begin{array}{lccccccc}\mathbf{0} & \mathbf{1} & \mathbf{2} & \mathbf{3} & \mathbf{4} & \mathbf{5} & \mathbf{6} & \mathbf{7} \\ \text { Not true of me now } & & \text { Somewhat true of me now } & & \text { Very true of me now }\end{array}$

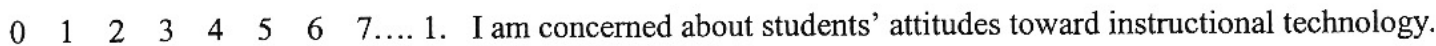

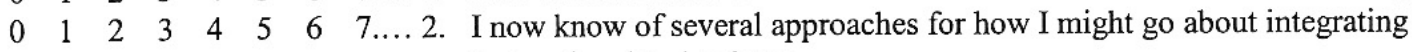
instructional technology.

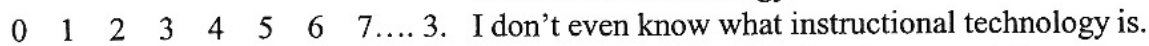

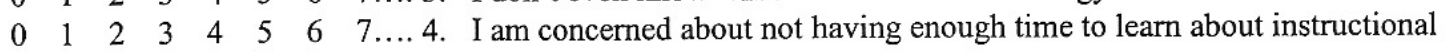
technology so that I can integrate it effectively.

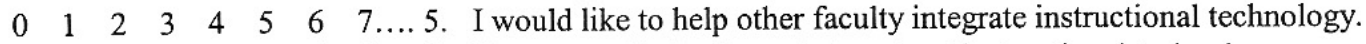

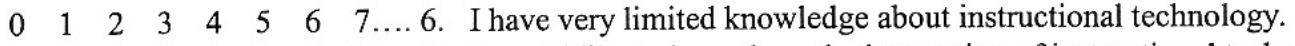

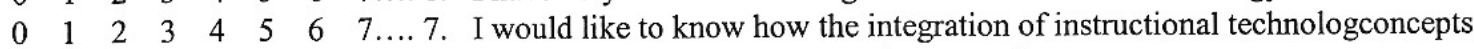
might affect me when I am trying to teach.

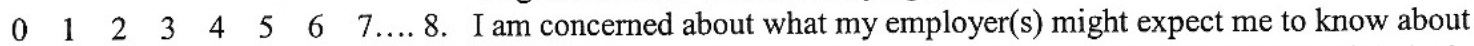
integrating instructional technology and how those expectations might be in conflict with what I like to do.

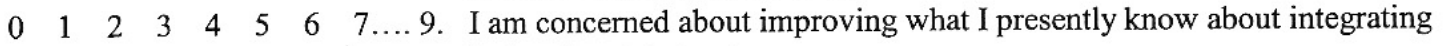
instructional technology.

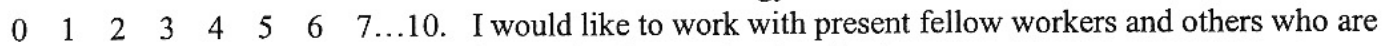
integrating instructional technology.

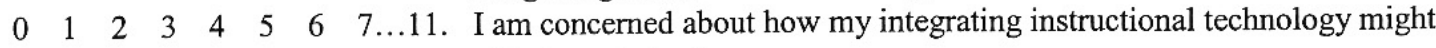
affect my students.

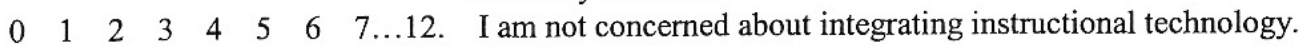

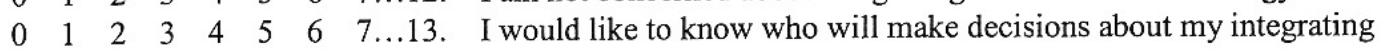
instructional technology.

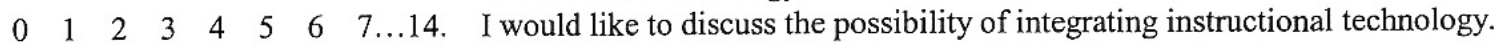

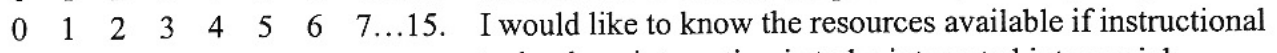
technology integration is to be integrated into my job.

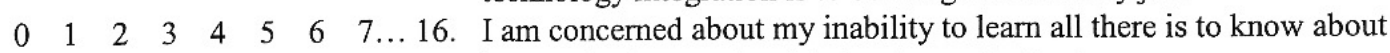
integrating instructional technology effectively.

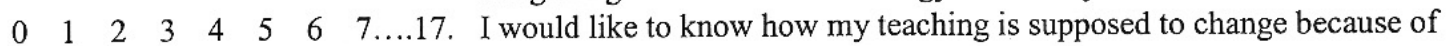
integrating instructional technology.

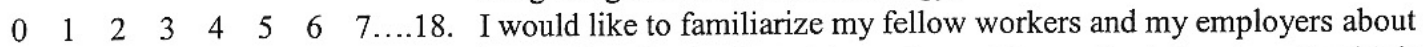
instructional technology integration as I learn about it and work with it more.

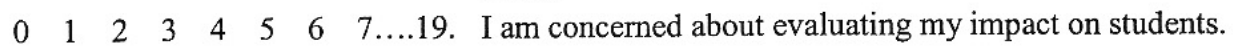




$\begin{array}{cccccccc}\mathbf{0} & \mathbf{1} & \mathbf{2} & \mathbf{3} & \mathbf{4} & \mathbf{5} & \mathbf{6} & \mathbf{7} \\ \text { Not true of me now } & & \text { Somewhat true of me now } & & \text { Very true of me now }\end{array}$

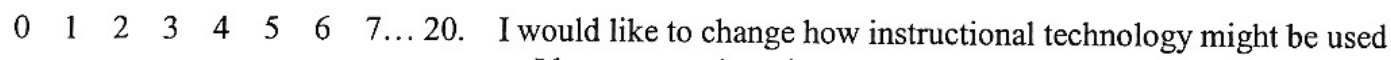
as I learn more about it.

$\begin{array}{llllllllll}0 & 1 & 2 & 3 & 4 & 5 & 6 & 7 \ldots 2 & 21\end{array}$. I do not care much about integrating instructional technology; my schedule prevents me from caring too much.

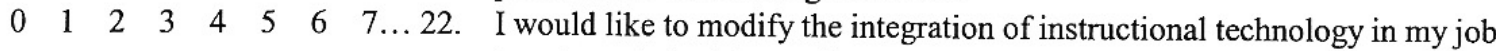
based on students' experiences.

$\begin{array}{lllllllllll}0 & 1 & 2 & 3 & 4 & 5 & 6 & 7 \ldots & 23\end{array}$. Although I don't care much about integrating instructional technology, I am concerned about it.

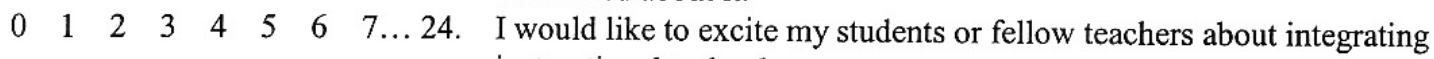
instructional technology concepts.

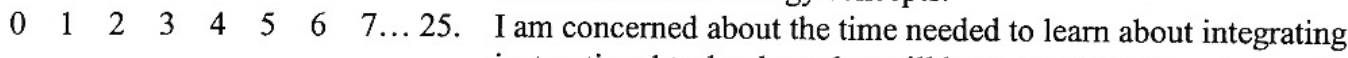
instructional technology that will keep me away from doing what I am supposed to be doing as part of my job.

$\begin{array}{lllllllllll}0 & 1 & 2 & 3 & 4 & 5 & 6 & 7 \ldots & 26\end{array}$. I would like to know what integrating instructional technology will require in the immediate future.

$\begin{array}{llllllllll}0 & 1 & 2 & 3 & 4 & 5 & 6 & 7 \ldots 2 & 27\end{array}$. I would like to coordinate my efforts in learning about instructional technology integration with fellow workers.

$\begin{array}{lllllllllll}0 & 1 & 2 & 3 & 4 & 5 & 6 & 7 \ldots & 28\end{array}$. I would like to have more information on the time required to learn about instructional technology.

$\begin{array}{llllllllll}0 & 1 & 2 & 3 & 4 & 5 & 6 & 7 \ldots & 29\end{array}$. I would like to know what other people are doing in relation to integrating instructional technology.

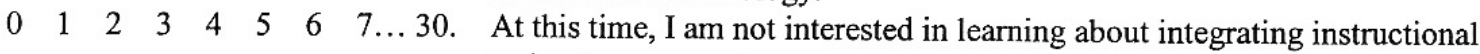
technology concepts.

$\begin{array}{llllllllll}0 & 1 & 2 & 3 & 4 & 5 & 6 & 7 \ldots 31 & \text { I } & \text { I would like to determine how to supplement and enhance instructional }\end{array}$ technology integration.

$\begin{array}{llllllllll}0 & 1 & 2 & 3 & 4 & 5 & 6 & 7 \ldots & 32\end{array}$. I would like to use feedback from my students to change how I integrate instructional technology.

$\begin{array}{llllllllll}0 & 1 & 2 & 3 & 4 & 5 & 6 & 7 \ldots & 33\end{array}$. I would like to know how my job will change when I begin integrating instructional technology.

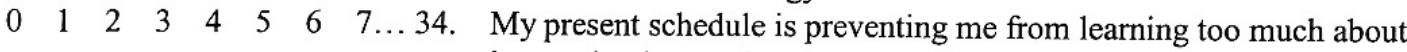
integrating instructional technology.

$\begin{array}{llllllllll}0 & 1 & 2 & 3 & 4 & 5 & 6 & 7 \ldots & 35 & \text { I }\end{array}$ instruction is better than the methods I presently use or plan to employ when I do my job. 
Appendix E

Example of Coded Combined Unit/Lesson Feedback Sheet and Unit Score Sheet 


\section{Unit/Lesson Feedback Sheet}

Following your assessment of the unit/lessons, use this sheet to indicate what you see as the major strengths (give 3), and the major suggestions for improvement (give 3).

\begin{tabular}{|c|c|}
\hline \multicolumn{2}{|c|}{ Unit Overview } \\
\hline $\begin{array}{l}\text { Strengths } \\
\text { 1. Easy to navigate[Page Design] } \\
\text { 2. Major goals help paint a good picture } \\
\text { of unit[Assessment/Objectives] } \\
\text { 3. Lesson set up is consistent[Page Design] }\end{array}$ & \begin{tabular}{|l} 
Suggestions \\
1. \\
2. Mosy to navigate[Page Design] \\
3. Need lesson objectives and \\
assessment[Assessment/Objectives] \\
4. Need lesson extensions[Activities/Motivation] \\
5. More Telecom activity more a part of the \\
unit[Activities/Motivation] \\
6. Link IGO's[Clarity/Explanations]
\end{tabular} \\
\hline \multicolumn{2}{|c|}{ Lesson 1} \\
\hline $\begin{array}{l}\text { Strengths } \\
\text { 1. Material section is well } \\
\text { developed[claritylExplanations] } \\
\text { 2. Easy to read[Page Design] } \\
\text { 3. Very motivating topic for high } \\
\text { school[Activities/Motivation] }\end{array}$ & $\begin{array}{l}\text { Suggestions } \\
\text { 1. How are the self assessments used? } \\
\text { students fill them out but they aren't asked } \\
\text { to do anything with them. [clarity/Explanations] } \\
\text { 2. They could analyze answers-respond to a } \\
\text { questions-create a product ie. } \\
\text { information[Activities/Motivation] } \\
\text { 3. Content needs developed [Activities/Motivation] } \\
\text { 4. and some closure brought to } \\
\text { lesson[Clarity/Explanations } \\
\text { 5. Explain use of self } \\
\text { assessment[ClaritylExplanations] } \\
\text { 6. Lesson content needs } \\
\text { developed/explained[Clarity/Explanations] }\end{array}$ \\
\hline \multicolumn{2}{|c|}{ Lesson 2} \\
\hline $\begin{array}{l}\text { Strengths } \\
\text { 1. } \text { Color scheme is pleasant to read[Page } \\
\text { Design] } \\
\text { 2. Good outside link to WWW[Page } \\
\text { Design] } \\
\text { 3. Easy to understand[Clarity/Explanations] } \\
\text { 4. } \\
\text { PPT - pathways is } \\
\text { excellent[Activities/Motivation] }\end{array}$ & $\begin{array}{l}\text { Suggestions } \\
\text { 1. PDF file "current health.."is out of order. } \\
\text { Page } 2 \text { and } 3 \text { are switched[Page Design] } \\
\text { 2. Need objectives and } \\
\text { assessment[Assessment/Objectives] } \\
\text { 3. Where is the crossword? [Clarity/Explanations] }\end{array}$ \\
\hline
\end{tabular}




\section{Lesson 3}

Strengths

1. Kids will like the fatal vision activity[Activities/Motivation]

2. Hands on experiment gives visual aid[Activities/Motivation]

3. BAC gives good instructions and activity[Activities/Motivation]
Suggestions

1. Student activities should be varied to incorporate more IT's. The patterns of read, do the activity sheet, turn it in is monotonous to the student[Activities/Motivation]

2. Need to vary instructional strategies[Activities/Motivation]

3. IGO's need linked[Clarity/Explanations]

\begin{tabular}{|c|c|}
\hline \multicolumn{2}{|c|}{ Lesson 4} \\
\hline $\begin{array}{l}\text { Strengths } \\
\quad 1 . \\
2 . \\
3 .\end{array}$ & $\begin{array}{l}\text { Suggestions } \\
\text { 1. This is basically a text book lesson. You } \\
\text { need more technology integration and } \\
\text { student actions[Activities/Motivation] } \\
\text { 2. Change to more student centered IT } \\
\text { lesson[Activities/Motivation] } \\
\text { 3. Complete the materials resources } \\
\text { section[Clarity/Explanations] }\end{array}$ \\
\hline \multicolumn{2}{|c|}{ Lesson 5} \\
\hline $\begin{array}{l}\text { Strengths } \\
\text { 1. Good resources and outside link } \\
\text { [Clarity/Explanations] } \\
\text { 2. PPT is informative[Activities/Motivation] } \\
\text { 3. Many different topics which are } \\
\text { motivating and } \\
\text { interesting[Activities/Motivation] }\end{array}$ & $\begin{array}{l}\text { Suggestions } \\
\text { 1. In the paper folding activity, it would be } \\
\text { helpful to include the purpose of the } \\
\text { activity. What are you trying to } \\
\text { communicate? [Clarity/Explanations] } \\
\text { 2. What do you want them to gain? } \\
\text { [ClaritylExplanations] } \\
\text { 3. In teacher and student activity } 3 \text { the word } \\
\text { should read submit[Spelling/Grammar] } \\
\text { 4. Give details about what will be done with } \\
\text { the email activity[Clarity/Explanations] } \\
\text { 5. Web quest needs directions or } \\
\text { link[clarity/Explanations] }\end{array}$ \\
\hline \multicolumn{2}{|c|}{ Additional Comments } \\
\hline $\begin{array}{l}\text { 5. Need to include objectives and assess } \\
\text { extensions and instructional strategies } \\
\text { integration for students, concept deve } \\
\text { good materials included[General Positiv }\end{array}$ & $\begin{array}{l}\text { nt in each lesson [objectives/Assessment]as well as } \\
\text { tivities/Motivation]Lesson activities lack variation, IT } \\
\text { ment and often closure[Activities/Motivation]. Lots of } \\
\text { opyrighted materials[copyright]. }\end{array}$ \\
\hline
\end{tabular}


Appendix F

Code Book for Combined Unit/Lesson Feedback Sheet and Unit Score Sheet 


\section{Code Book}

Categories and Themes in Combined Unit/Lesson Feedback Sheets and Unit Score Sheets. (Categories are bolded, themes are not bolded).

\section{Spelling/Grammar}

Typos

Spelling

Proofread

Check your Titles

Check "students booklets” and "student display"

Resources numbers are incorrect

Use quotation marks

Reword

Bullet missing

will will

if should be of.

Run-on sentence

Activity1 should say page 5

Student needs proofreading in pdf sheet not rubric or peer review sheet(indicates typo)

PowerPoint lesson 3 - \#1 needs fixed.

\section{Activities/Motivation}

Fun activities/Good activities

Where is the Telecom?

Have students...

Good use of literature across curriculum

Allow few modifications for upper grade

Printable drill sheets

Add media (when for motivation/engagement)

Lots of print and online info about topic

Voice email

Interactive PPT

Excel graph

Get "buy in"

Good introductory lesson especially

Nice crossword puzzle for reinforcement

Record songs and add to website

Related to real world situations

Intro activity seems long

"Binge drinking” timely topic

Like the pretest and myths

virtual fieldtrip is nice

When developing a site for 3rd graders -use more media -think of what your bulletin board looks like

Concept

Use websites to add additional fun facts about 
Hot potatoes quiz is nice

Extension present but does it really address diverse learners or other content areas?

Student page doesn't really do anything

Never happened in lesson

Include audio or video

Add ITs

Use the carving pumpkins website as part of the lesson to give students ideas before they start carving

pumpkins to the booklets

Are facts researched to be only about tongues?

"Wall of Traditions is nice"

Poor integration of technology

Mini lesson Handouts

Good activities

Printable and interactive

Peer review

Grammar Doctor, Reptile man

Excellent web sites

Have a student make a recording of each book for students who are absent or those who would like to listen again at home

Good way to do instructional strategies

Lot of ITs included

Good ITs

Parent Involvement

Add extensions

Add an internet site on....

KWL chart

Self-evaluation is good

Good use of schedule planner

Online fables are nice

Parent signing page

Good Storysite

Could link to ....from other lesson

Should provide some editing

Every lesson is exactly the same except for the title, and the subject they are

brainstorming

One lesson being repeated does not make a unit.

Lesson show no progression in skills

Same as lesson 1 (when meaning not enough difference in lessons)

Write a unit with progression skills

Extensions

Reviews of previous material

Web sites (if for activity/research, etc.)

PowerPoint (good, nice, great, cute)

\section{Clarity/Explanations}


Good directions

Elaborate

link to textbook publisher- nice

On student page -nothing shown for lesson 1 and 5

List journal writing under assessment

I cannot find the book on which this lesson is based anywhere

PDF a Venn diagram and link it

This is not the meat group. It is the meat and meat alternative group, vegetable

sources of protein should be introduced

Need more concrete assessments

Perhaps link to site about writing process or make a PDF

Nice map of...

Could make a PPT about writing on Harriet Tubman

Use more creativity with lesson titles

power point is read aloud nice for early learners

Quiz directions want students to circle the best answer-Hard to do online

Provide "graph" in PDF Format so that it can be used for "Extension" activity

Provide list

Tree and leaf booklet for copying

Did you want your email address posted on here? You could have lots of kids emailing

you

Include "inter activity" in student section

Add audio or video (if as examples)

Link worksheet(Teacher prep) to

Checklist

Assembled stories - maybe in PDF format?

Make activities table index

Give student same link as teachers

Out of site URL

Some objectives appear to be for the teacher not the student

Student activity 2 in teacher section varies from SA\#2 in student section

Some of this may belong in concept development

Include a link back to Trek 21 page for unit

Images showing how to hold marbles are nice

Nice progression of ideas

ppoint for discussions outline

Ppt is nice for slope

Restate objectives as measurable. How do you measure "increase awareness of?"

Succinct

email connection to teachers is good

Develop learning idea more fully

Materials need to be completed

Why is santa story in staley lesson?

Not in student concepts

Write measurable objectives

Write objectives/assessment 
Helpful hints are nice

Point it out

Need checklist

Template used to control work

will students take field trip also on their own or only with use of projector

Closure

Link directly to teacher email

Way too much time for each lesson

What if you don't have Inspiration?

Student pictures and sentences to make a class PowerPoint presentations

Needs more explanations

Procedures are easy to follow

Not listed under materials

Personalize all objectives in teacher and student activities.

Links are helpful (if talking about resources, etc.)

Needs teacher prep

Web sites (if talking about teacher resources)

Rubric/Add rubric (if having to do with clarity)

Reword Teacher prep. It should state...

Need instructional strategies

Great resources

Not used in lessons

Parent using rubric

Rewrite objectives and assessments to more clearly reflect lesson goals

Reword objective

Student and teacher procedures sometimes overlap

Listed but not used

Provide worksheet

Materials list but not

No extension addresses other curricular areas

Will teacher do...

Good summary

Specific CSO's are not targeted

All materials and resources are linked

active verbs in teacher and student procedures

Add line graph quiz to extensions at top.

Check wording

Excellent Introductory Sites

\section{Links}

Check your links

Couldn't go on, get past

... cannot be found (when referring to link not working)

Link "return to top"

Activity bookmark worksheets - one of each for each 
Only right answers are linked in PPT, need to also include wrong ones

Fix activities bookmark

Links don't work

Links worked

Sound box is there but no sound

Some of the sound in the PPT does not play

PowerPoints don't work

Clipart not showing up under resources

Mailbox link is paid access only

Move PPT sound files to PPT folder

bookmarks

\section{Page Design}

Nice design

Good design

easy to tell which lesson you are on because font color change

Not all hyperlinks are changing color

It is difficult to get back to teacher page when you go to student page

Download should be quicker

Book title should be in italics not quote in concept development

Don't use all capital letters

Hidden in plain view is linked twice-delete one link

Eye catching page - very attractive

says to click the "enter key"-where is it

Several navigation problems

Navigation

Good outside link to WWW

Links at sides and bottom

Addresses need to be in blue address bar

Made word doc chart an interactive PDF

Button graphic is a good "visual clue" for

Link to Table of Contents from here?

Separate steps for student unit on a different page and bullet with graphics

Different clipart may be..??? with state and sounds associated with state.

Separate parent, teacher, student pages

Choice of printing out form or filling out online is good

Why is the same sentence repeated several times under resources?

Fix a few problems with PPT

possibly disable the home link so I know that that is where I am

In Student Procedure, could the link go right to student section for each lesson

and not the overview every time

Many of the links in "Extensions" and "resources" repeats from lesson 1 and others -why not just put them in a separate page and link to it

Flash is nice

Try to make/improve resolutions. $2^{\text {nd }}$ document

Include a link to your email so people can contact you 
Add media (when referring to adding graphics etc. to page

Why is the link on "activities" under teacher activities?

Prerequisites are in two places

Could link to

Limit time for music

Reviewed in Netscape and had problems

Include date last edited

Give each page a title

The scrolling banner is a nice touch

Page too long

Nice colors

Hard to read

But not sure if form will work

Bullet list

Love the print friendly copy of lessons

Link to it

New window

Links (if referring to navigation)

Navigation

I could not get to the ppt. because my computer does not have PowerPoint in it

Could be linked in the teacher procedures to make it handy

Might want to link

Bookmark sites in teacher prep

Teacher/Parent/student link

need a link on student pages to get back to the home page

Could hyperlink video under student activities to make it easier for the student to view Could use internal links to day1, day2 \& day3

Can't get to..., Can't get back....

\section{Copyright}

Permission?

Copyright

Infringement

Give credit

\section{Assessment/Objectives}

Use tools

Need one assessment to activity

Vary verbs

How do you measure (mentioning unmeasurable objective)

Lesson appropriate for k-1 or special ed. not for stated grade levels

High level thinking addressed

How are you going to assess

Good quiz

Add rubric (if having to do with needs for assessment)

Elevate learner outcomes to higher level skills when possible 
Check on student progress

Six lessons - four goals

Under write: change it to say I try to get at least five.(all lessons need to fixed)

Objectives states that students will match inventors and inventions, but I couldn't find anything similar in the...

Well written objectives

Fix objectives and assessment

Make measurable

Make objectives match assessment

\section{Generic}

Good (Nice, Neat) Unit

This really doesn't "feel" like a coherent unit

Movies used in extension

Not complete

She put a lot of work into this unit.

Is ... really a certified teacher?

WOW

Well written

A nice unit with some more development

Use of statues is nice

Timelines important to concept learn

Easy to see how unit can be used for multiple subjects

Great site- ties into the lesson nicely

Content

Good links

2nd members names

Teacher Activity 2-member's name

Provide alternative directions for using compass learning. It is a paid subscription service Good variety of websites

Add audio

... may be offensive 
Appendix G

Phone Text for Initial Contact of Study Participants 
Hello

This is Christine Weigandt. I was a graduate assistant in the Trek 21 project in 2002 when you were an Instructional Leader. I am calling ask you to participate in a study I will be conducting as partial fulfillment for my Doctorate degree in Technology Education. The purpose of the study is to examine differences in evaluations of P-12 web-based instructional units by Instructional Leaders in the Trek 21 project.

The study consists of an interview that is expected to take between 30 minutes and an hour.

Confidentiality will be maintained throughout the study - interviews will be audiotaped, but tapes and transcripts of interviews will not be labeled with your name, only pseudonyms will be used. The tapes will be stored at my home, and I will be the only person with access to the data. At the end of the study, the tapes will be destroyed.

If you do choose to participate, you may refuse to answer any question, or ask that tape recording be stopped at any time.

Your participation in the study is entirely voluntary. Your status with the project will not be affected in any way if you choose not to participate.

Thank you. Please let me know if you are willing to participate in this study. You can reach me at 692-8705 or at cweigandt@aol.com. 
Appendix $\mathrm{H}$

Letter to Study Participants 
May 5, 2004

Dear

Thank you for agreeing to participate in this study. The purpose of the study is to examine differences in evaluations of the P-12 web-based instructional units by Instructional Leaders in the Trek 21 project.

Confidentiality will be maintained throughout the study - interviews will be audiotaped, but tapes and transcripts of interviews will not be labeled with your name, only pseudonyms will be used. The tapes will be stored at my home, and I will be the only person with access to the data. At the end of the study, the tapes will be destroyed.

You may refuse to answer any question, or ask that tape recording be stopped at any time. Your interview should take between 30 minutes and one hour to conduct.

Your participation in the study is entirely voluntary. Your status with the project will not be affected in any way if you choose at any time not to participate.

Thank you.

Sincerely,

Christine Weigandt

110 Wedgewood Dr Apt 9

Morgantown WV, 26505

304-599-8705 
Appendix I

Interview Protocol 
Script for Interview:

Good morning, (afternoon, evening). Thank you for agreeing to participate in my study. The goal of me research is to understand what influences the criteria by which instructional leaders evaluate proficiency in the use of instructional technologies. This information will be used for my Doctoral dissertation and may be used for professional manuscripts and presentations for academic audiences.

I want to point out several things to you before we start:

- Your participation is entirely voluntary.

- Your refusal to participate will not be revealed by the procedures of the study.

- You may refuse to respond to any question in the interview.

- Your responses, or lack thereof, will be kept confidential.

- I would like to audio-tape this interview, but your consent to being taped is entirely voluntary.

- The tapes and transcripts of your interview will not be labeled with your name.

- No attempt will be made to use demographic or descriptive information concerning the school in which you teach to identify your tapes and transcripts.

- Only I will have access to your tapes and transcripts.

- You may request a copy of the transcript of your interview.

- Your interview should take between 30 minutes and one hour to conduct.

Thank you for agreeing to participate in this study.

\section{Question \#1}

What did you feel was your role as an Instructional Leader?

\section{Question \#2}

From your perspective as an Instructional Leader, what were the participants in the Trek 21 P-12 institute expected to do?

\section{Question \#3}

What did you feel was your role as a unit reviewer?

\section{Question \#4}

Here is the Trek 21 evaluation rubric. How close were the priorities on this tool to your priorities for units?

\section{Question \#5}

Could you describe what your own rubric for the evaluation of P-12 units would be like?

\section{Question \#6}


What was your overall perception of the quality of the units that you reviewed?

\section{Question \#7}

Were the units you reviewed what you expected or were you surprised by them? Please explain.

\section{Question \#10}

If you were preparing future Instructional Leaders to be reviewers, how would you describe the units they will be reviewing?

\section{Question \#11}

How would you rate the overall pedagogical expertise of the participants whose units you reviewed in comparison with your own?

\section{Question \#12}

How would you rate the overall technical expertise of the participants whose units you reviewed in comparison with your own?

\section{Question \#13}

How do you feel about integrating technology into teaching?

\section{Question \#14}

Tell me about your professional background (how long have you been teaching, what grades are you teaching and have you taught)?

\section{Question \#15}

Tell me about any other evaluation experiences you have had that come to mind.

\section{Question \#16}

Is there anything I haven't asked you that you think I should know?

Thank you again for agreeing to participate in this study. 


\title{
Resume
}

\section{Christine Weigandt}

Chris.Weigandt@mail.wvu.edu

\section{EXPERIENCE}

\author{
05/2003 - present \\ Curriculum Specialist \\ West Virginia University Virtual Medical Campus (VMC) \\ - Design web-based instructional modules to assist various professionals in preparation for \\ response to acts of terrorism, using the Sharable Content Object Reference Model \\ (SCORM), established theories of adult learning, and principles of Instructional Design. \\ - Work with Subject Matter Experts, establish objectives, write and edit content, determine \\ assessment questions, and design graphics and interactive activities to be developed by \\ graphic designers. \\ - Managed course development team for 4 courses, contributed to 2 additional courses \\ - Hired as full-time Curriculum Specialist after eight months as Instructional Design Graduate \\ Assistant
}

05/2003 - 10/2004

College of Business \& Economics

Instructional Designer, Consultant

- Designed methods to convert Personal Financial Planning Course content from a face-toface and videoconferencing format to web-based delivery, as well as to enhance the face-toface version. Included converting lectures to text, drafting graphics, developing presentations, and creating activities and animations.

$08 / 2001-05 / 2003$

Graduate Assistant

West Virginia University College of Human Resources \& Education

Trek 21

- Provided professional development in the integration of instructional technologies for K-12 teachers and WVU faculty.

- Designed and delivered educational seminars and wrote training manuals. -Assisted over 100 Subject Matter Experts in creation of more than 125 educational web units containing over 650 lessons.

- Managed all communications for project.

- Assisted in project management, including assigning tasks, planning events, and establishing deadlines.

- Organized solicitation of contributions equaling more that $\$ 1,000$ from local businesses to support meeting of participant teachers and faculty members.

01/2001 - 05/2001

Instructional Designer, Graduate Assistant

West Virginia University College of Engineering and Mineral Resources

Safety and Environmental Management Program

- Designed 20-minute training modules for development by PureSafety.com into Web courses.

- Researched content, formulated objectives, wrote text and narration, and created activities and assessment. Modules included industrial health and safety topics and college orientation.

- Edited all of project's modules before final submission to PureSafety.com.

11/1985 - 08/2000

Bel-Ray Company, Inc., Farmingdale, NJ

- Created a Material Safety Data Sheet (MSDS) database and authoring system, as well as various other programs and databases in a proprietary software application.

- Managed all distribution of MSDSs by creating an automated tracking system.

- Wrote instruction manuals and trained employees in use of MSDS systems.

- Prepared and provided employee training on Safety, Health, and Regulatory issues.

- Wrote MSDSs for over 1,000 products in several formats, according to US and other standards.

- Prepared local, state, and federal regulatory reports

- Designed and managed production all in-house safety and regulatory labeling per local, state, federal, and foreign regulations.

- Created various Standard Operating Procedures. 
- Responded to customer and employee health, safety, and environmental questions.

\section{EDUCATION}

PAPERS AND PRESENTATIONS
DOCTOR OF EDUCATION, anticipated graduation: August, 2005

West Virginia University, Morgantown, WV

Major: Technology Education

Minor: Instructional Design

GPA: 4.0

Department of Human Resources and Education Fellowship - 2002-2003/2003-2004

MASTER OF ARTS, December, 2001

West Virginia University, Morgantown, WV

Major: Technology Education

GPA: 4.0

BACHELOR OF ARTS, January, 2000

Thomas Edison State College, Trenton, NJ

Major: Psychology

GPA: 3.8

Who's Who Among Students in American Universities \& Colleges

Arnold Fletcher Award - Exceptional Achievement in Independent Learning

Weigandt, C., \& Wells, J. (2003). Evaluating the Evaluators: Variations in Instructional Leaders' Assessments of Instructional Technology Integration. Paper presented at the 2003 National Educational Computing Conference (NECC), Seattle, WA.

Weigandt, C., Palak, D., Wells, D., Mitchem, K., \& Wells, J. (2003). Instructional Technology: Building Toward a Higher Level. Paper presented at the 2003 Annual Conference of the Eastern Educational Research Association (EERA), Hilton Head, SC.

White, K., Weigandt, C., \& Wells, J. (2002). Trek 21 PT3 Project: Evolution of Professional Development. Paper presented at 2002 International Conference of the Society for Information Technology \& Teacher Education (SITE), Nashville, TN. 